\title{
oct 21908
}

ASI ) - I'R $-61-513$

PAR I II

\section{MASTER}

\section{HIGH-TEMPERATURE, VAPOR-FILLED THERMIONIC CONVERTER}

TECHNICAL REPORT NO. ASD-TR-61-513, Part II

June 1962

Flight Accessories Laboratory Aeronautical Systems Division Air Force Systems Command Wright-Patterson Air Force Base, Ohio

Project No. 3145, Task No. 60962

(Prepared under Contract No. AF 33(616)-7422 by General Atomic Division of General Dynamics Corporation, San Diego, California

Authors: A. E. Campbell, F. D. Carpenter, 


\section{DISCLAIMER}

This report was prepared as an account of work sponsored by an agency of the United States Government. Neither the United States Government nor any agency Thereof, nor any of their employees, makes any warranty, express or implied, or assumes any legal liability or responsibility for the accuracy, completeness, or usefulness of any information, apparatus, product, or process disclosed, or represents that its use would not infringe privately owned rights. Reference herein to any specific commercial product, process, or service by trade name, trademark, manufacturer, or otherwise does not necessarily constitute or imply its endorsement, recommendation, or favoring by the United States Government or any agency thereof. The views and opinions of authors expressed herein do not necessarily state or reflect those of the United States Government or any agency thereof. 


\section{DISCLAIMER}

Portions of this document may be illegible in electronic image products. Images are produced from the best available original document. 


\section{NOTICES}

When Government drawings, specifications, or other data are used for any purpose other than in connection with a definitely related Government procurement operation, the United States Government thereby incurs no responsibility nor any obligation whatsoever; and the fact that the Government may have formulated, furnished, or in any way supplied the said drawings, specifications, or other data, is not to be regarded by implication or otherwise as in any manner licensing the holder or any other person or corporation, or conveying any rights or permission to manufacture, use, or sell any patented invention that may in any way be related thereto.

Qualified requesters may obtain copies of this report from the Armed Services Technical Information Agency, (ASTIA), Arlington Hall Station, Arlington 12, Virginia.

This report has been released to the Orfice of Technical Services, U. S. Department of Commerce, Washington 25, D. C., in stock quantities for sale to the general public.

Copies of ASD Technical Documentary Reports should not be returned to the Aeronautical Systems Division unless return is required by security considerations, contractual obligations, or notice on a specific document. 
ASD-TR-61-513, Part II

\section{FOREWORD}

This report was prepared by General Dynamics/General Atomic Division, San Diegio, California on Air Force Contract AF33(616)-7422, Project No. 3145, "High Temperature, Vapor-Filled Thermionic Converter". Robert W. Pidd was the General Atomic project manager for this contract. Capt. E. F. Redden of the Static Energy Conversion Section, Flight Vehicle Power Branch, Flight Accessories Laboratory was the ASD project engineer.

This research program was initiated on $1 \mathrm{July}, 1960$ and continued through 31 January 1962. The first phase of the program was presented in ASD Technical Report 61-513, Part I (General Atomic report GA-2530, dated 31 August 1961). The present report covers the research conducted during the period of 1 August 1961 through 31 January 1962.

This is the final report on Contract AF33(616)-7422. The contractor's report number is GA-2911. 
-

BLANK 
ASD-TR-61-513, Part II

ABSTRACT

This report describes progress on a research and test program being conducted under Contract AF33(616)-7422 on the development of a high temperature, vapor-filled thermionic converter for application with a nuclear reactor for space-vehicle electrical power generation. Problems associated with the design and operation of a thermionic converter employing a UC - ZrC emitter, a cesium plasma for space charge neutralization, and a high-temperature collector are described. Emitter fabrication techniques are also described. A test cell employing a cylindrical UC - ZrC emitter, which was pressure bonded to a tantalum sleeve, and a lowtemperature copper collector, was fabricated and operated for 400 hours to provide experimental data. The emitter was operated at temperatures of the order of $2000^{\circ} \mathrm{C}$ while the collector temperature was maintained at $200^{\circ} \mathrm{C}$ to $300^{\circ} \mathrm{C}$.

This report also includes a conceptual design study for a thermionic power reactor incorporating the thermionic converter under development. It was concluded that a thermionic fuel element would be about 20 inches long and 0.68 inch in diameter and would incorporate 10 thermionic cells. The load voltage per fuel element would be about 14.5 volts and two elements would be connected in parallel (electrically) to provide an output of 29 volts. The overall design would provide an electrical power level of approximately 1 megawatt. 
TABLE OF CONTENTS

Page

Number

PART A - CELL FABRICATION AND TESTING

I. INTRODUCTION $\ldots \ldots \ldots \ldots \ldots \ldots \ldots$ A. 1

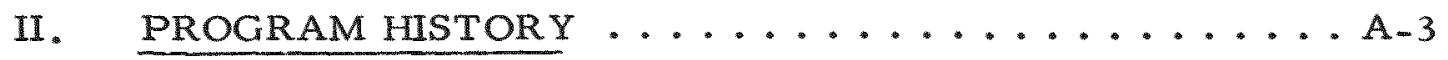

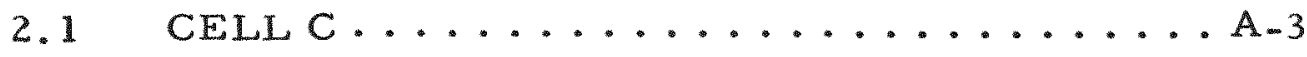

$2.2 \quad \mathrm{CELL} \mathrm{C}^{\prime} \ldots \ldots \ldots \ldots \ldots \ldots . \ldots \ldots$

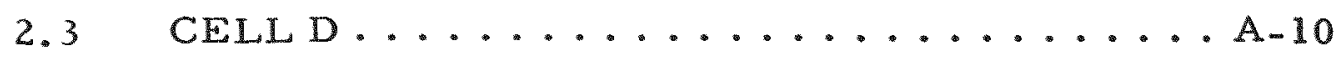

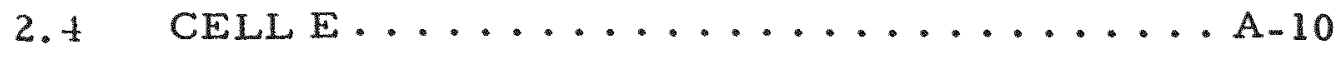

III. DEVELOPMENT AND FABRICATION OF

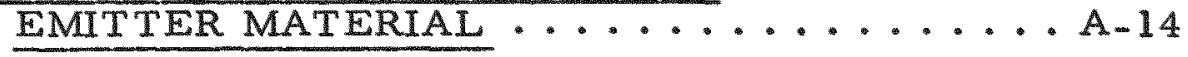

IV. OPERATION AND LIFE TESTING OF CELL D ...... A-19

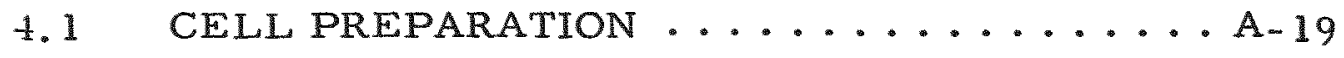

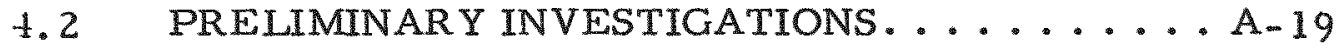

4.2.1 Operation and Instrumentation .............. 19

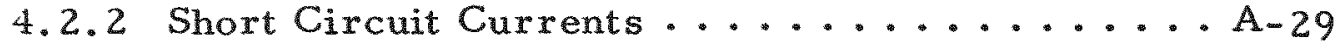

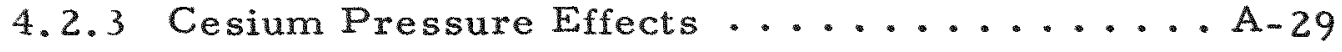

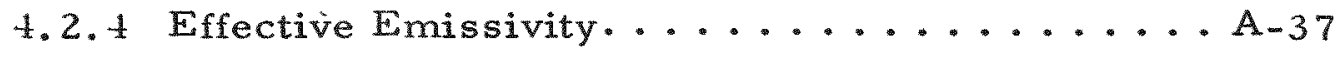

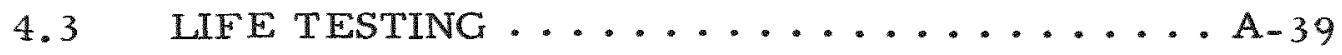

4.3.1 Observation of True Emitter Work Function.... A- 12

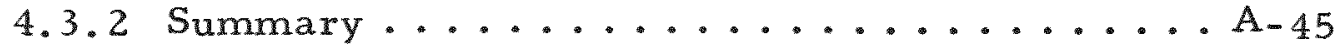

V. SUMMARY AND CONCLUSIONS .................... 47

5.1 SUMMARY OF EMITTER FABRICATION

TECHNIQUES...................... 4

5.2 SUMMARY OF CELL OPERATION .......... A-49 
ASD-TR-61-513, Part II

TABLE OF CONTENTS (cont'd)

PART B - - THERMIONIC REACTOR FUEL ELEMENT

CONCEPTUAL DESIGN STUDIES

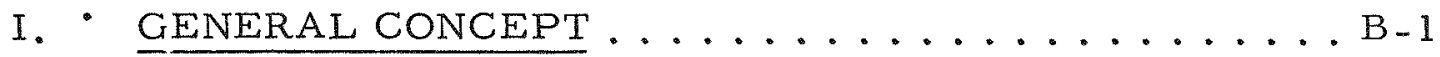

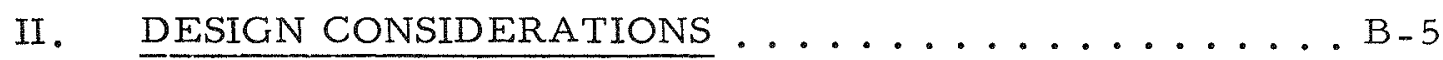

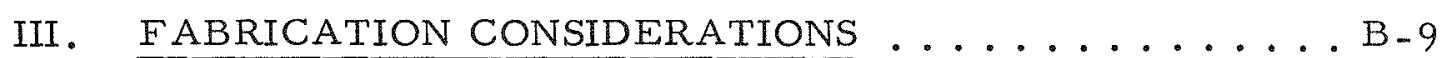

IV. FUEL ELEMENT DESCRIPTION .................. 12

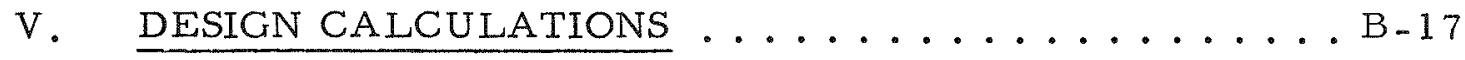

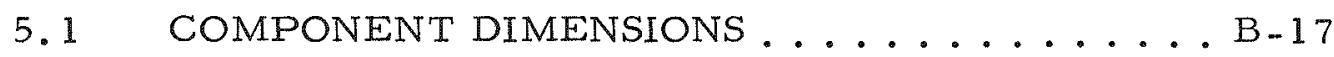

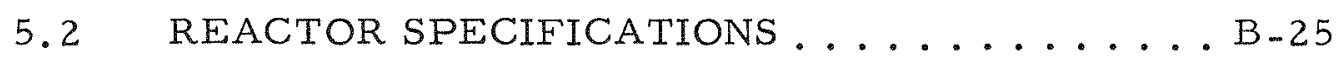

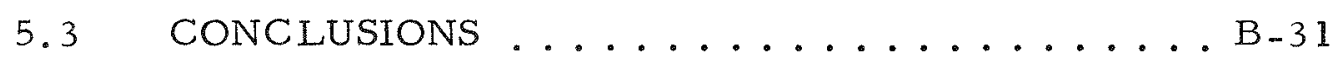

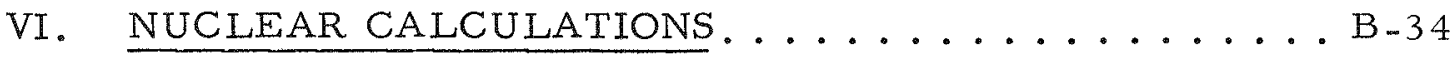

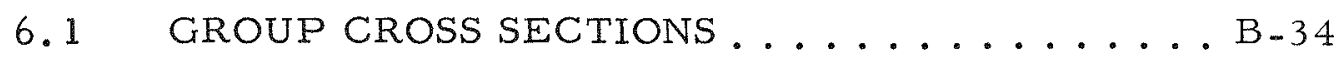

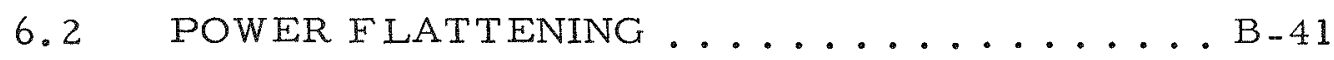

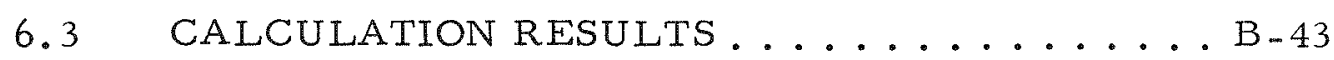

REFERENCES 


\section{LIST OF ILLUSTRATIONS}

Figure

Number

\section{A. 1}

A. 2

A. 3

A. 4

A. 5

A. 6

A. 7

A. 8

A. 9

A. 10

A. 11

A. 12
Cross-section of Cell $C^{\prime}$

Thin-Carbide, stem-insert emitter (all dimensions are in inches)

Cross-section of Cell E (all dimensions are in inches) A-11

Thin-carbide, integral-stem emitter (all dimensions are in inches)

Die arrangement for hot pressing carbide to tantalum sleeve

Voltage-current characteristics of low-impedance cell. $T_{E}=1603^{\circ} \mathrm{K}$. Horizontal axis $20 \mathrm{milli}-$ amps/division

A- 13

A -16

A-20

Number

A. 6

A-9

A-20

A -22

Voltage-current characteristics for $\mathrm{T}_{\mathrm{E}}=1323^{\circ} \mathrm{K}$. Horizontal axis 1 volt/division. Vertical axis 10 milliamps/division.

Voltage-current characteristics for $T_{E}=1520^{\circ} \mathrm{K}$.

$A-22$ Horizontal axis 1 volt/division. Vertical axis 20 milliamps/division.

Voltage-current characteristics for $\mathrm{T}_{\mathrm{E}}=1598^{\circ} \mathrm{K}$. Horizontal axis 1 volt/division. Vertical axis 50 milliamps/division.

Voltage-current characteristics for $T_{E}=1696^{\circ} \mathrm{K}$. A -23 Horizontal axis 1 volt/division. Vertical axis 100 milliamps/division.

Voltage-current characteristics for $\mathrm{T}_{\mathrm{E}}=1753^{\circ} \mathrm{K}$. $\mathrm{A}-24$ Horizontal axis 1 volt/division. Vertical axis 200 milliamps/division. 
ASD-TR-61-513, Part II

\section{LIST OF ILLUSTRATIONS (cont'd)}

Figure

Page

Number

Number

A.13 Voltage-current characteristics for $T_{F}=1863^{\circ} \mathrm{K}$.

Horizontal axis 1 volt/division. Vertical axis

500 milliamps/division.

A. 14

Voltage-current characteristics for $T_{E}=1953^{\circ} \mathrm{K}$.

Horizontal axis 1 volt/division. Vertical axis

5 amps/division.

A. 15

Voltage-current characteristics for $\mathrm{T}_{\mathrm{F}}=2028^{\circ} \mathrm{K}$.

Horizontal axis 1 volt/division. Vertical axis

5 amps/division.

A. 16

Voltage-current characteristics for $T_{E}=2071^{\circ} \mathrm{K}$.

Horizontal axis 1 volt/division. Vertical axis

5 amps/division.

A.17 Voltage-current characteristics for $\mathrm{T}_{\mathrm{E}}=2118^{\circ} \mathrm{K}$.

Horizontal axis 1 volt/division. Vertical axis

10 amps/division.

A.18 Oscillations in DC power quadrant. Frequency =

$59 \mathrm{KC}$. AC power about 10 percent of $\mathrm{DC}$

(ref. Fig. A. 14)

A.19 Oscillations in DC power quadrant. Frequency = $660 \mathrm{KC}$. AC power about 10 percent of $\mathrm{DC}$ (ref. Fig. A. 16)

A. 20

Instrumentation for determining power quadrant

characteristics. Microvoltmeter measures

voltage drop across precision shunt to determine

cell current

A. 21 Cell current versus cell voltage for $\mathrm{T}_{\mathrm{F}}=2173^{\circ} \mathrm{K}$, $\mathrm{P}_{\mathrm{C}_{\mathrm{S}}}=3 \times 10^{-2} \mathrm{~mm} \mathrm{Hg}$, and $\mathrm{T}_{\mathrm{C}_{\mathrm{S}}}=1750 \mathrm{C}$

A.22 Current density versus emitter temperature.

A -30

Vacuum emission data for General Atomic carbides.

A.23 Cell current versus cell voltage for $T_{E}=1923^{\circ} \mathrm{K}$, $P_{C_{S}}=0.2 \mathrm{~mm} \mathrm{Hg}$ 
ASD-TR-61-513, Part II

Figure

Number

A.24 Cell current versus cell voltage for $T_{E}=1943^{\circ} \mathrm{K}$,

$\mathrm{P}_{\mathrm{C}_{\mathrm{S}}}=0.2 \mathrm{~mm} \mathrm{Hg}$

A. 25

Cell current versus cell voltage for $\mathrm{T}_{\mathrm{E}}=2116^{\circ} \mathrm{K}$,

A -32

$P_{\mathrm{C}_{\mathrm{g}}}=0.2 \mathrm{~mm} \mathrm{Hg}$

A. 26

Cell current versus cell voltage for $\mathrm{T}_{\mathrm{E}}=2173^{\circ} \mathrm{K}$,

$P_{\mathrm{C}_{\mathrm{s}}}=0.2 \mathrm{~mm} \mathrm{Hg}$

A. 27

Cell current versus cell voltage for $\mathrm{T}_{\mathrm{E}}=1942^{\circ} \mathrm{K}$,

A. -33

$\mathrm{P}_{\mathrm{C}_{\mathrm{S}}}=0.8 \mathrm{~mm} \mathrm{Hg}$

A. 28

Cell current versus cell voltage for $T_{E}=2023^{\circ} \mathrm{K}$,

$\mathrm{P}_{\mathrm{C}_{\mathrm{s}}}=0.8 \mathrm{~mm} \mathrm{Hg}$

A. 29

Cell current versus cell voltage for $\mathrm{T}_{\mathrm{E}}=2098^{\circ} \mathrm{K}$,

A. -31

$\mathrm{P}_{\mathrm{C}_{\mathrm{s}}}=0.8 \mathrm{~mm} \mathrm{Hg}$

A.30 Cell current versus cell voltage for $T_{E}=2173^{\circ} \mathrm{K}$,

A. -34

$\mathrm{P}_{\mathrm{C}_{\mathrm{g}}}=0.8 \mathrm{~mm} \mathrm{Hg}$

A.31 Cell current versus cell voltage for $T_{E}=1923^{\circ} \mathrm{K}$,

A -35

$\mathrm{P}_{\mathrm{C}_{\mathrm{S}}}=0.2 \mathrm{~mm} \mathrm{Hg}$

A.32 Cell current versus cell voltage for $T_{E}=2098^{\circ} \mathrm{K}$,

A -35

${ }^{P_{C_{S}}}=0.2 \mathrm{~mm} \mathrm{Hg}$

A. 33

Cell current versus cell voltage for $T_{E}=2173^{\circ} \mathrm{K}$,

A. 36

$\mathrm{P}_{\mathrm{C}_{\mathrm{s}}}=0.2 \mathrm{~mm} \mathrm{Hg}$

A.34 Composite plot of cell output in watts for varying

A. 36 emitter temperatures and cesium pressures

A.35 Effective emissivity versus emitter temperature

A. 38 during final cell preparation. Small conduction and radiation losses are neglected.

A.36 Effective emissivity versus emitter temperature during preliminary investigation. Small conduction and radiation losses are neglected. 
ASD - TR-61-513, Part II

Figure

Number

LIST OF ILLUSTRATIONS (cont'd)

Page

Number

A.37 Power density versus cell life A-40

A. 38

Effective emissivity versus emitter temperature

A -46 during life tests. Small conduction and radiation losses neglected. All data at open circuit

B. 1

Resistivity of mixed carbides as a function of

$\mathrm{B}-7$ temperature (see ref. 7)

B. 2

Half-element assembly

B -13

B. 3

Exploded view of single cell

B - 14

B. 4

Cross section of single cell

B -15

B. 5

Cell diagram

B -19

B. 6

Relationship of emitter length to voltage loss

B -22

B. 7

Relationship of emitter volume fraction to voltage loss

$B-24$

B. 8

Relationship of average reactor electrical power

$B-24$ density factor to voltage loss

B. 9

Computed core diameter as a function of the

B -27 maximum $\mathrm{UC}$ weight fraction in emitter

B. 10

Computed fuel loading (in $\mathrm{kg}$ of $\mathrm{U}^{235}$ ) as a function

$B-27$ of the maximum UC weight fraction in emitter

B.11 Computed core weight (in $\mathrm{kg}$ ) as a function of the

$B-28$ maximum UC weight fraction in emitter

B.12 Computed total reactor weight (in $\mathrm{kg}$ ) as a function
of the maximum UC weight fraction in emitter

$B-28$

B.13 Computed core diameter as a function of the emitter

$B-29$ volume fraction

B.14 Computed fuel loading (in $\mathrm{kg}$ of $\mathrm{U}^{235}$ ) as a function
of the emitter volume fraction 
ASD-TR-61-513, Part II

Figure

Number

B. 15

B. 16

B. 17

B. 18

B. 19

B. 20
Computed core weight (in $\mathrm{kg}$ ) as a function of the emitter volume fraction

Computed total reactor weight (in $\mathrm{kg}$ ) as a function of the emitter volume fraction

Relationship of reactor electrical power level to critical core diameter

Relative fuel density as a function of core radius

Relative flux distribution as a function of core radius

Total power density as a function of core radius
Page

Number

B -30

B -30

B -32

B -45

$B-46$

B -47 
ASD-TR-61-513, Part II

PART A

CELL FABRICATION AND TESTING

\section{INTRODUCTION}

The program of cell testing conducted by General Dynamics/General Atomic Division for the Air Force has been directed toward the determination of the performance and lifetime characteristics of a nuclear thermionic system incorporating a mixed carbide as the fuel-emitter material, a cesium plasma for space charge neutralization, and a high temperature collector coated with cesium. The temperature ranges of interest were $1700^{\circ} \mathrm{C}$ to $2400^{\circ} \mathrm{C}$ for the emitter surface, and $700^{\circ} \mathrm{C}$ to $1200^{\circ} \mathrm{C}$ for the collector surface. It is in this temperature range that system studies indicate high performance for a space reactor system used for generating electrical power.

During the previous contract period, one cell (cell A) had been put into operation and was tested at a high temperature for 82 hours (ref. 1). It was noted at that time that the problem of emitter integrity had not been solved because of the evidence of carbide cracking and failure of the bond between the carbide emitter and the tantalum support structure for the emitter. In addition, our observations showed that a substantial deterioration of the thermionic emission itself occurred during the operation period of the cell. While the causes of this deterioration were not fully understood, it appeared that they might be related to the purity of the carbide sample, the degree of outgassing of the carbide sample, the amount of contaminant gas in the cell and, particularly, to the liberation of gases or other materials from the collector surface when that surface was operated at very high temperature. Therefore, the program of research during this reporting period (1 August 1961 through 31 January 1962) has been directed to a better understanding of the factors affecting performance as

Manuscript is released by the authors 15 Feb 1962 for publication as an ASD Technical Report. 
well as to achieving a greater period of cell operation at high performance. Progress has been made in all of these areas. Another cell (cell D) was put into operation during the last month and one-half of the contract period and 100 hours of operation was logged; a considerable amount of physical data on performance was obtained; and new information on the causes of performance decay was gained.

During this reporting period General Atomic proposed to the Air Force that the program objectives be restricted in order to allow a better determination of cell performance. Since there appeared to be such a variety and large number of factors effecting performance, it was felt that building a cell to achieve all contract objectives would not bring us quickly to a good understanding of performance factors. In particular, the effects of operating the collector at very high temperatures appeared to be a complicating factor. Therefore, we proposed that the cell utilizing the original basic geometrical design and a carbide emitter be operated with a low temperature collector to be made of copper and to be operated at temperatures of the order of $300^{\circ} \mathrm{C}$. It was with this cell (cell D) that the operational experience has been obtained. It was further proposed that once the performance of this cell was observed, the cont waing program should include a collector capable of sustaining operation at the higher temperatures of interest to the space application.

An rmproved cell, incorporating a new high-purity nickel collector for operation at collector temperatures of $600^{\circ} \mathrm{C}$ or higher, was being assembled at the end of the reporting period. This cell, designated cell E, will incorporate an emitter benefiting from improved manufacturing techniques ard wsll be available shortly for use in a continuing program.

A parallel program of design studies was conducted during the course of the cell testing program. These studies established a typical thermionic tuel element configuration based on nuclear, electrical, and fabrication consderations. The design studies are summarized in Part B of this report. 


\section{PROGRAM HISTORY}

By the end of the previous reporting period, 31 July 1961, the first complete experimental cell (cell A) had been assembled and sufficient testing completed to determine the performance characteristics of the cell. The details of these accomplishments were previously reported (ref. 1). The electrical output power of Cell A was less than anticipated. After considerable investigation this result was attributed to poisoning of the emitter. It was concluded that this emitter poisoning, or lowering of the emission current densities achievable at a given emitter temperature, probably resulted from the presence of nitrogen gas in the cell. During cell operation, reactions between the nitrogen and the hot carbide emitter were possible with a resultant increase in the effective work function of the emitter sur face. The primary source of the nitrogen was traced to the molybdenum collector. With the vacuum equipment then available, molybdenum could not be outgassed sufficiently to insure partial pressures of nitrogen less than $10^{-6} \mathrm{~mm} \mathrm{Hg}$. In all probability, considerably higher nitrogen pressures occurred after the cell had been sealed and operated. Accordingly, to eliminate the molybdenum and hopefully the source of nitrogen, the decision was made to fabricate the next cell with a copper collector.

\subsection{CELLC}

The fabrication and assembly of the follow-on copper collector cell (cell C) was undertaken during August and September 1961. The design of this cell was similar to that of Cell A with the exception of the copper collector and the addition of a high-temperature thermocouple for monitoring the temperature of the emitter. The need for a reliable indication of the emitter temperature became apparent from the operation experience gained from Cell A. In Cell $\mathrm{A}$, the emitter temperature was determined by means of an input power-pyrometer temperature calibration performed 
prior to final closure of the cell. This method as sumed that the effective emissivity between the emitter and the collector remained constant during cell operation. Since the validity of this as sumption was somewhat in doubt and, in addition, the emission characteristics of the emitter were lower than expected, there existed considerable uncertainty regarding the accuracy of the predicted emitter temperatures. If a better understanding of cell operation was to be realized in Cell $C_{\text {, a }}$ reduction in the emitter temperature uncertainty was essential.

The emitter thermocouple used in Cell C consisted of tungsten vs. tungsten-rhenium wire in a 0.040 inch tantalum sheath, insulated with $\mathrm{BeO}$. The sheathed thermocouple junction was inserted in an axial hole in the carbide section of the emitter with the junction located approximately midway along the length of the emitter and about 0.060 inch from the emitter surface. Sheathed lead wires exited from the cell through a hole drilled in the emitter support plate. The seal between the copper support plate and the tantalum sheath presented particular difficulties. This seal formed a part of the cesium container and consequently had to be capable of $300^{\circ} \mathrm{C}$ operation and $400^{\circ} \mathrm{C}$ bakeout temperature, and be compatible with the cell environment. A satisfactory means of making this seal was found by melting a thin section of copper directly onto the sheath. The melted copper wets but does not alloy with tantalum and forms a smooth copper bead around the sheath.

Early in September 1961, the emitter thermocouple had been installed and the cell nearly completed. After subsequent pre-operational cell. testing; however, a partial electrical short developed in the thermocouple. This produced erratic and erroneous readings of the thermocouple and thereby rendered it useless. Because the thermocouple installation was a late addition to the cell, no provision existed in the cell design to facilitate replacement of the thermocouple without disassembling a major portion of the cell. 
In addition to this thermocouple problem, the questionable structural integrity of the emitter and the high probability of damaging the insulator in dismantling the cell made a rapid repair of the cell impossible. The advisability of repairing the cell also was questioned in light of an improved cell design which had been established, the availability of a more reliable insulator, and the development of a radiation-heated emitter which gave promise of eliminating the cracking problem associated with the bonded carbide-to-tantalum type emitter. The decision was made to replace Cell $\mathrm{C}$ with an improved version designated $\mathrm{Cell} \mathrm{C}^{\prime}$.

\subsection{CELL $\mathrm{C}^{\prime}$}

One important design feature introduced in Cell $\mathrm{C}^{\prime}$ was the order of assembling the individual components into a completed cell. In Cell C, the emitter, emitter thermocouple, and collector had to be installed early in the assembly procedure. If any of these components failed during the later stages of cell fabrication, replacement necessitated a major dismantling of the cell. To eliminate this highly undesirable requirement, Cell $\mathrm{C}^{\prime}$ was designed so that the emitter, emitter thermocouple, and collector were the last components to be added to the cell assembly. This design change offered the additional benefit of allowing the integrity of almost all the other components of the cell to be tested and assured prior to the attachment of the final three components. Thus a base assembly could be built, tested, and outgassed independently of emitter, emitter thermocouple, or collector considerations. The base assembly could, therefore, be easily reused if any of the se three components needed replacement. A cross-section of Cell $C^{\prime}$ is illustrated in Figure A. 1. Since the new insulator did not incorporate the flexible welding flanges of the Cell C type insulators, sufficient flexibility was built into the modified collector support plate to allow adequate alignment of the collector with respect to the emitter. 


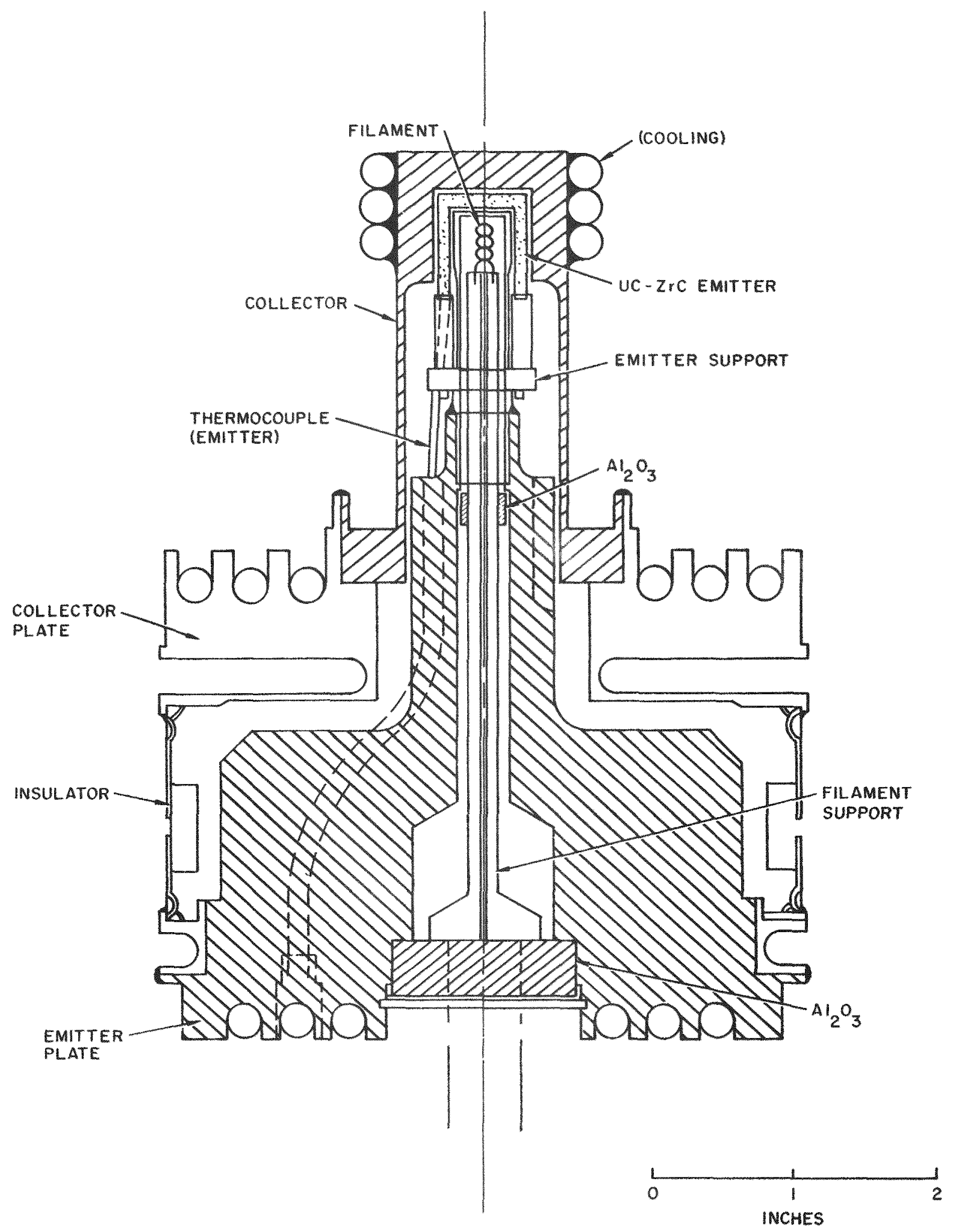

Fig. A.1 - Cross-section of Cell C' 
The emitter to be used in Cell $\mathrm{C}^{\prime}$ consisted of a carbide cup surrounding an inner tantalum sleeve. The carbide was to be heated by radiation from the tantalum rather than by conduction. This eliminated the need for zirconium braze between the tantalum sleeve and the carbide cup. Thermal testing of this type of emitter in Cell $\mathrm{C}^{\prime}$ determined that carbide surface temperatures up to about $1800^{\circ} \mathrm{C}$ could be achieved. However, higher surface temperatures resulted in excessive temperatures for the inner tantálum radiating sleeve. Additional thermionic emission data became available at that time which indicated that carbide surface temperatures of $2000^{\circ} \mathrm{C}$ or higher might be required for efficient cell performance. It was apparent, then, that the radiation-heated emitter would not meet the necessary operational requirements. Accordingly, completion of Cell $\mathrm{C}$ was delayed until a suitable emitter could be developed.

The surface temperature limitation imposed on the radiation-heated emitter was a direct result of the large temperature difference required between the tantalum sleeve and the carbide emitter to transport the necessary heat fluxes by radiation. Any appreciable reduction in this temperature difference could only be achieved by employing conduction heat transfer. Hence, the bonded tantalum-to-carbide type emitter was reexamined. The critical feature of this emitter was the coupling of the tantalum sleeve to the carbide cup. For the emitters used in Cells $\mathrm{A}$ and $\mathrm{C}$, this coupling was accomplished by means of a zirconium braze. A thick wall ( 0.125 inch) carbide section was first pressed and finished and then brazed to the thin wall (.020 inch) tantalum sleeve. The thick carbide walls were necessary for structural stability during the fabrication process. In addition, this thick high-conductivity section tended to maintain a more uniform temperature over the surface of the emitter if small vacancies occurred at the braze interface. Experience showed; however, that if a braze interface temperature of approximately $2150^{\circ} \mathrm{C}$ was exceeded or if small cracks occurred in the carbide section, further cracking usually 
developed with large area failures in the tantalum-to-carbide braze. This led to large temperature differences on the emitter surface and made the emitter unusable.

The possibility of fabricating a thin wall carbide, thick wall tantalum emitter was investigated. By pressing the carbide material directly onto the tantalum, the necessity for the zirconium braze was eliminated. Also, by finely grooving the tantalum surface, a greater surface area was established for the carbide to adhere to the tantalum. Thus, even if cracking of the carbide occurred, the interface bond might remain intact. In addition, use of the thin section carbide moved the interface closer to the emitter surface and reduced the interface temperature to only slightly higher than the surface temperature.

By late October 1961, the thin carbide wall emitter was developed. A compromise had to be made; however, in the means of attaching the emitter to its support stem. In order to achieve a high density in the pressed carbide (the high density was necessary to maintain a good bond at the carbide-tantalum interface), the long tantalum stem could not be an integral part of the main tantalum emitter structure. The presence of the long stem drastically altered the heating characteristics of the pressing die and resulted in the formation of a low density carbide on portions of the cylindrical area of the emitter. The compromise emitter-emitter stem configuration is shown in Figure A.2. The emitter and stem were fabricated as separate components. The stem insert was machined to a tight sliding fit with respect to the hole drilled in the emitter tantalum. By heating the insert, a diffusion bond was formed between the two tantalum surfaces.

In November 1961, the thin-carbide-wall, stem-insert type of emitter was installed in Cell $C^{\prime}$. The emitter thermocouple was inserted and its calibration checked by pyrometer up to $2000^{\circ} \mathrm{C}$. The collector was then welded to the base assembly to complete the cell assembly. Final outgassing of the complete cell was undertaken. At the completion of the 


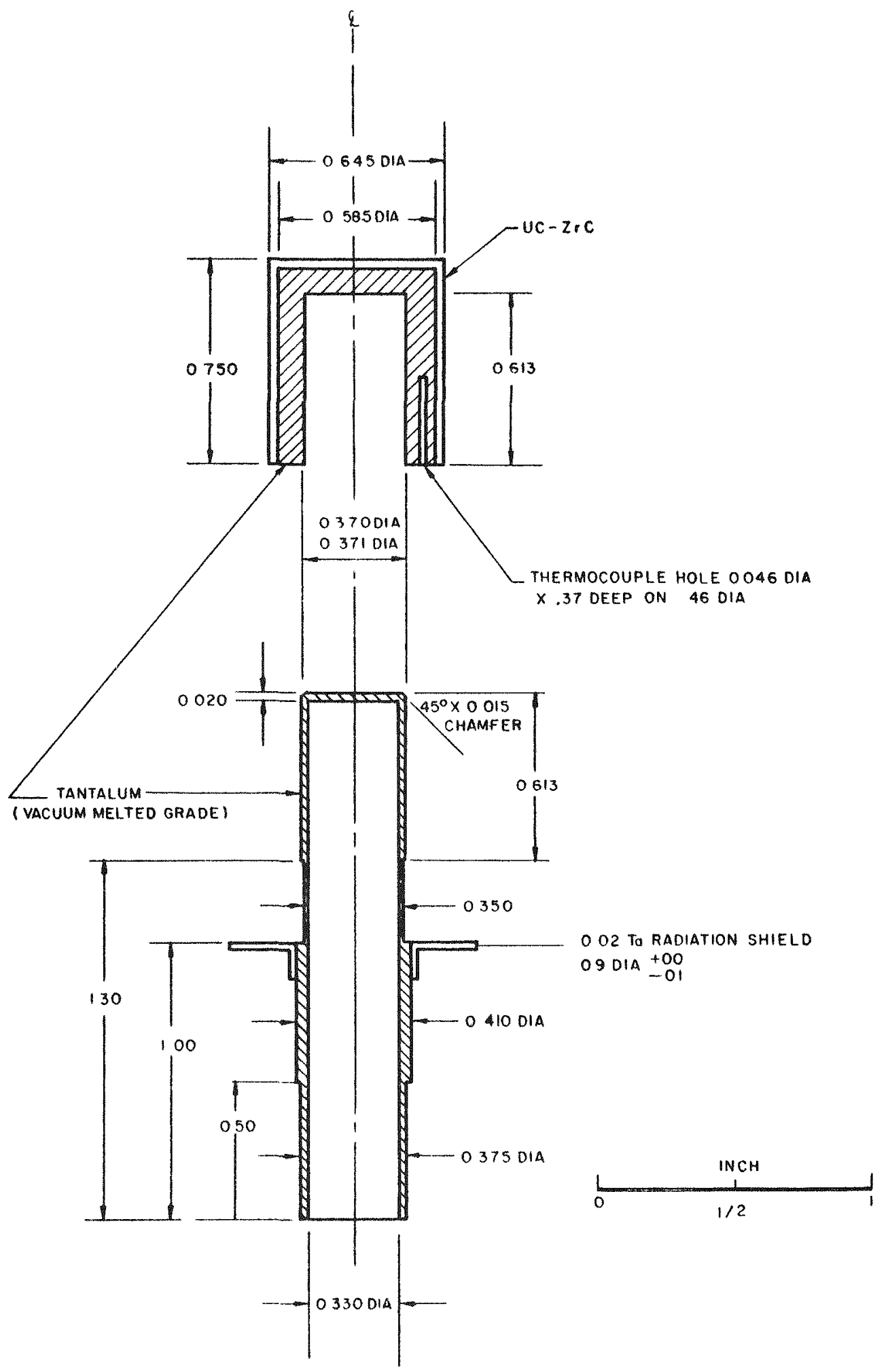

Fig. A. 2 - - Thin-Carbide, stem-insert emster $\ell_{\epsilon} 11$ dimensions are in inchusl 
last outgassing procedure, just prior to the admission of cesium, a leak developed in the emitter.

The emitter was removed from $\mathrm{Cell} \mathrm{C}^{\prime}$ and sectioned. Visual inspection revealed that a small hole had been melted in the tantalum insert. It was also found that while good diffusion bonding had occurred over most of the insert to emitter interface, some areas existed where the bond was poor. The leak had occurred at one of these poorly bonded areas. The cause of the local overheating of the tantalum insert then appeared to be a reduction in the thermal conductance at the hole location plus the possible misalignment of the heater filament which could have locally increased the heat flux applied at the hole location.

Since an additional cell, Cell $D$, had been constructed essentially concurrently with $\mathrm{Cell}^{\prime}$, the decision was made to divert effort to the completion of Cell D.

2.3 CELL D

While Cell D employed the same type of emitter as Cell C', extensive testing indicated that with careful filament alignment, the emitter should operate satisfactorily. Cell closure was completed in December 1961 and the cell placed in operation. The details of the performance characteristics of Cell D are presented in Section IV.

\section{$2 . \pm$ CELLE}

During January 1962, work progressed on the assembly of Cell E. Cell E employs a high purity nickel collector capable of operating at temperatures of $600^{\circ} \mathrm{C}$ or higher. Minor modifications are included in the cell design (see Fig. A.3) to improve the over-all structural stability of the cell and to increase the pumping speed obtainable during outgassing.

Further experimenting with the hot pressing of high density carbide onto long solid tantalum bodies resulted in the development of an improved emitter design which should eliminate the uncertainties associated with the thin-carbide-wall, stem-insert type of emitter. The length of the 


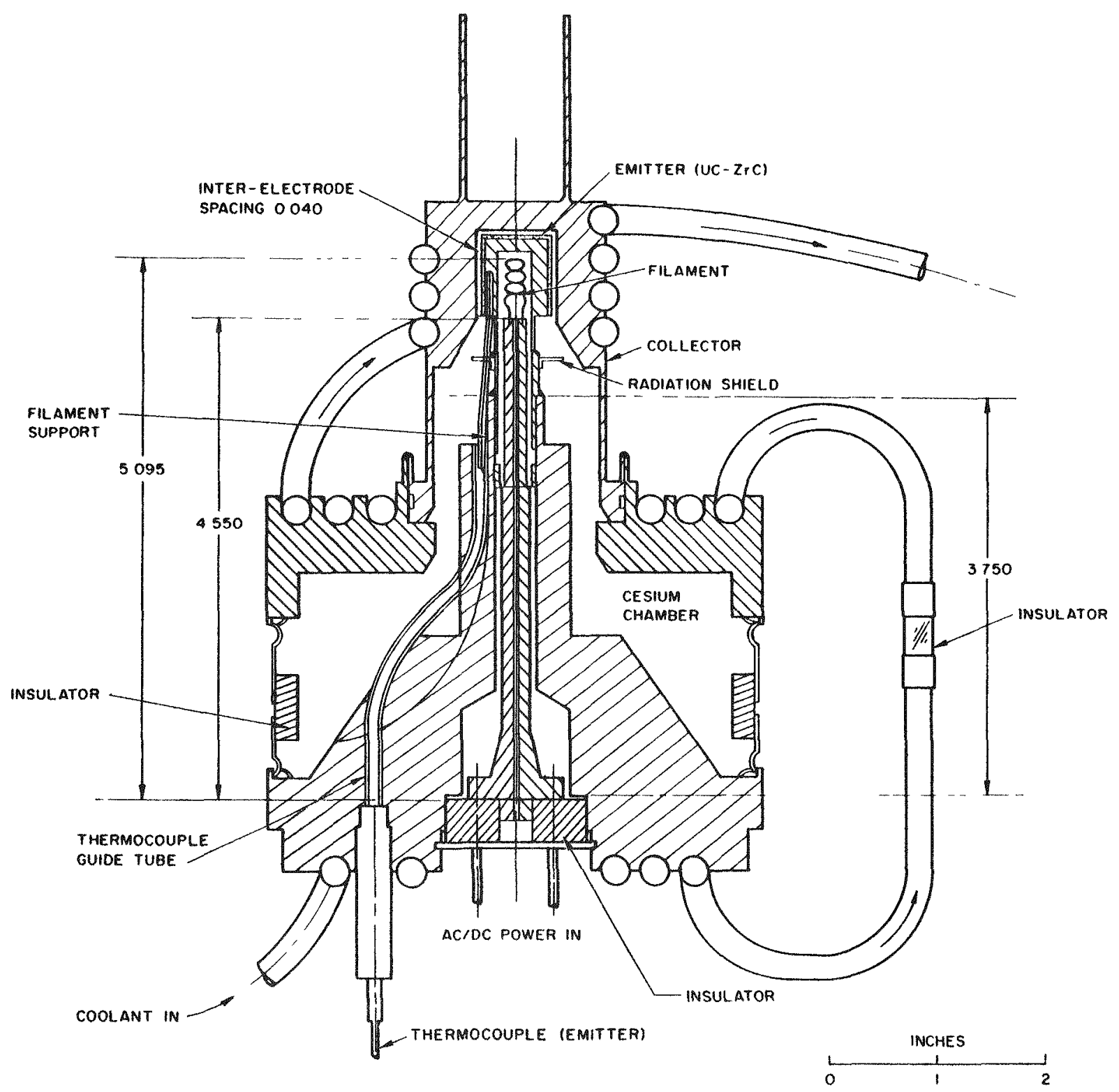

Fig. A.3 - - Cross-section of Cell E (all dimensions are in inches) 
tantalum portion of the emitter has been increased sufficiently to permit a short length of support stem to be machined as an integral part of the emitter. An additional length of support stem is then welded to the emitter section to complete the emitter assembly (see Fig. A.4). Testing of this thin-carbide-wall, integral-stem emitter has indicated satisfactory performance and accordingly this type of emitter is planned for use in Cell E. 


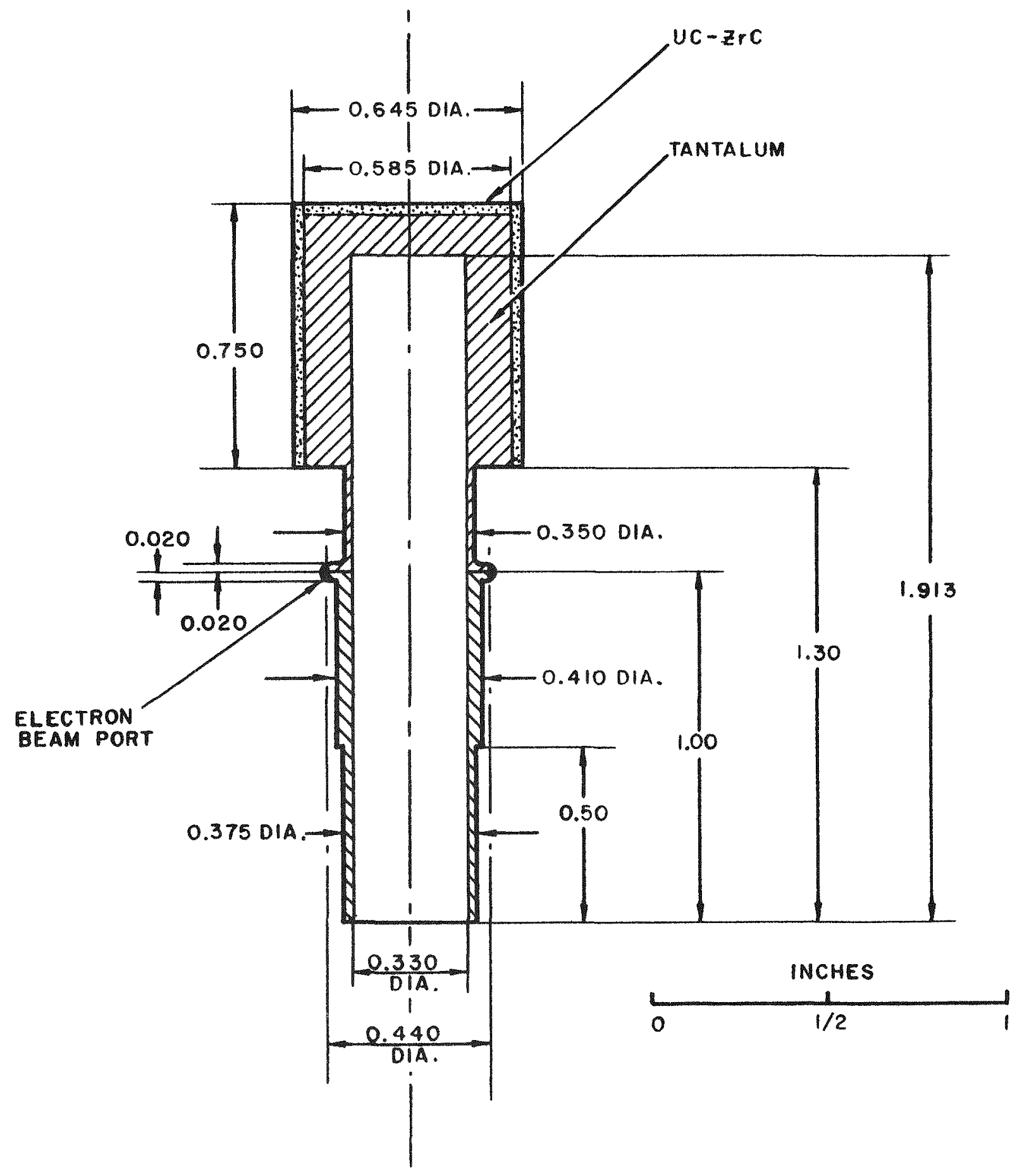

Fig. A.4 - - Thin-carbide, integral-stem emitter (all dimensions are in 1nches) 


\section{DEVELOPMENT AND FABRICATION OF EMITTER MATERIAL}

The basis for the selection of the emitter material used in this high temperature thermionic converter was described in the previous report (rei. 1). Also described therein were the developmental stages in which the emitter evolved from a right cylindrical carbide cup composed of three pieces $(2$ tubes +1 cup), through a two piece emitter $(1$ tube +1 cup of increased length), to a one piece right cylinder carbide cup, all of which were zirconium brazed to a tantalum sleeve.

The transition of each of these stages to the next involves an advancement in the state of the art of fabrication as well as an elimination of some undesirable physical characteristics of the emitter design. The use of these three types of emitters, which are thick carbide bodies ( 0.125 inch) bonded to a thin (0.020 inch) tantalum tube, requires high temperatures at the carbide-tantalum interface to achieve the desired temperature of the carbide emitting surface. This is because the heating of the emitter is caused by electron bombardment of the inside of the tantalum sleeve and conduction heating of the carbide. The major part of the temperature drop is in the carbide body which has a lower thermal conductivity than tantalum. As a result, the brazed interface area between the carbide and the tantalum operates close to its failure temperature in order to maintain the high emitter surface temperature. A radiant-heated carbide emitter was developed during this reporting period to resolve this problem. This emitter did alleviate the sources of difficulties associated with the brazed joint since the carbide and the tantalum were not in direct contact; however, the required heat flux could not be transferred from the tantalum to the carbide without excessive vaporization of the tantalum because of the low thermal emis sivity of the tantalum surface. 
Continued efforts were then made to resolve these problems by hotpressing the carbide directly onto tantalum, thus eliminating the zirconium braze; and by decreasing the thickness of the carbide while increasing that of the tantalum, thus reducing the temperature at the carbide-tantalum interface for a given emitting surface temperature.

Previous experience in hot pressing 10:90 mole-\% UC-ZrC directly onto tantalum supports had been gained during the preparation of samples for the study of the thermionic emission of carbide materials. This involved the hot press of the above material directly into a recessed tantalum dish of flat surface geometry. Hot pressing the carbides onto supports of cylindrical geometry; however, had never been attempted prior to this program. To demonstrate the feasibility of such a process, several experiments were conducted using tantalum sleeves machined to the approximate dimensions of the emitter design and with grooves cut into the cylindrical and top flat surfaces. A schematic of the hot pressing die is indicated in Figure A. 5(a). The multi-grooved tantalum provides a greater surface area for the carbide to adhere. The finished carbide layer is approximately 0.020 inch thick, as measured from the O.D. of the tantalum tube. The grooves in the tantalum are 0.020 inch deep x 0.020 inch wide and are separated from each other by 0.020 inch. The outside diameter of the pressed carbide emitter was purposely increased to 0.685 inch for several reasons. First, through experience, higher density of the carbide can be achieved by decreasing the length-todiameter ratio and; secondly, cutting the diameter of the pressed carbides to the desired value exposes material which is cleaner than the as-pressed surfaces.

After the hot pressing of carbide around a cylindrical support had been demonstrated to the feasible, the finished emitter was developed through several stages. Initially it was intended to leave a half inch of thick tantalum tube below the carbide, as indicated in Figure A. 5(a), from 

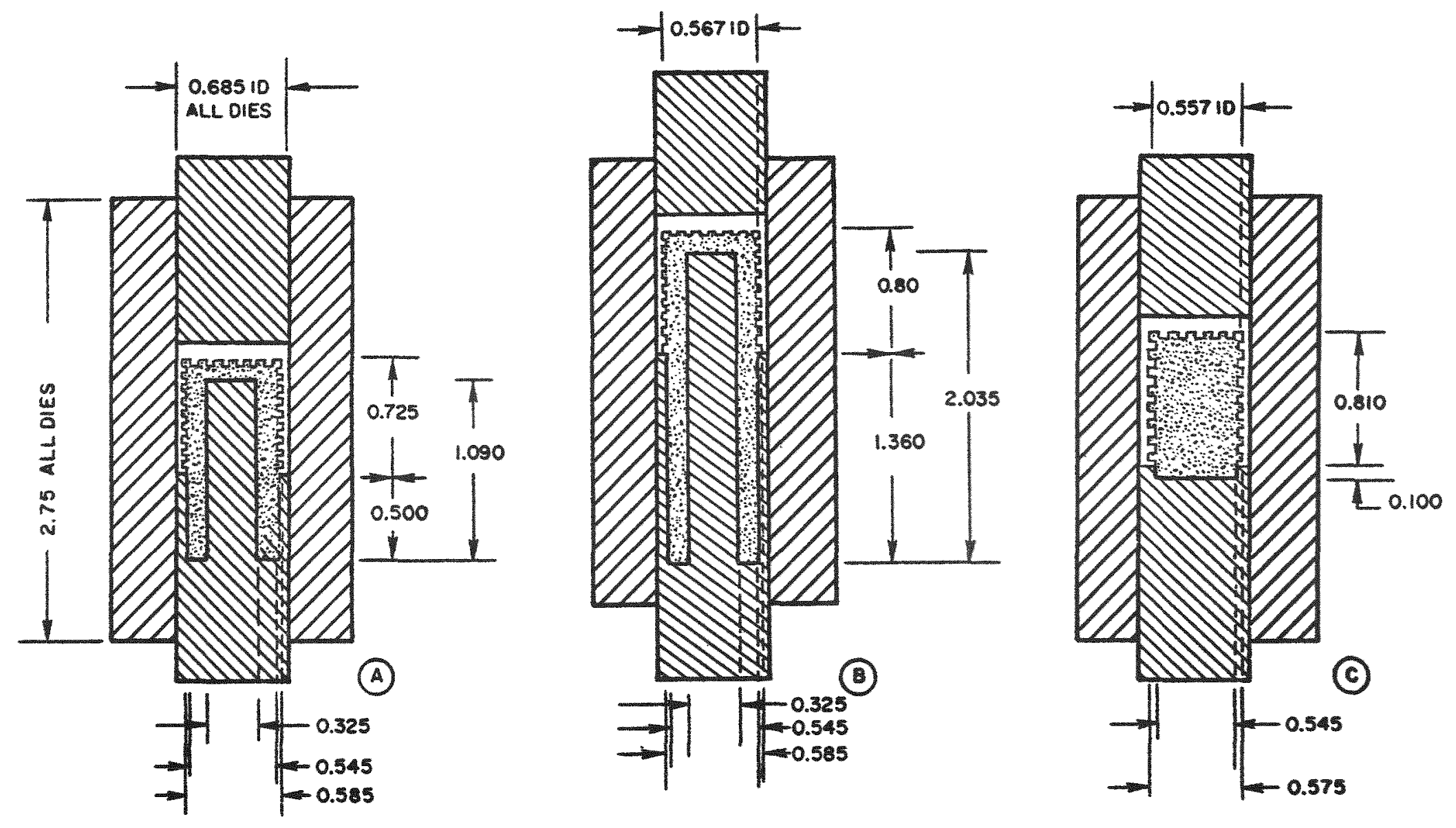

GROOVES IN TANTALUM ARE 0.020 IN WIDE $\times 0.020$ IN DEEP SPACED 0.020 IN. APART.

DIMENSIONS ARE FOR TANTALUM.

BOTTOM GRAPHITE PUNCH SNUGLY FITTEO TO TANTALUM.

TIGHT SLIOING FIT BETWEEN PUNCH AND DIES.

Fig. A. 5 - - Die arrangement for hot pressing carbide to tantalum sleeve 
which the stem could be machined and then brazed to a tantalum tube for support. This braze was to be made at the lower end of the thin wall thermal barrier in order to maintain the braze at lower temperatures.

Sectioning such an emitter revealed distortions of the tantalum cup. Radiographs indicated that during the hot pressing, the tantalum flowed outwardly toward the wall of the graphite die. This is desirable because the flow of the tantalum helps to densify the carbide material in the cylindrical annular space. In order to compensate for this, it was decided that the vertical wall on the tantalum tube should be tapered before pressing. It was also felt that the emitter could be pressed with a thick tantalum tube which was long enough so that its lower portion could be machined into the form of the support stem (see Fig. A.5(b)). This would eliminate the developmental work needed in making the brazed joint between the tantalum sleeve and the tantalum stem. The inner hole in the tantalum tube in Figure A.5(b) constitutes the electron gun compartment and also provides the vacuum tightness between the electron gun and cell.

The hot pressing of such an emitter, as shown in Fig. A. 5(b), was accomplished but had one major fault. In order to include the long tantalum tube in the graphite dies, the plungers had to be lengthened. This drastically changed the heating characteristics of the die and, thus, the density of the carbide in the cylindrical portion of the emitter. Electron beam heating of such an emitter in a celll revealed that this low density portion tended to further sinter, / causing a' reduction in volume and separation of the carbide from the tantalum; This resulted in an excessive temperature gradient on the emitter surface.

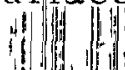

This experiment clearly indicated that a high density of the pressed carbide must be mantained. In considering this fact, it was surmosed that the best possible pressing condition would be to eliminate the tantalum stem, thereby allowing good heating characteristic of the die during 
hot pressing. The plasticity of the tantalum at pressing temperatures closely simulates a condition much like hydrostatic pressing and, therefore, leads to good densification of the carbide.

Pressing the carbide emitter material onto a solid tantalum cylinder (see Fig. A. 5(c)) posed the problem of how to join the emitter to the stem to provide vacuum tightness. This problem was solved by drilling the cylinder after the hot pressing and inserting a machined $(0.020$ inch wall thickness) tantalum insert. This insert was carefully machined to a tight sliding fit.

By heating the inside of this insert with the electron gun, the insert was expended into the tantalum cylinder and, at high temperature in a vacuum of $10^{-6} \mathrm{~mm} \mathrm{Hg}$, a diffusion bond was formed between the two tantalum surfaces. Sectioning such an emitter revealed a diffusion bond was achieved.

Several emitters were produced in the above manner and proved to be able to meet the operating conditions. The first emitter was incorporated in cell $\mathrm{C}^{\prime}$ but failed. Analysis of the failure indicated a melted area on the inner tantalum insert which was surmised to be the result of filament misalignment. The second emitter was installed in Cell D and the filament was carefully aligned. This cell was then operated for 400 hours (refer to Section IV).

In order to increase the reliability of this type of emitter, further experimentation was accomplished to develop an emitter which would eliminate the insert type support stem. In this emitter the carbide is hot pressed directly to a long tantalum cylinder. The bombardment heating cavity and $a$ short stem is machined after hot pressing. The short stem is then electron-beam welded to an additional supporting stem. Such an emitter has been fabricated, tested thermally and inserted in Cell $\mathrm{E}$ for testing. 


\section{OPERATION AND LIFE TESTING OF CELL D}

\subsection{CELL PREPARATION}

Cell D was completely assembled on December 13, 1961 and baked out for a period of 24 hours at temperatures in the range of $350^{\circ} \mathrm{C}-400^{\circ} \mathrm{C}$. The cell pressure at the end of this period was $8 \times 10^{-6} \mathrm{~mm} \mathrm{Hg}$. In addition, the individual cell parts (i.e. the copper collector, base assembly and emitter) had undergone separate and extensive outgassing. The collector, for example, was outgassed prior to assembly for over 24 hours at $400^{\circ} \mathrm{C}$. The emitter was then operated in vacuo at $2273^{\circ} \mathrm{K}$ for two hours. The pressure during this time varied only slightly (from $1.1 \mathrm{x}$ $10^{-5} \mathrm{~mm} \mathrm{Hg}$ to $1.4 \times 10^{-5} \mathrm{~mm} \mathrm{Hg}$ ) and decreased only to $9 \times 10^{-6} \mathrm{~mm} \mathrm{Hg}$ when the emitter was returned to room temperature. It was concluded that outgassing the cell and emitter had reached the point of diminishing return. That is, for three or more days of further outgassing, pressure might be reduced by a factor of three.

At this point, the cesium ampule was mechanically crushed. Only a momentary and slight increase in cell pressure was noted, indicating the entrained gas in the ampule was minimal. The high temperature-high vacuum valve was secured and the cesium was allowed to bake in. After 18 hours, the cell impedance had dropped from 350 megohms to an absolute short. The short was found to be caused by an accumulation of cesium in the inter-electrode spacing.

\subsection{PRELIMINARY INVESTIGATIONS \\ 4.2.1 Operation and Instrumentation}

A variety of emitter temperatures and cesium pressures was investigated during the first 30 hours of cell operation. It was first established that the cell impedance should be higher than the load impedance by a factor of at least $10^{3}$. Figure A.6 illustrates an instance where the 


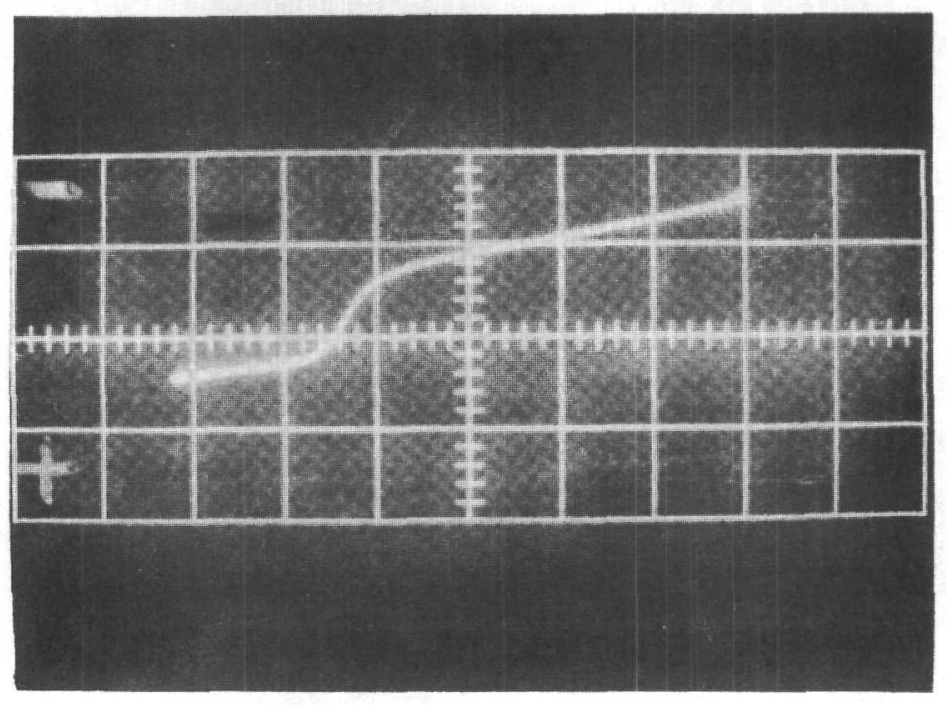

Fig. A.6 -- Voltage-current characteristics of low-impedance cell. $\mathrm{T}_{\mathrm{E}}=1603^{\circ} \mathrm{K}$. Horizontal axis 20 milliamps/division

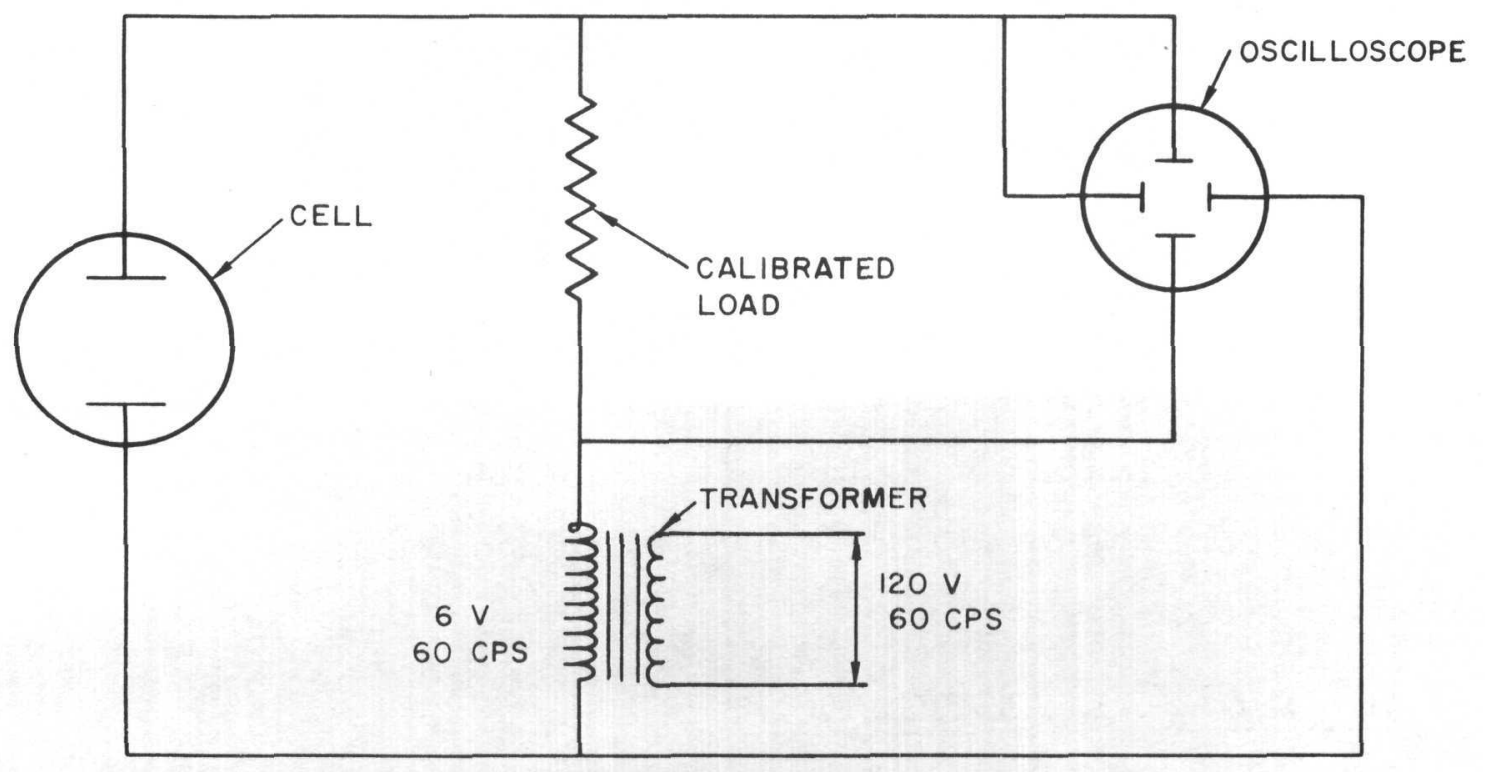

Fig. A. 7 - Instrumentation for continuous cell characteristics 
cell impedance was $250 \mathrm{ohms}$ (approximately) and the load impedance was 25 ohms. The ohmic character of a cell under these conditions has masked the available useful information, such as: the saturated thermionic current, the ion current magnitude, and the value of the open circuit voltage.

A cell impedance of 5 kilohms was obtained by an adjustment of cesium control temperature, insulatox and collector temperature. Moreover, the load impedance was reduced to minimize any possible cell current shunting to ground.

The cell was instrumented for continuous monitoring of the currentvoltage output as schematically indicated in Figure A.7. A series of oscillographs were then taken with the cesium control temperature maintained constant at $175^{\circ} \mathrm{C}$. The emitter temperature was varied from $1323^{\circ} \mathrm{K}$ to $2118^{\circ} \mathrm{K}$. Figures A.8 through A. 19 display the cell output current and voltage.

In the course of investigation, high frequency oscillations were observed in the DC power quadrant. The oscillations are shown in Figures A. 18 and A.19. As indicated, they represent only a small portion of the DC output.

The method of driving the cell with a 60-cycle transformer and recording the output on oscillographs yields a good deal of information expediently. The accuracy of interpreting the pictures; however, is questionable. Moreover, as high current levels of the cell are approached, occasional arc discharges are observed in the applied voltage quadrant (see Figs. A, 11 and A.13). Investigators have noted current densities in the range of $50 \mathrm{amps} / \mathrm{cm}^{2}$ (see ref. 2). Applying positive voltage by way of heavy duty transformers could conceivably overheat a low temperature (copper) collector.

The cell was, therefore, instrumented differently, as indicated in Figure A.20. Available in this arrangement is the power quadrant alone. Because of the finite but low resistance of the lead lines and bus bars, the 


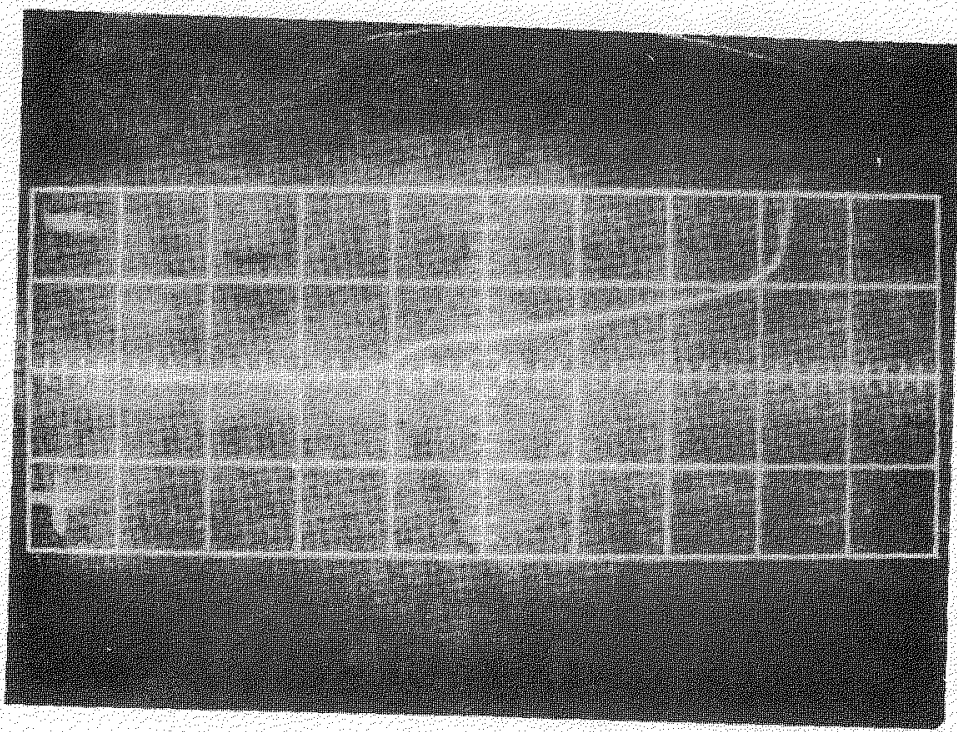

Fig. A.8--Voltage-current characteristics for $\mathrm{T}_{E}=1323^{\circ} \mathrm{K}$. Horizontal axis 1 volt/division. Vertical axis 10 millamps/division.

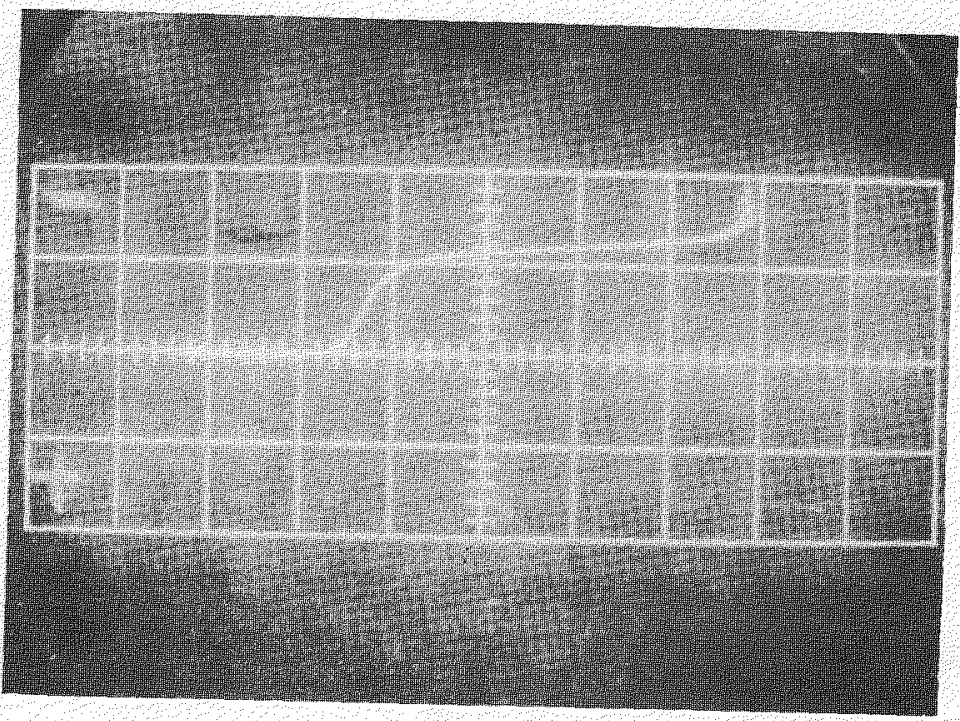

Fig. A.9-Voltage-current characteristics for $\mathrm{T}_{\mathrm{F}}=1520^{\circ} \mathrm{K}$. Horizontal axis 1 volt/division. Vertical axis $20^{\circ} \mathrm{milliamps} /$ division. 


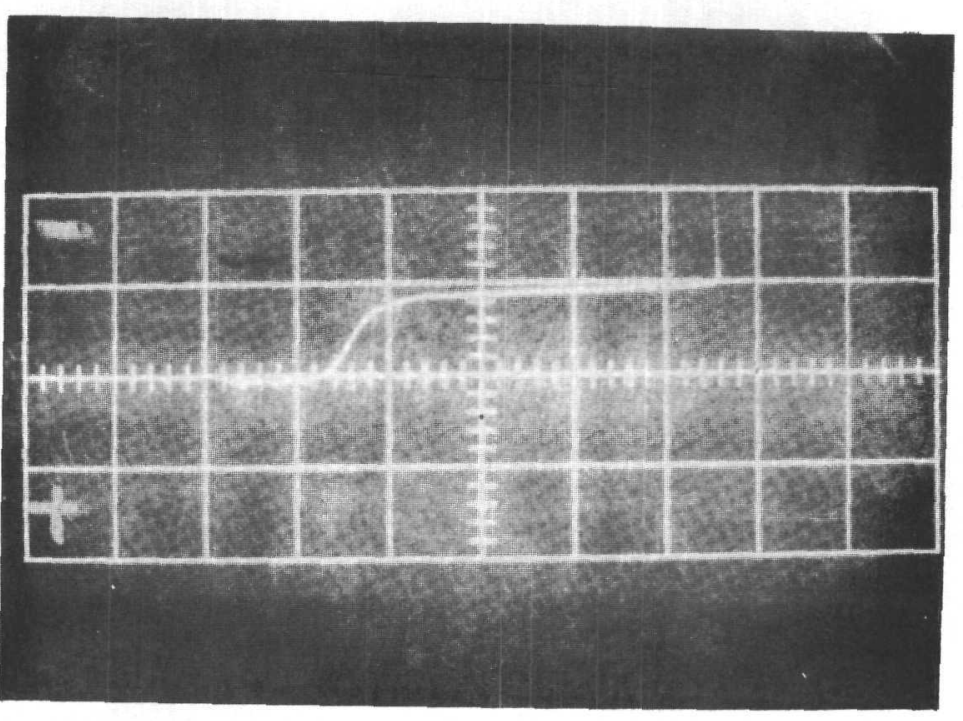

Fig. A. 10 -- Voltage-current characteristics for $\mathrm{T}_{\mathrm{E}}=1598^{\circ} \mathrm{K}$. Horizontal axis 1 volt/division. Vertical axis 50 milliamps/division.

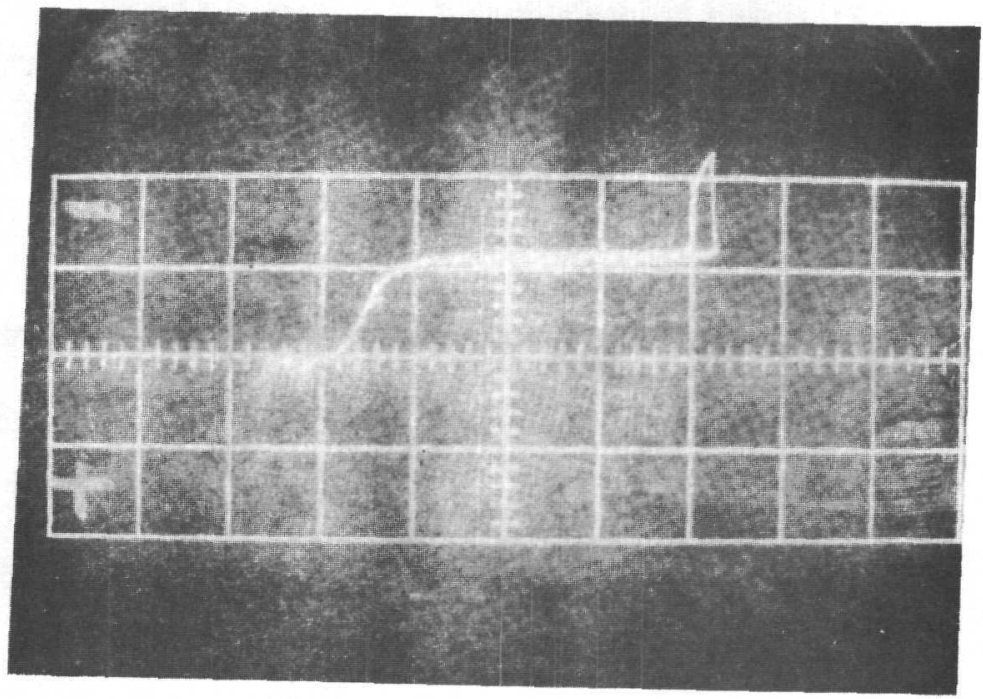

Fig. A. 11 -- Voltage-current characteristics for $\mathrm{T}_{\mathrm{E}}=1696^{\circ} \mathrm{K}$. Horizontal axis 1 volt/division. Vertical axis 100 milliamps/division. 


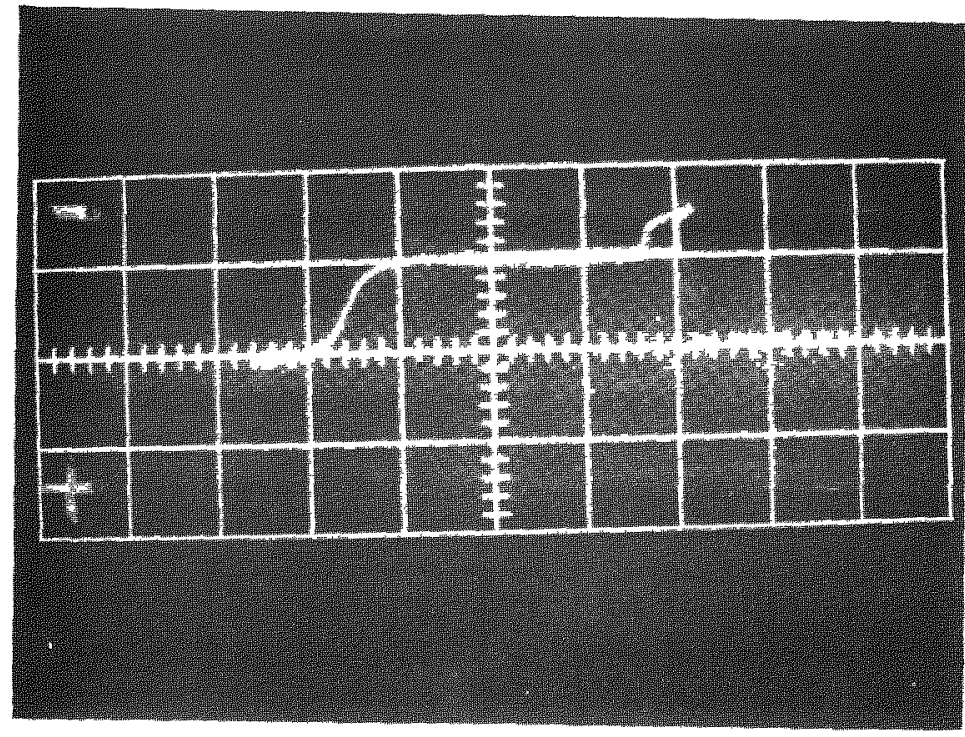

Fig. A.12-- Voltage-current characteristics for $\mathrm{T}_{\mathrm{E}}=1753^{\circ} \mathrm{K}$. Horizontal axis 1 volt/division. Vertical axis $200 \mathrm{millu}$ amps/division.

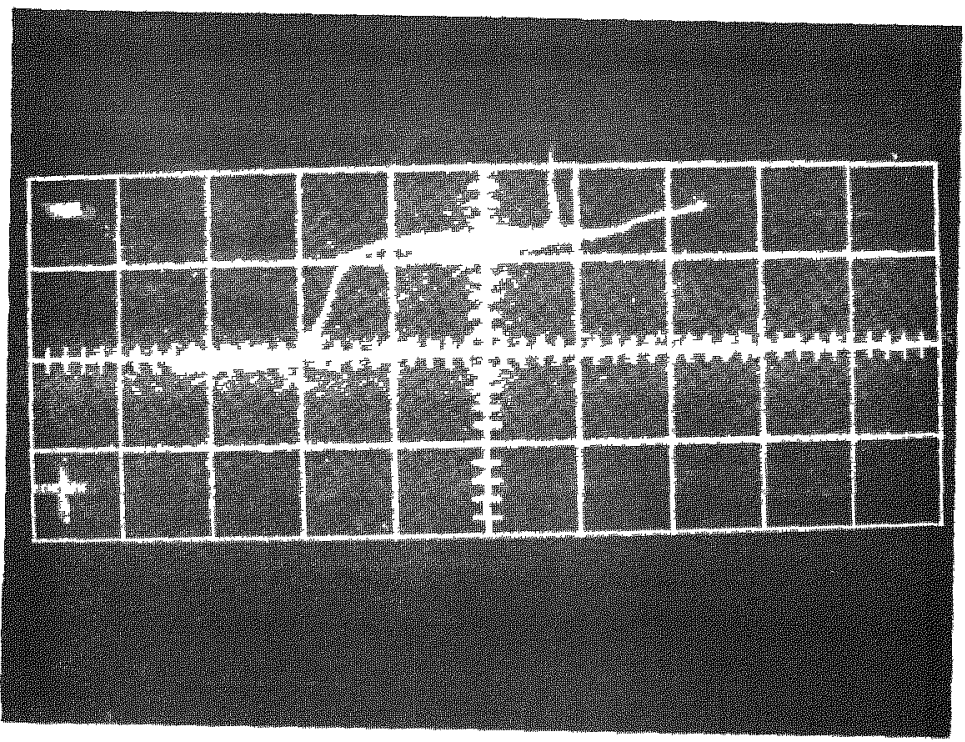

Fig. A. 13 - Voltage-current characteristics for $\mathrm{T}_{\mathrm{E}}=1863^{\circ} \mathrm{K}$. Horizontal axis 1 volt/division Vertical axis 500 milliamps/division. 


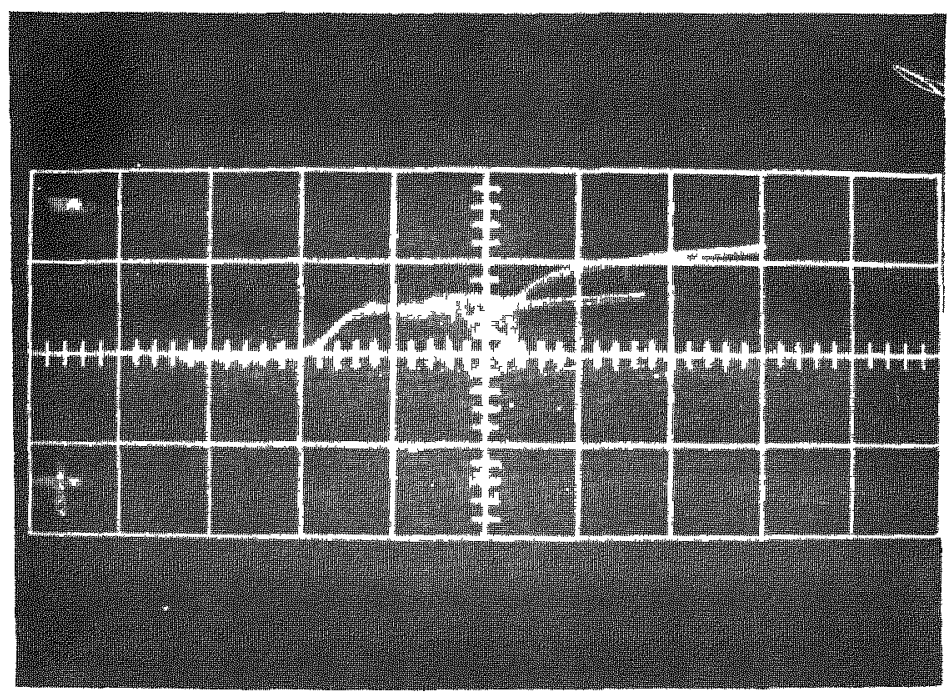

Fig. A.14--Voltage-current characteristics for $\mathrm{T}_{\mathrm{E}}=1953^{\circ} \mathrm{K}$. Horizontal axis 1 volt/division. Vertical axis 5 amps/dıvision.

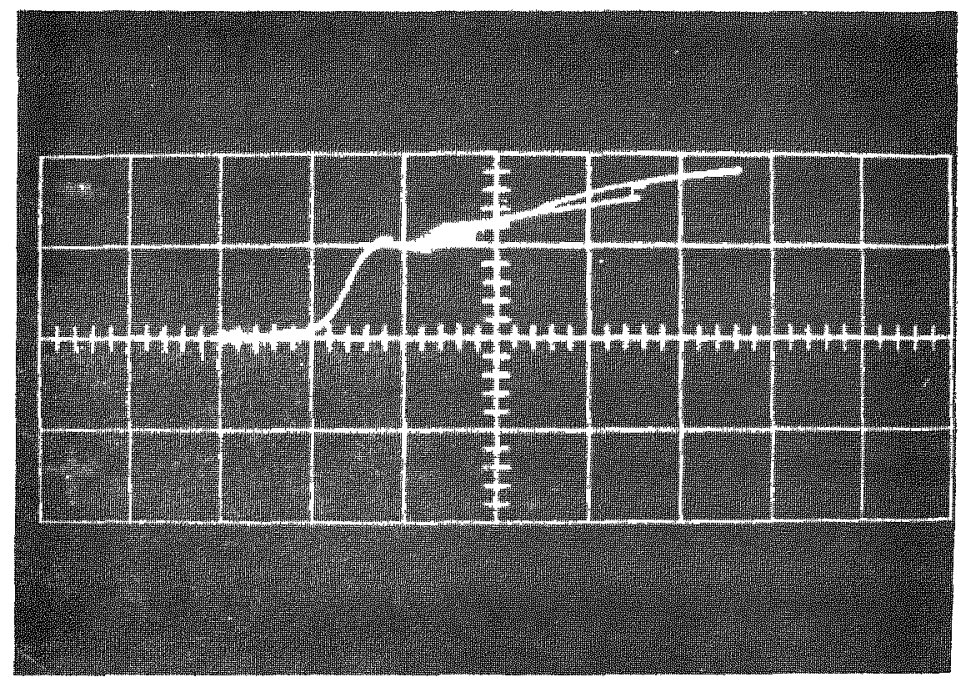

Fig. A. 15 -- Vollage-current characteristics for $\mathrm{T}_{\mathrm{E}}=2028^{\circ} \mathrm{K}$. Horizontal axis 1 volt/divisıon.Vertical axis 5 amps/division. 


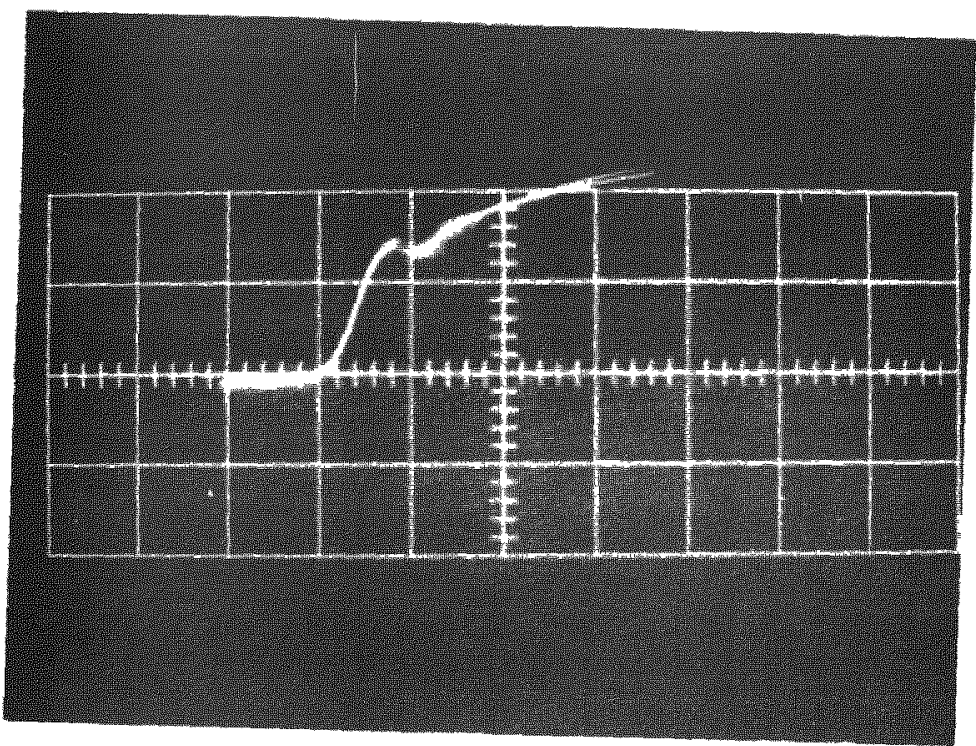
Fig. A. 16 - Voltage-current characteristics for $\mathrm{T}_{\mathrm{E}}=2071^{\circ} \mathrm{K}$. Horizontal
axis 1 volt/division. Vertical axis 5 amps/division.

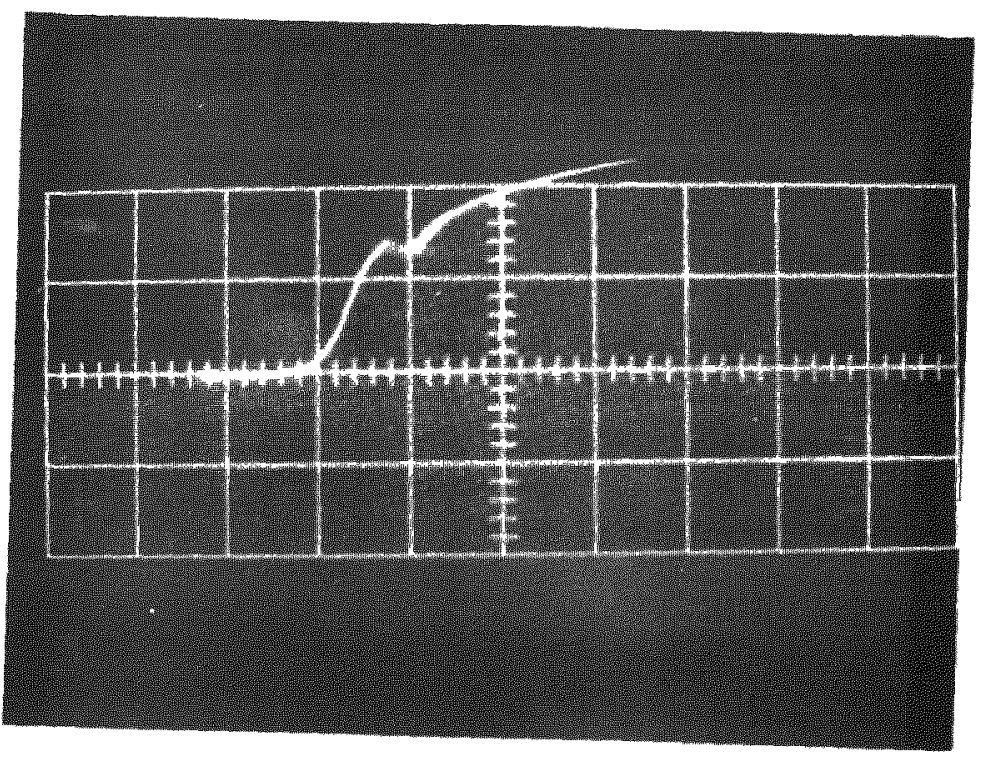

Fig. A. 17 - Voltage-current characteristics for $T_{F}=2118^{\circ} \mathrm{K}$. Horizontal axis 1 volt/division. Vertical axis $10 \mathrm{~m}$ amps/division. 


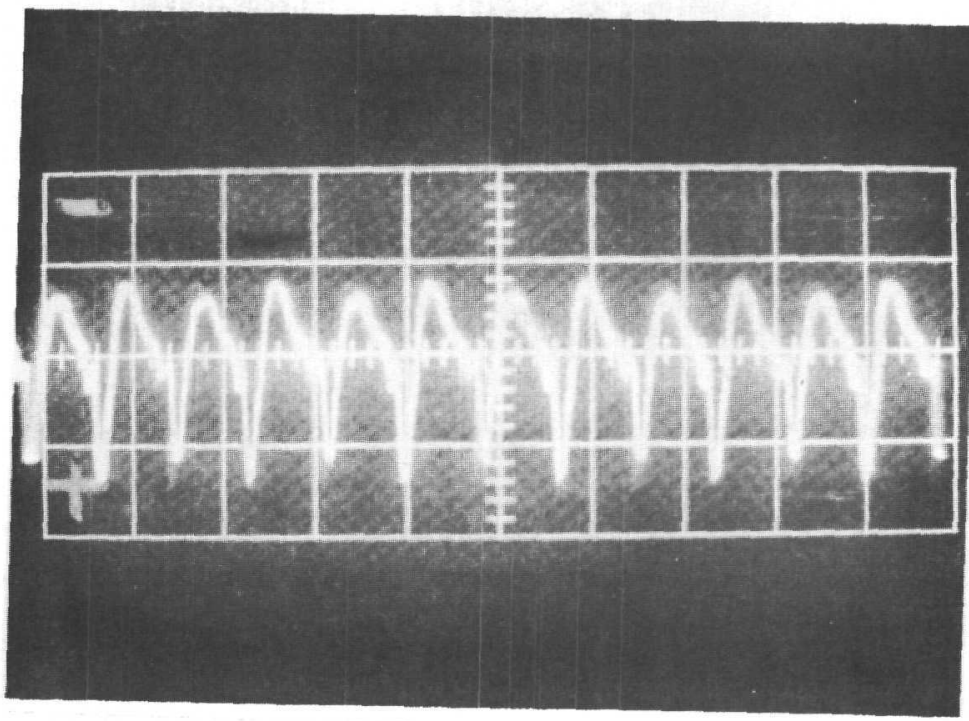

Fig. A. 18 -- Oscillations in DC power quadrant. Frequency $=59 \mathrm{KC}$. AC power about 10 percent of DC (ref. Fig. A.14)

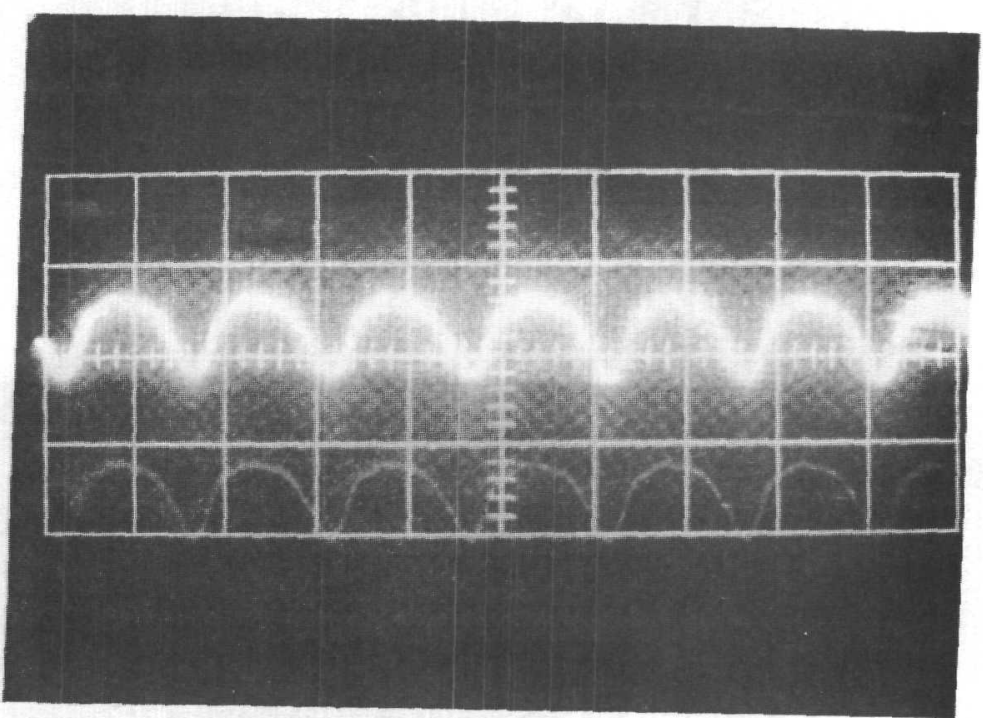

Fig. A. 19 - Oscillations in DC power quadrant. Frequency $=660 \mathrm{KC}$. AC power about 10 percent of DC (ref. Fig. A.16) 


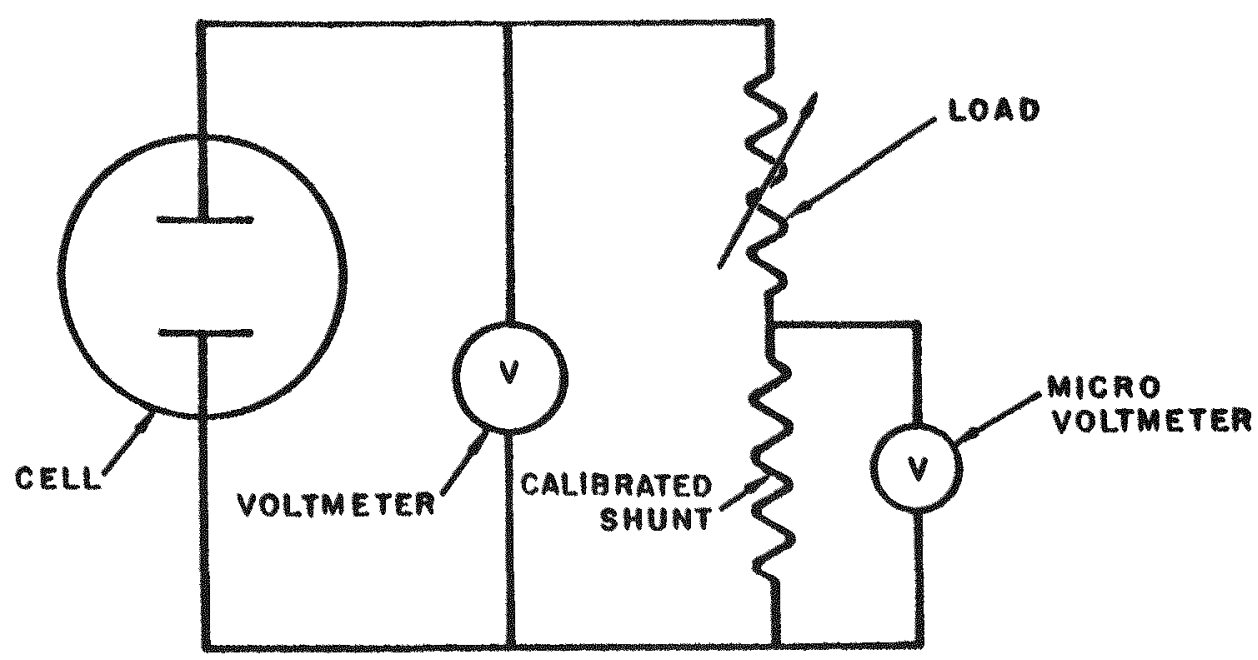

Fig. A. 20 -. Instrumentation for determining power quadrant characteristics. Microvoltmeter measures voltage drop across precision shunt to determine cell current.

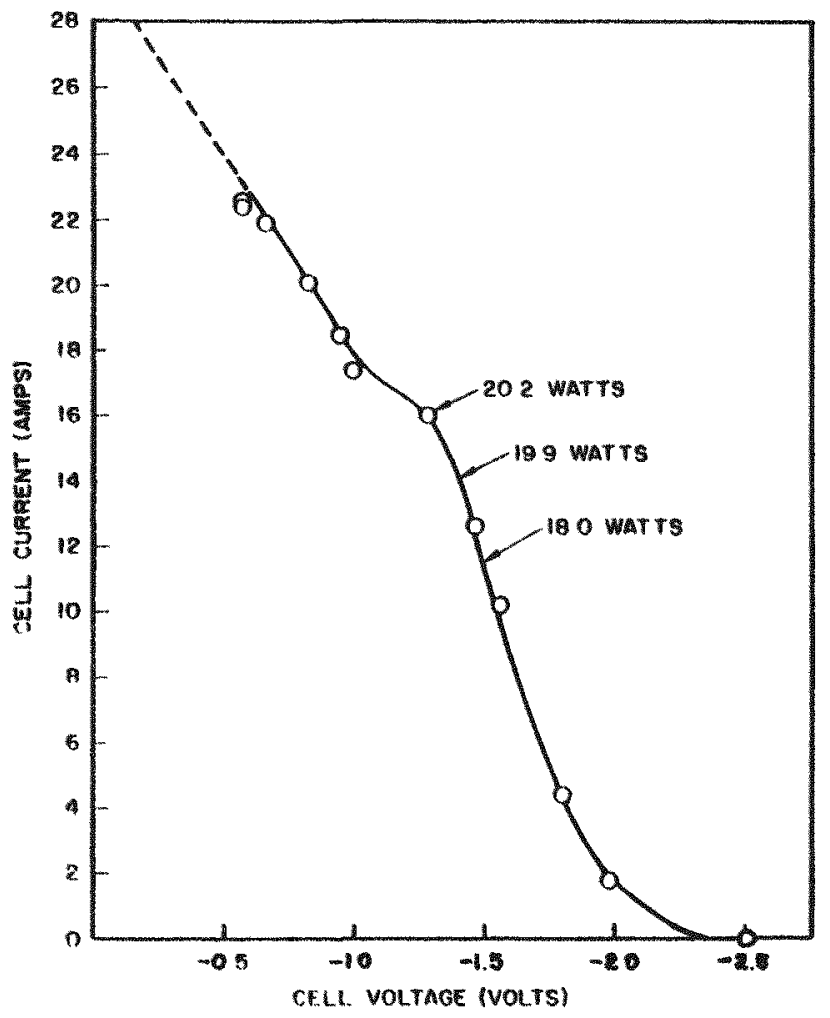

Fig. A. 21-- Cell current versus cell voltage for $T_{F}=2173^{\circ} \mathrm{K}$,

$$
P_{\mathrm{Cs}_{\mathrm{S}}}=3 \times 10^{-2} \mathrm{~mm} \mathrm{Hg} \text {, and } \mathrm{T}_{\mathrm{Cs}}=175^{\circ} \mathrm{C}
$$


exact short circuit current is not available. Figure A.21 is a standard plot of current vs. voltage for an emitter temperature of $2173^{\circ} \mathrm{K}$ and cesium control temperature of $175^{\circ} \mathrm{C}$. Figure A.2l also represents the maximum power output of Cell D.

\subsubsection{Short Circuit Currents}

A summary plot of the short circuit currents is shown in Figure A.22, together with vacuum emission data for 10:90 mol-\% UC-ZrC obtained in this laboratory. These data are the result of numerous measurements made from many samples of this particular carbide composition supplied by the metallurgical group supporting this project effort.

\subsubsection{Cesium Pressure Effects}

Previous experience in the operation of cesium cells suggested that the power output could be increased by higher cesium control temperatures (see refs. 2 and 3). Figures A.23 through A.26 are current vs. voltage plots for the indicated emitter temperatures and cesium control temperature of $225^{\circ} \mathrm{C}$. A diminution of cell current was immediately observed. Comparing Figures A.26 and A.21 for the same emitter temperature but different control temperatures indicates that, at the higher control temperature, the cell output is reduced by a factor of two. Figures A.27 through A. 30 show a further reduction in cell output at higher control temperatures of $275^{\circ} \mathrm{C}$. Contrary to other findings (see ref. 4) that the output at twice the cesium control temperature is higher by factors of 2 or 3 , the cell output had fallen by a factor of 5 . To establish that this trend was not irreversable, the cesium control temperature was returned to previous values in an attempt to repeat earlier observations. Figures A. 31 through A. 33 confirm the first observations for the appropriate operating conditions and include reference to previous figures for the purpose of comparison. It appears, then, that there is an unresolved conflict of data which should be subjected to further experiment.

A composite plot of cell output in watts as a function of emitter temperature for constant control temperature is shown in Figure A. 34 . 


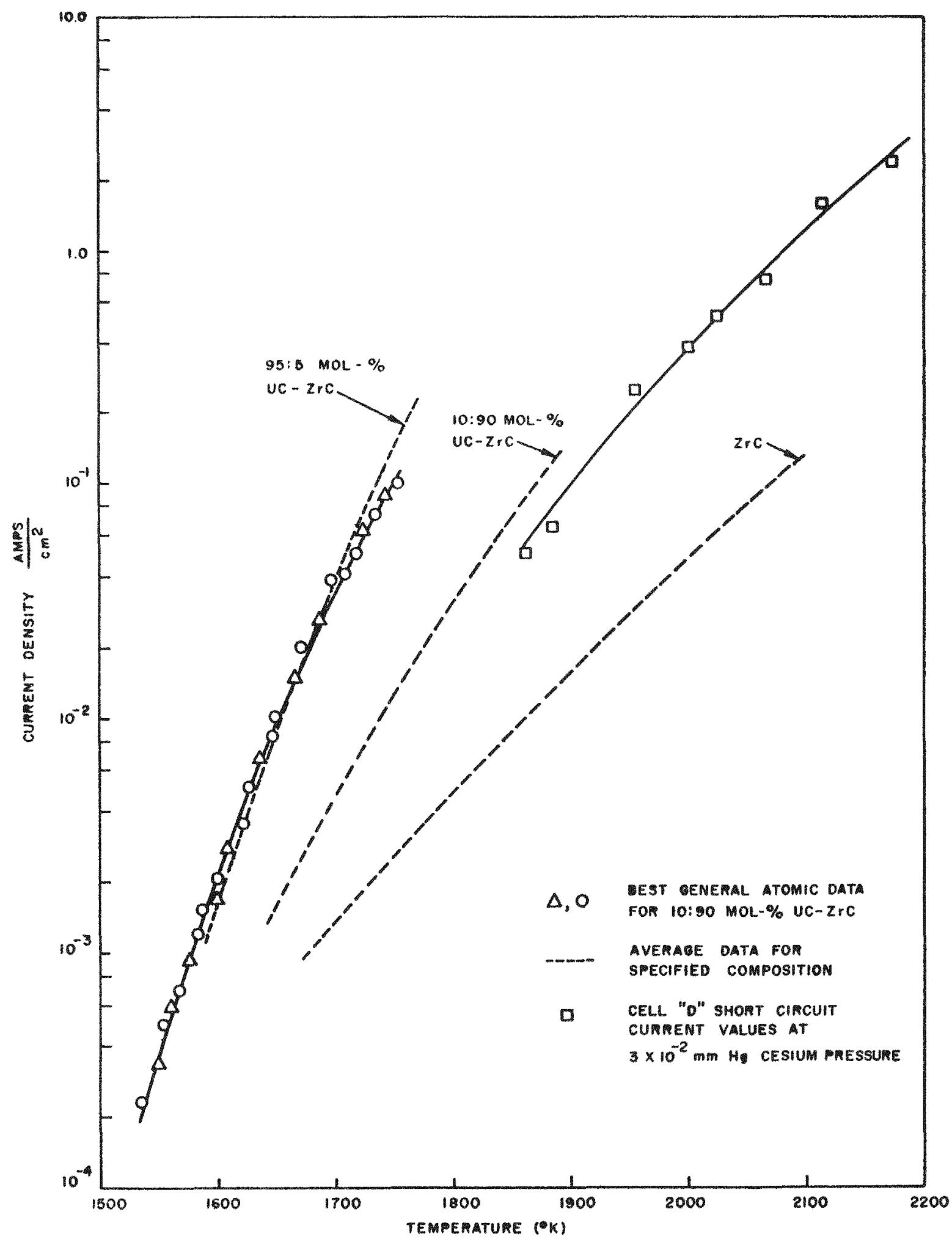

Fig. A.22 - - Current density versus emitter temperature. Vacuum emission data for General Atomic carbides. 


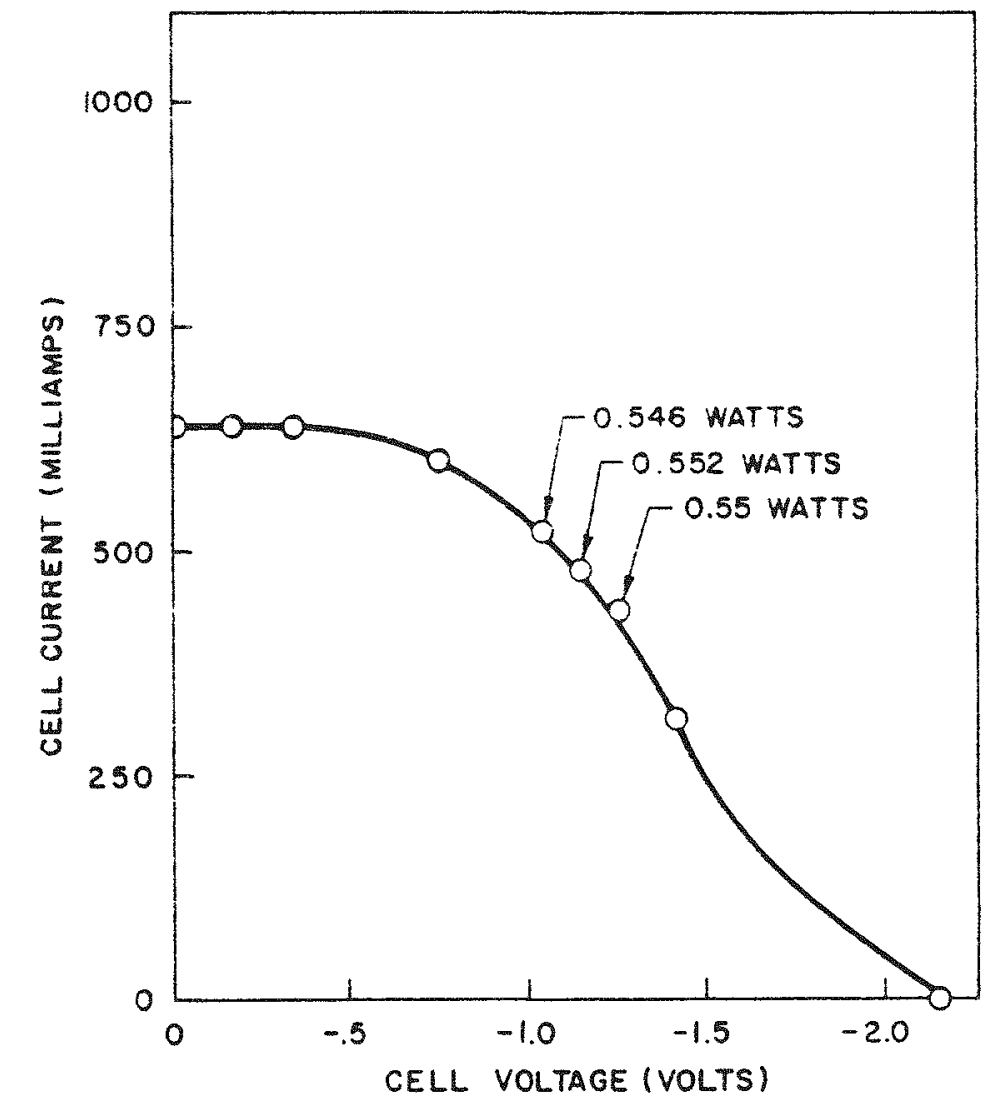

Fig. A.23 - Cell current versus cell voltage for $\mathrm{T}_{\mathrm{E}}=1.923^{\circ} \mathrm{K}, \mathrm{P}_{\mathrm{C}_{\mathrm{S}}}=0.2 \mathrm{~mm} \mathrm{Hg}$

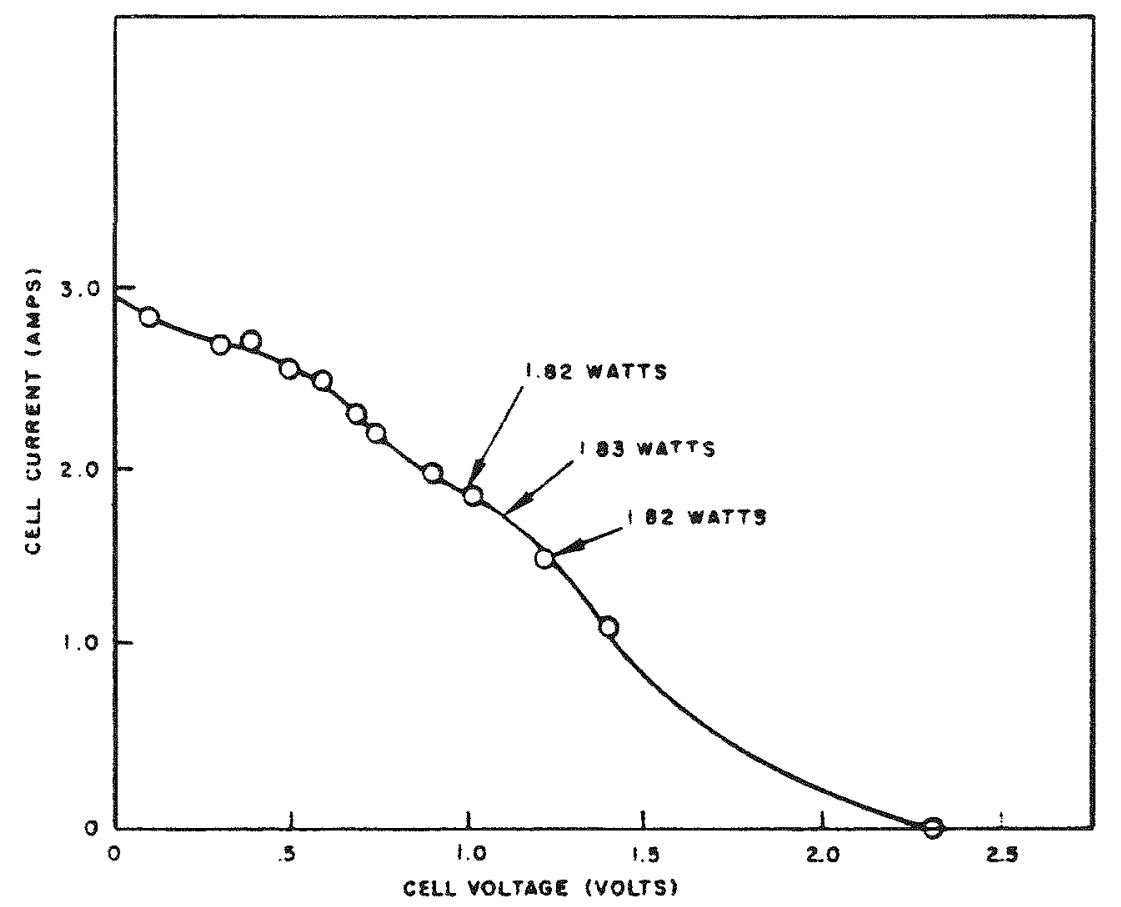

Fig. A.24 - - Cell current versus cell voltage for $\mathrm{T}_{\mathrm{E}}=1943^{\circ} \mathrm{K}, \mathrm{P}_{\mathrm{C}_{\mathrm{S}}}=0.2 \mathrm{~mm} \mathrm{Hg}$ 


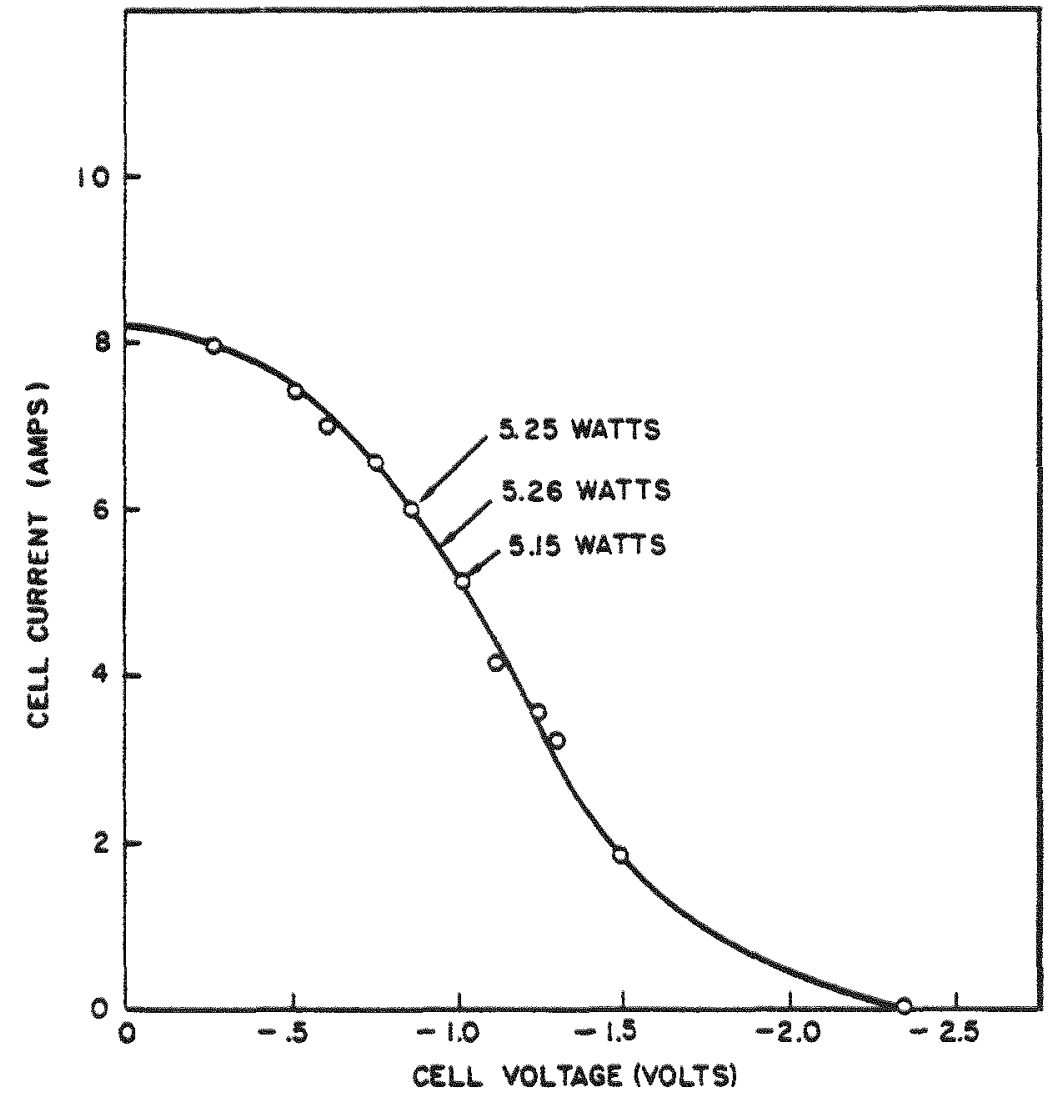

Fig. A.25 - - Cell current versus cell voltage for $T_{E}=2116^{\circ} \mathrm{K}, P_{C_{s}}=0.2 \mathrm{~mm} \mathrm{Hg}$

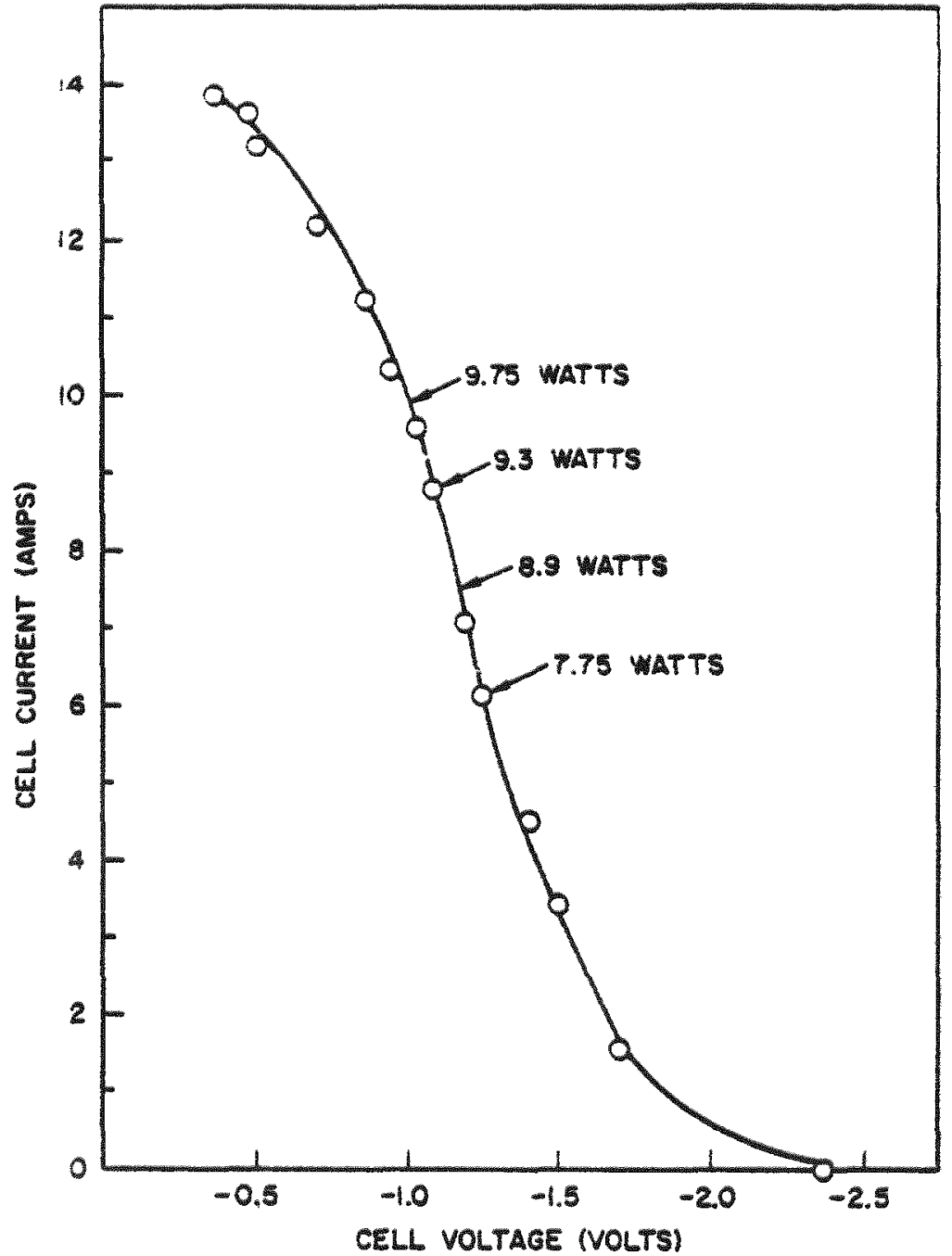

Fig. A.26 - Cell current versus cell voltage for $T_{E}=2173^{\circ} \mathrm{K}, P_{C_{s}}=0.2 \mathrm{~mm} \mathrm{Hg}$ 


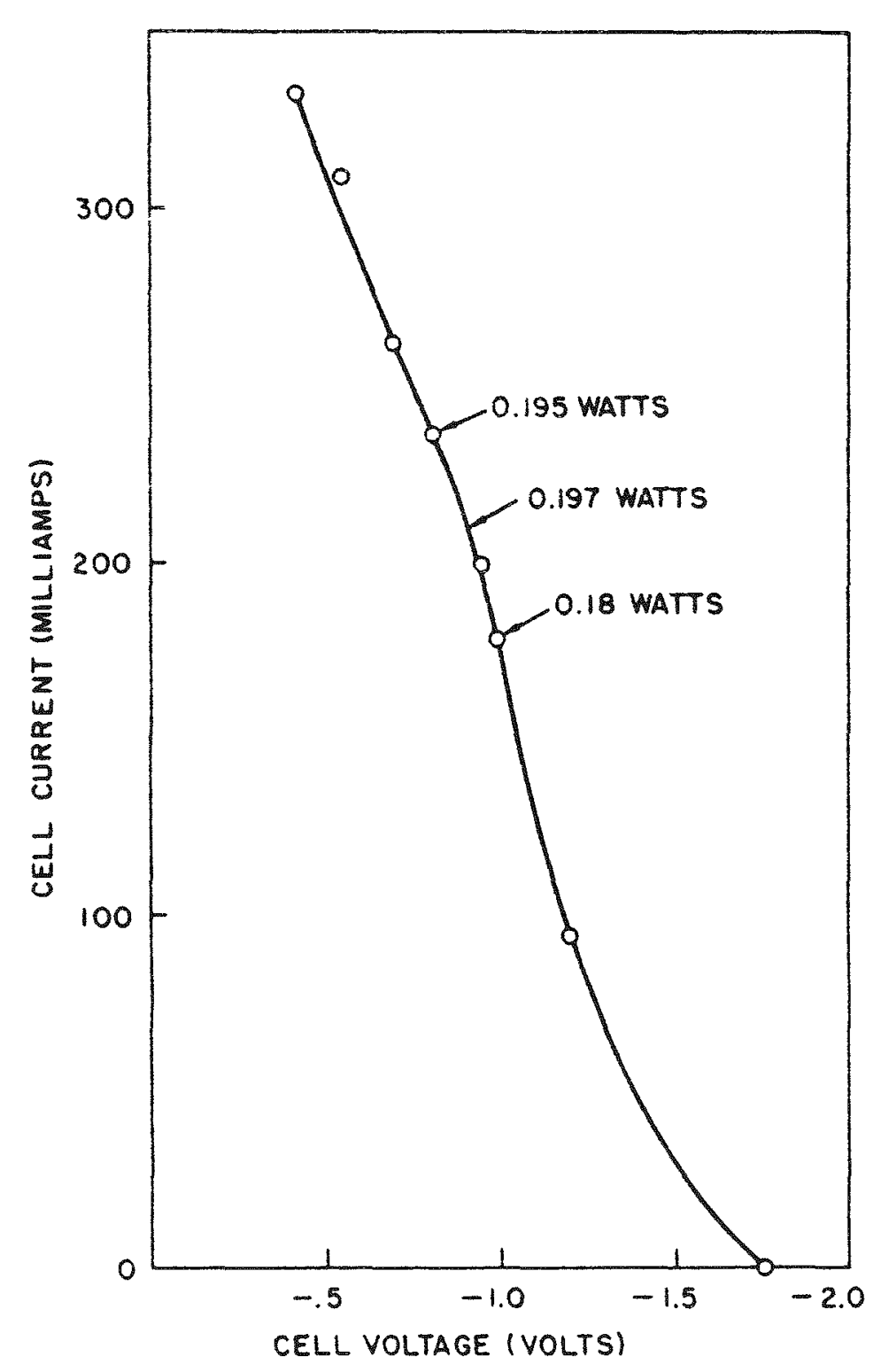

Fig. A.27 - Cell current versus cell voltage for $\mathrm{T}_{\mathrm{E}}=1942^{\circ} \mathrm{K}, \mathrm{P}_{\mathrm{CS}_{\mathrm{S}}}=0.8 \mathrm{~mm} \mathrm{Hg}$

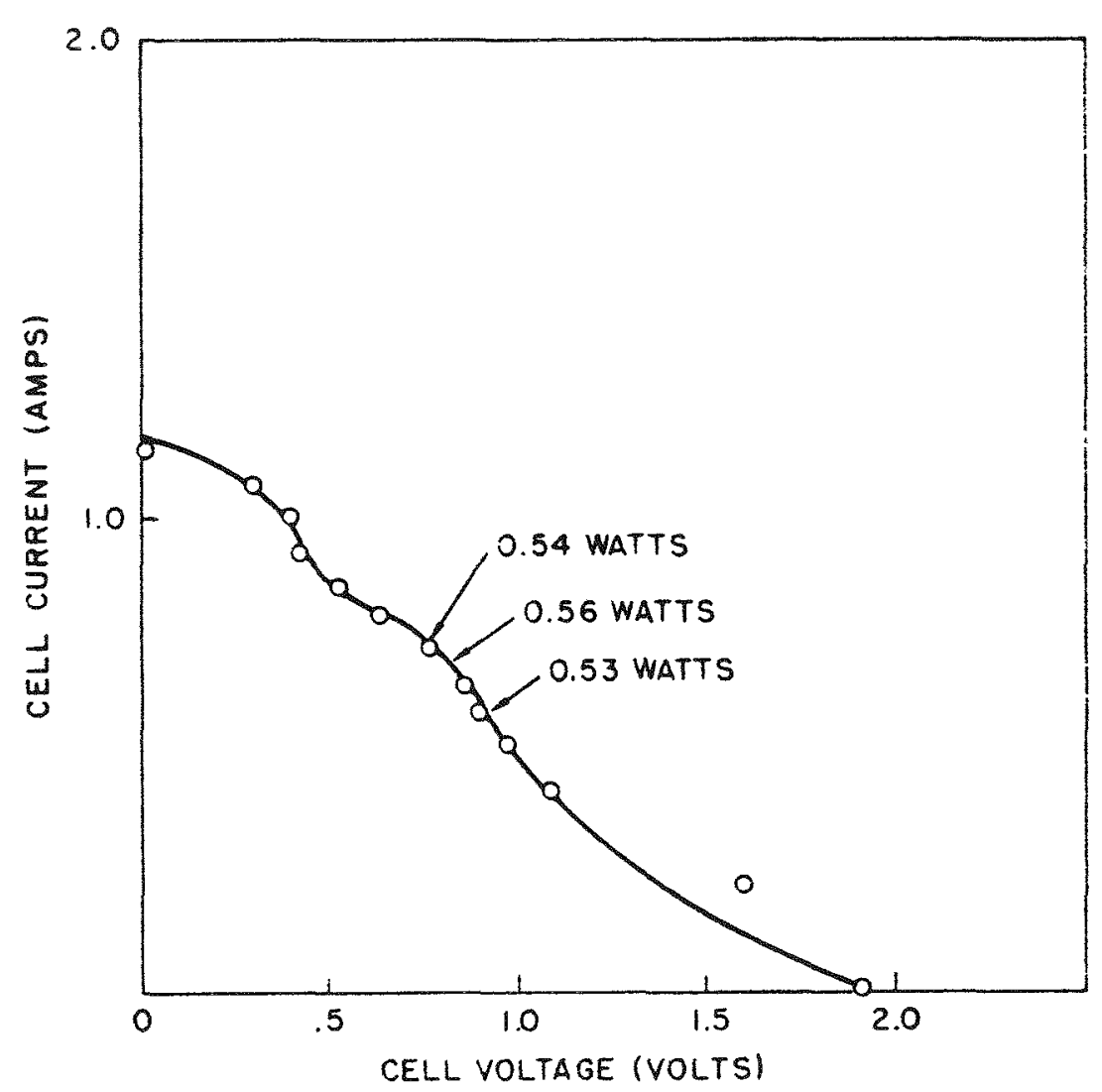

Fig. A.28 .. Cell current versus cell voltage for $\mathrm{T}_{\mathrm{E}}=2023^{\circ} \mathrm{K}, \mathrm{P}_{\mathrm{C}_{\mathrm{S}}}=0.8 \mathrm{~mm} \mathrm{Hg}$ 


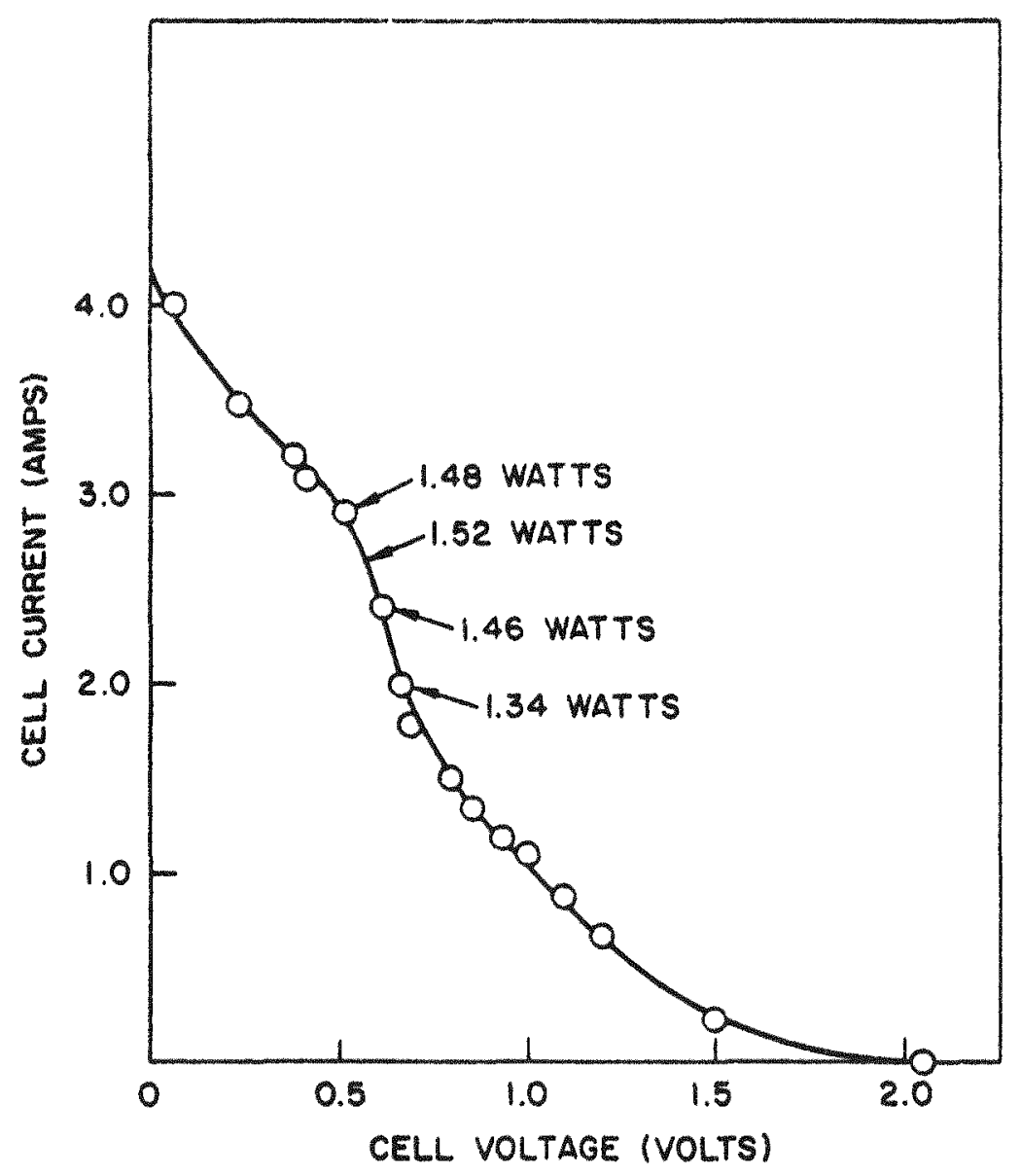

Fig. A.29 .. Cell current versus cell voltage for $\mathrm{T}_{\mathrm{E}}=2098^{\circ} \mathrm{K}, \mathrm{P}_{\mathrm{C}_{\mathrm{s}}}=0.8 \mathrm{~mm} \mathrm{Hg}$

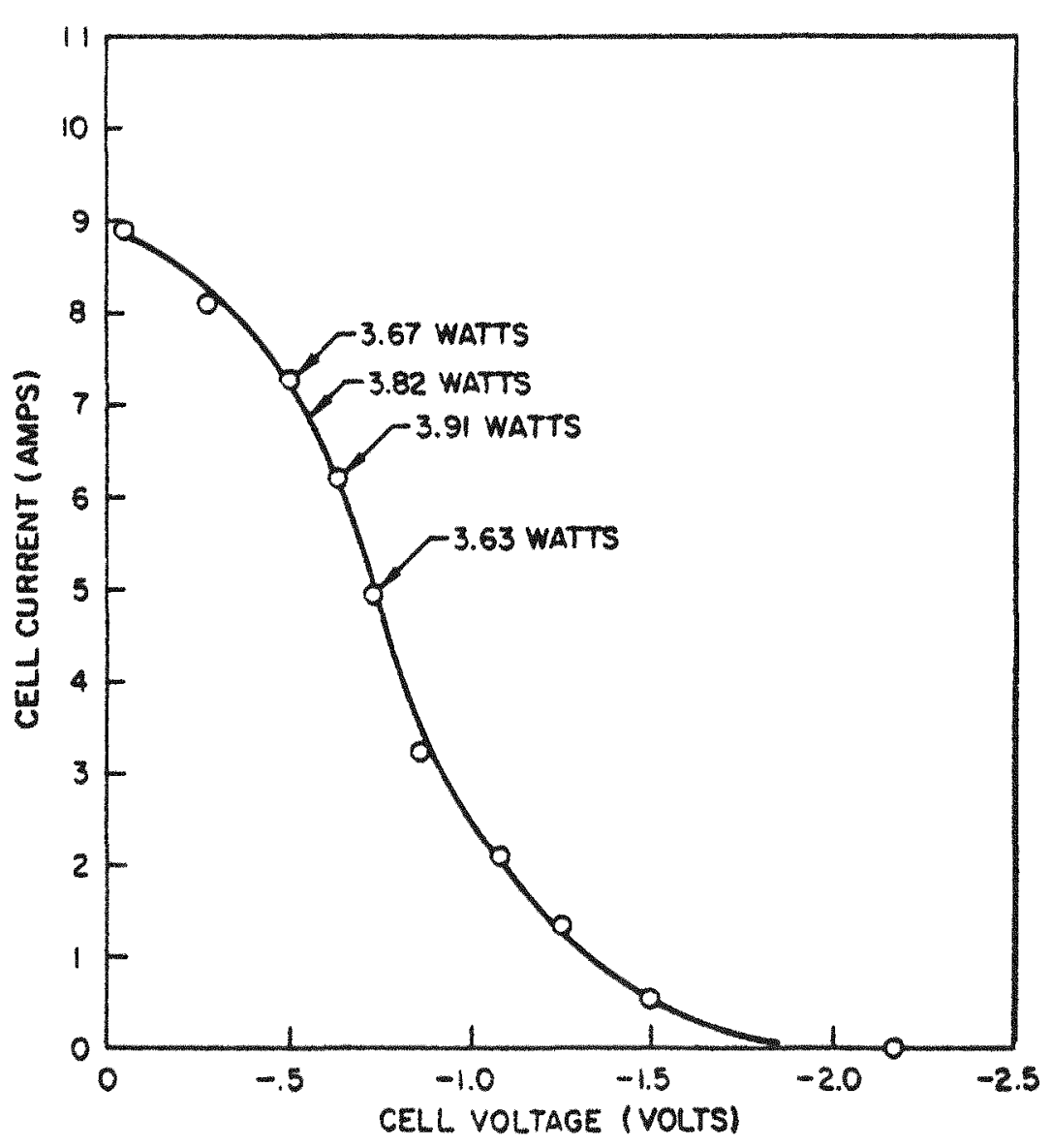

Fig. A.30 ... Cell current versus cell voltage for $T_{E}=2173^{\circ} \mathrm{K}, P_{C_{s}}=0.8 \mathrm{~mm} \mathrm{Hg}$ 


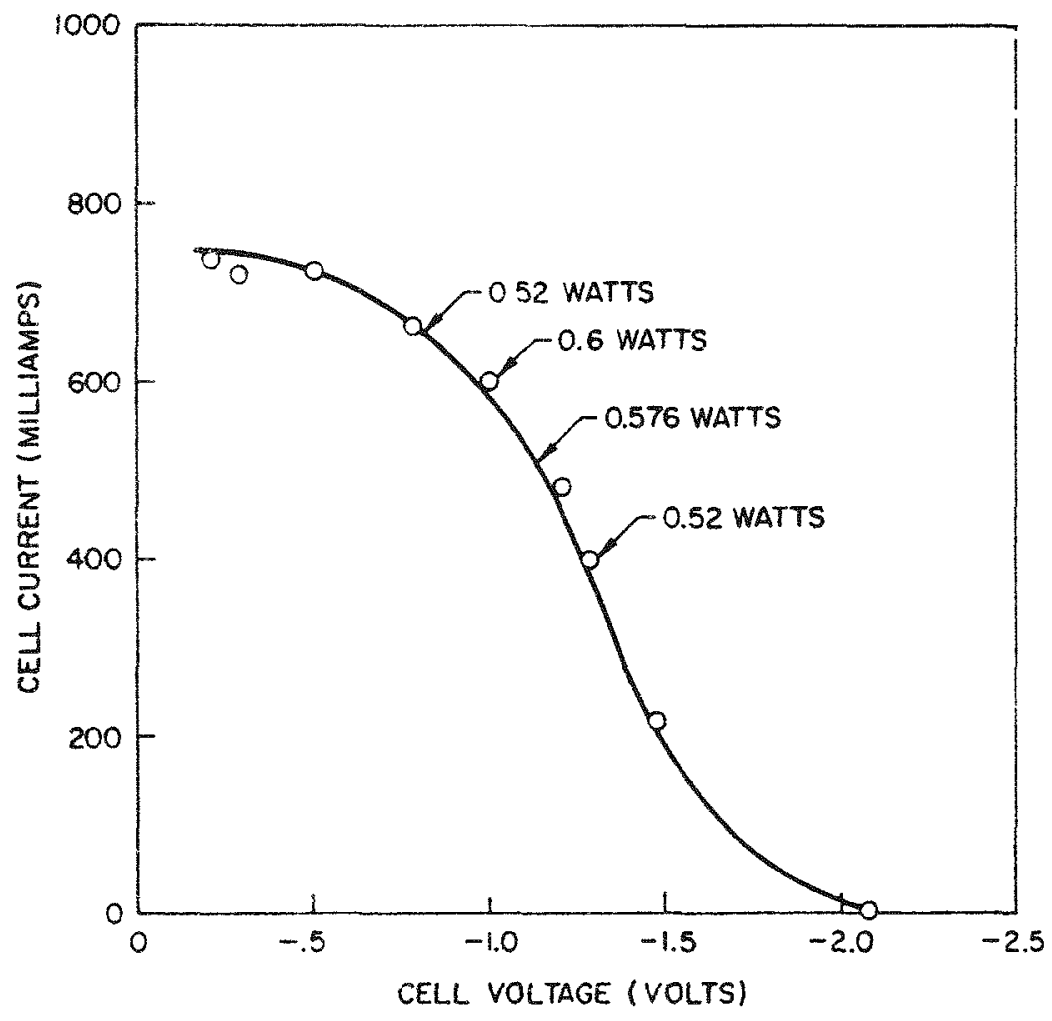

Fig. A. $31-$ - Cell current versus cell voltage for $\mathrm{T}_{\mathrm{E}}=1923^{\circ} \mathrm{K}, \mathrm{P}_{\mathrm{CS}_{\mathrm{s}}}=0.2 \mathrm{~mm} \mathrm{Hg}$

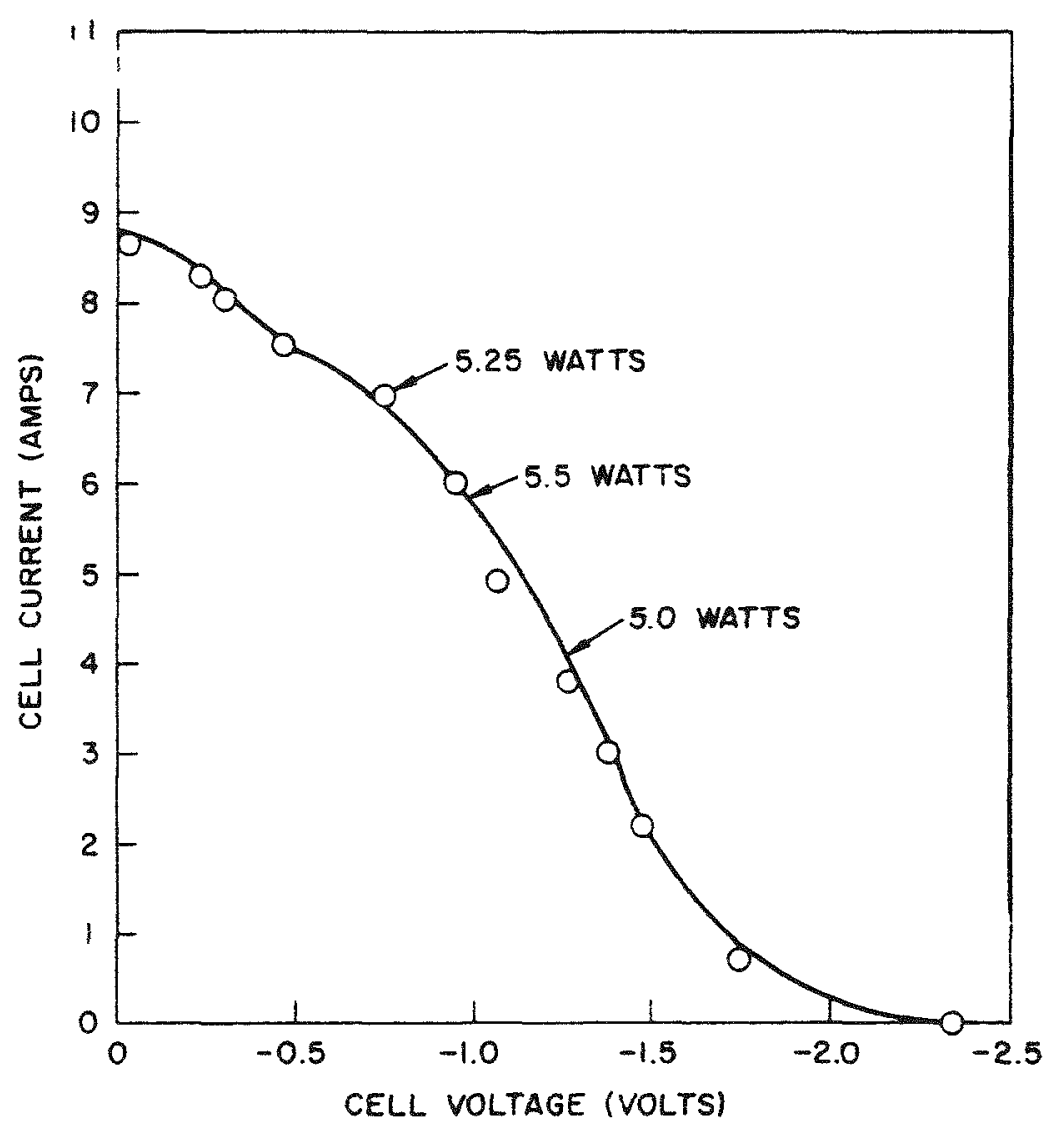

Fig. A.32 - C C 11 cursent versus cell voltage for $\mathrm{T}_{\mathrm{E}}=2098^{\circ} \mathrm{K}, \mathrm{P}_{\mathrm{Cs}_{\mathrm{s}}}=0.2 \mathrm{~mm} \mathrm{Hg}$ 


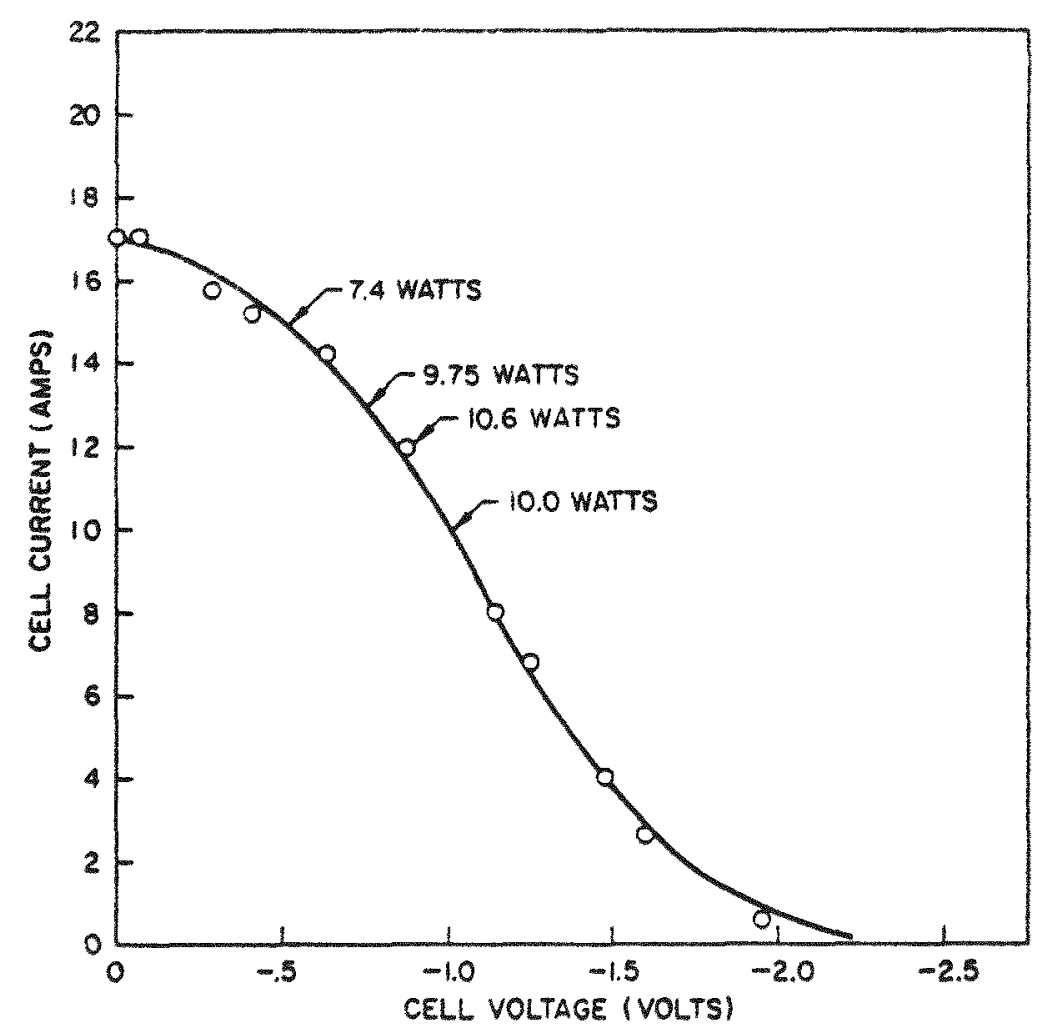

Fig. A.33-- Cell current versus cell voltage for $\mathrm{T}_{E}=2173^{\circ} \mathrm{K}, \mathrm{P}_{\mathrm{Cs}}=0.2 \mathrm{~mm} \mathrm{Hg}$

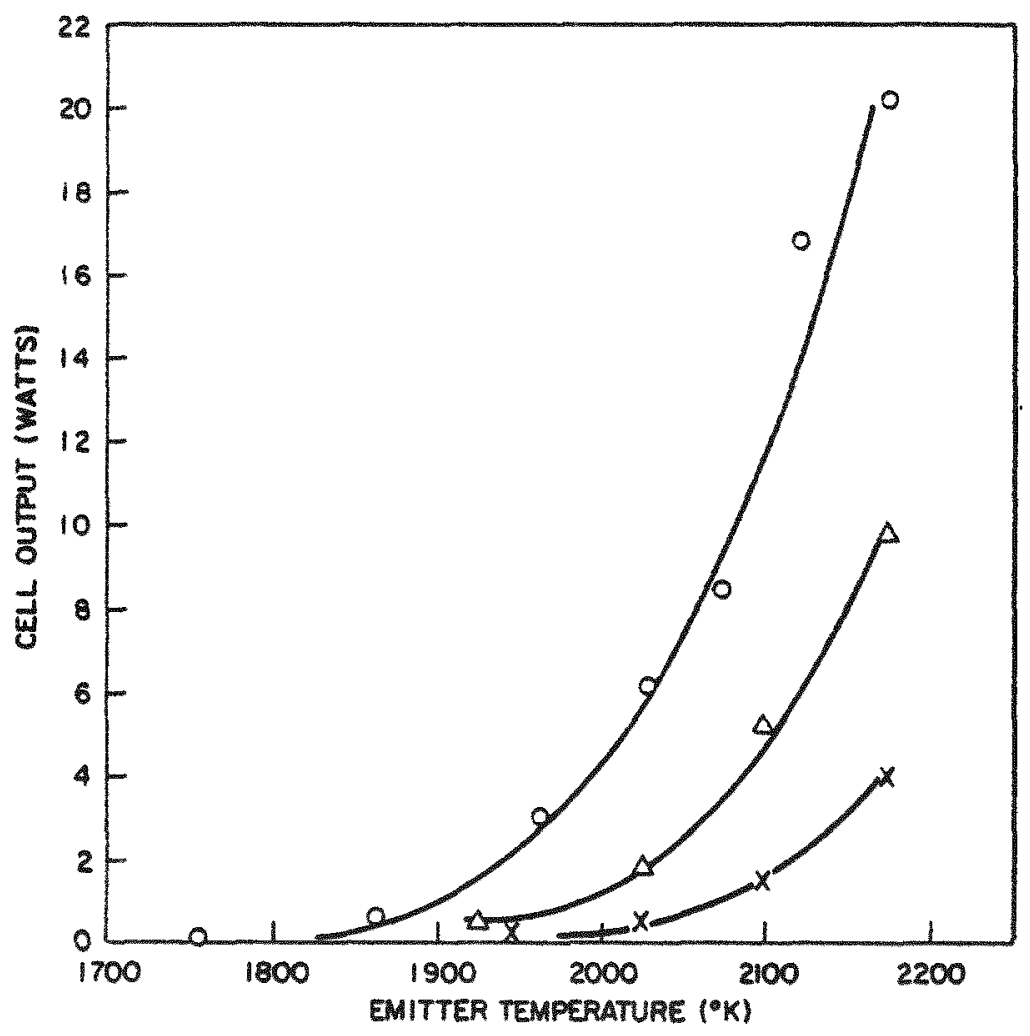

Fig. A.34 - - Composite plot of cell output in watts for varying emitter temperatures and cesium pressures 


\subsubsection{Effective Emissivity}

The effective emissivity of the cell over the entire range of emitter temperature is shown in Figures A.35 and A.36. The emissivity remained within the values of .35 to .43 and was, as expected, not a function of cesium control temperature or collector temperature. The effective emissivity is determined by measuring the total electron bombardment power necessary to obtain a particular emitter temperature. If the cell obeyed the condition of a black body (i.e. an emissivity of unity), the amount of bombardment power required to yield this emitter temperature is given by the Stephan-Boltzmann Law:

$$
\begin{aligned}
& P_{B B}=\sigma T^{4}(\epsilon=1) \\
& P_{B B}=\begin{array}{l}
\text { power in watts required to maintain a black body at } \\
\text { temperature. }
\end{array} \\
& \sigma \quad=\text { the Stephan-Boltzmann constant } \\
& T \quad=\text { emitter temperature in }{ }^{\circ} \mathrm{K}
\end{aligned}
$$

However, the power input to the emitter for a given temperature is observed to be much less than that for a black body. The ratio of the actual power input to the black body power is the effective emissivity for the cell. The measurement neglects small radiation and conduction losses for the bombardment geometry. Including these losses would lower the effective emissivity slightly. Likewise, the cell circuit is best left open to avoid Peltier losses.

With the exception of reduced emission at higher cesium temperatures, the initial behavior of Cell D compares quite favorably with planar geometry carbide cathodes operated in this laboratory. The cell components such as the base assembly insulator operated at $350^{\circ} \mathrm{C}$ and were thermal-cycled in a cesium environment extensively. The collector operated at $325^{\circ} \mathrm{C}$ for one eight hour period and the entire cell exterior was operated in vacuo of $3 \times 10^{-7} \mathrm{~mm} \mathrm{Hg}$. The cell was operated well below its available output 


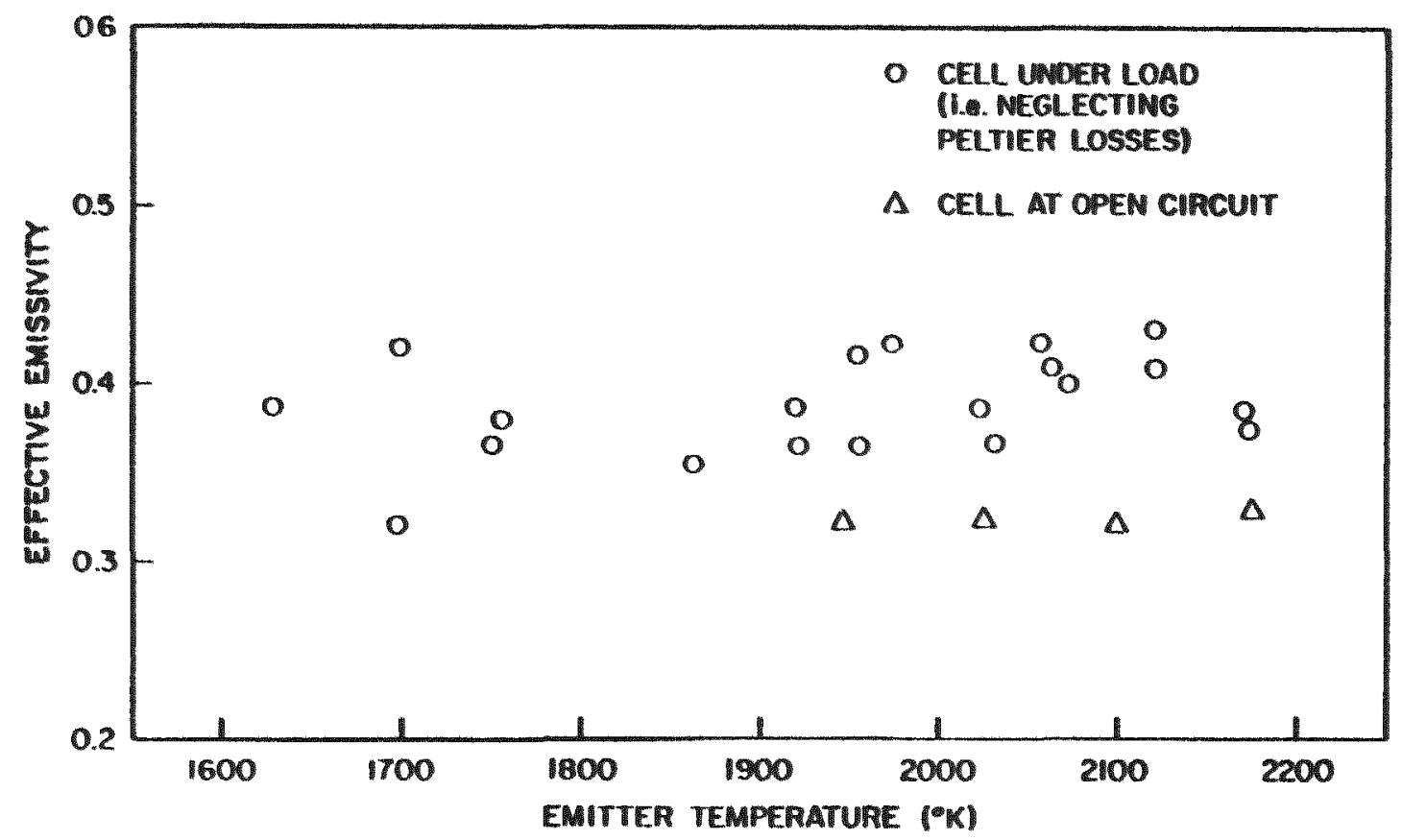

Fig. A.35 - - Effective emissivity versus emitter temperature during final cell preparation. Small conduction and radiation losses are neglected.

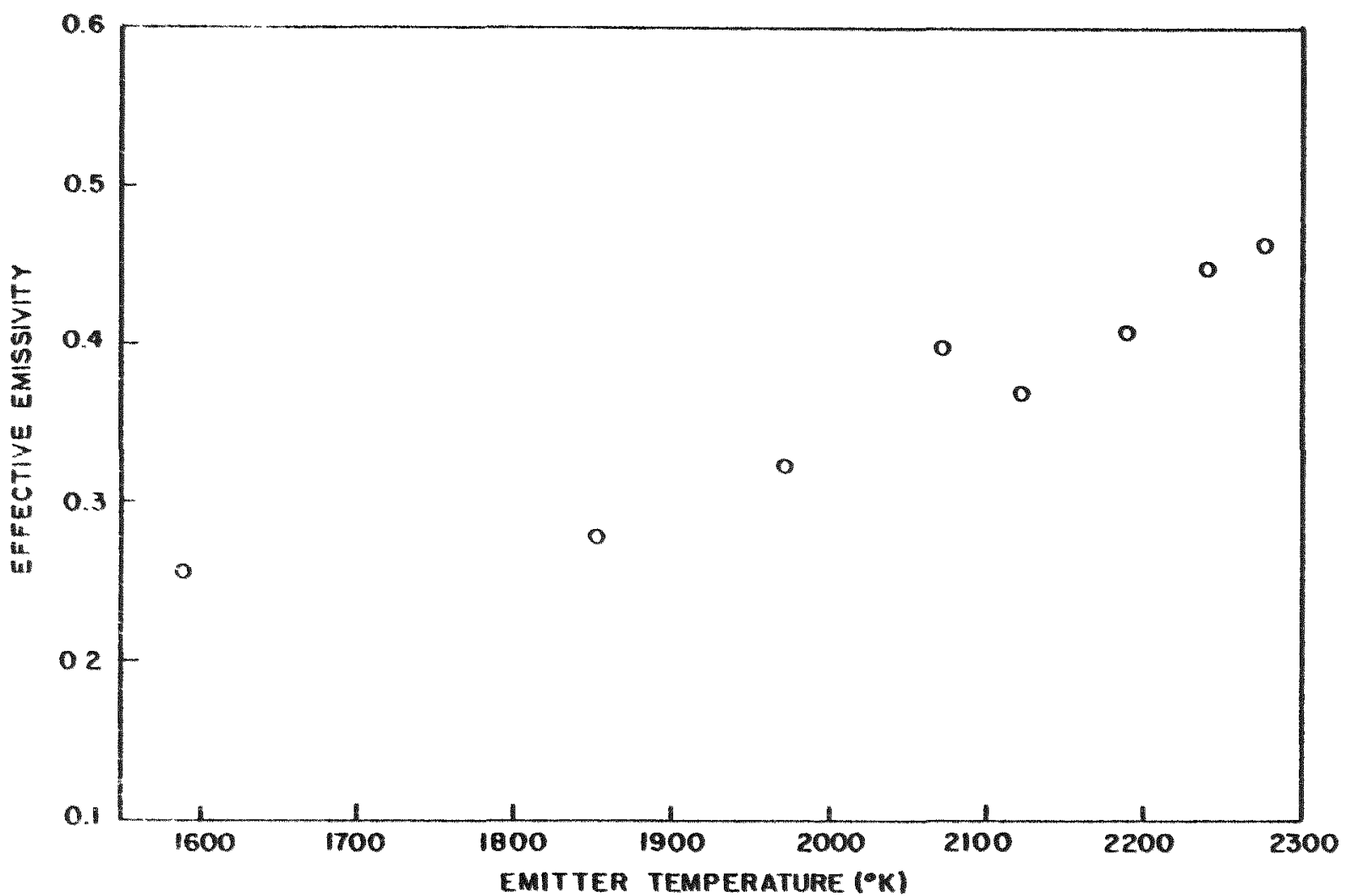

F: liminary investigation. Small conduction and radiation losses are neglected. 
and the components within their design limitations in order to proceed confidently with the life testing program.

\subsection{LIFE TESTING}

At the conclusion of the preliminary investigations, Cell D had operated a total of 30 hours. In the interest of obtaining life data pertaining to emitter integrity, cell output, effective emissivity and contact potential, the cell commenced continuous operation on December 27, 1961 at a power level of 1 watt $/ \mathrm{cm}^{2}$. The conditions necessary to sustain this output were an emitter temperature of $2103^{\circ} \mathrm{K}$ and cesium vapor pressure of $3 \times 10^{-2} \mathrm{~mm} \mathrm{Hg}$. Within the first 24 hours of operation at these conditions, a slight decline of cell power was noted. Figure A.37 is offered as record of the cell output as a function of continuing operation. After an elapsed time of 150 hours, the emitter temperature was increased to $2203^{\circ} \mathrm{K}$ with the cesium control temperature remaining at $175^{\circ} \mathrm{C}$. The cell responded initially yielding 1.2 watts $/ \mathrm{cm}^{2}$. Within 15 hours, this input had fallen to about $1 / 2$ watt $/ \mathrm{cm}^{2}$ (the level previous to increasing the emitter temperature). Changes in emitter temperature of $300^{\circ} \mathrm{C}$ to $400^{\circ} \mathrm{C}$ reflect only transient increases in the power level.

To explain the decreasing output of the cell it was postulated that uranium carbide was vaporizing from the surface of the emitter faster than the surface concentration was being replenished by diffusion from the body of the emitter. This would result in a depletion of uranium on the surface and an associated decrease in electron emission. To test this hypothesis advantage was made of the fact that the activation energy for vaporization is greater than the activation energy for diffusion, as generally observed for most materials. This means that the rate of vaporization changes more rapidly with temperature than does the rate of diffusion and 


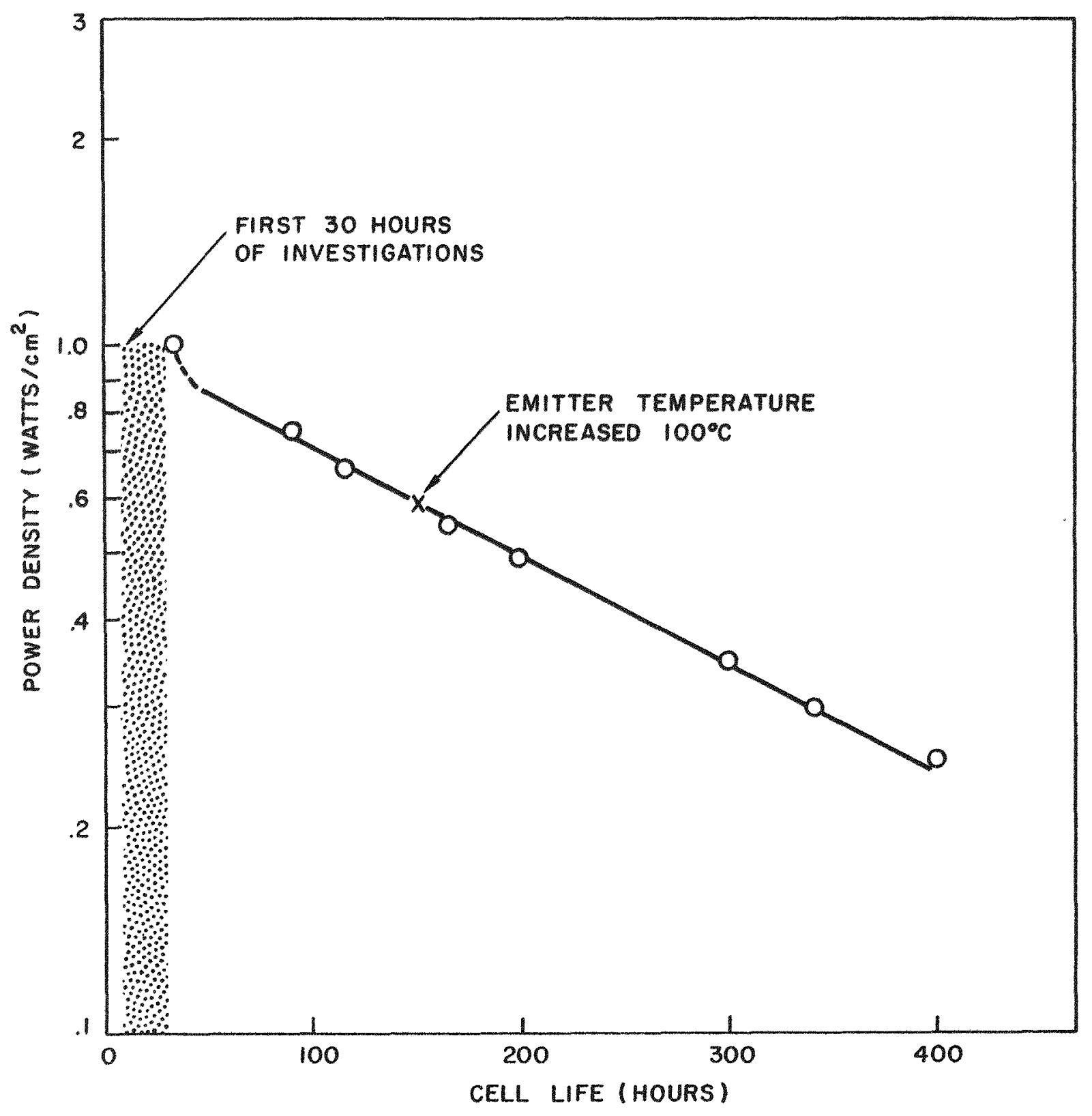

Fig. A.37 -- Power density versus cell life 
suggests that some lower temperature could be found at which the diffusion of uranium to the surface would be more rapid than the vaporization of uranium, thereby replenishing the surface uranium concentration and increasing the emission. The emitter temperature was, therefore, decreased to $1273^{\circ} \mathrm{K}$ for a period of 20 hours to allow surface uranium replenishment. Upon returning the emitter temperature to $2103^{\circ} \mathrm{K}$ the power output had increased by a factor of 2 , but dropped rapidly ( 3 to 4 hours) to its value before the replenishment treatment. Another low temperature treatment was performed at $1673^{\circ} \mathrm{K}$ for five hours with similar results, that is, an initial increase in emission followed by a rapid dropoff to its value before the low temperature treatment. Two facts now became apparent which contradict the vaporization - diffusion explanation of the decreased output:

(1) The output in both cases rapidly returned to its value before the low temperature treatment. In the extreme case where the diffusion was continued until no concentration gradient remained it would be expected that the output would return to its original value of 1 watt $/ \mathrm{cm}^{2}$ and would then decay according to the same rate observed earlier. Although the diffusion treatments conducted did not yield the original output, they should have resulted in some intermediate value of recovery, and the same rate of decay. This would have meant that some permanent effect of the treatment should be observed, which was not the case.

(2) The rate of decay appeared to be independent of temperature as evidenced by the continuation of the line in Figure A. 37 without any change of slope when the emitter temperature was changed from $2103^{\circ} \mathrm{K}$ to $2203^{\circ} \mathrm{K}$. Since both the rate of vaporization and the 
rate of diffusion are strongly temperature dependent, it would follow that any balance between the two would also be temperature dependent. Therefore, if the decay of output were governed by a balance between vaporization and diffusion, the rate of decay would have been temperature dependent.

\subsubsection{Observation of True Emitter Work Function}

Seeking further to explain the reduction in cell output, some simple measurements were taken on the cell to determine the emitter work function via the scheme of Peltier cooling. The evaporation of electrons from emitting surfaces has been analyzed in the literature. The result, known as Peltie $\mathrm{r}$ cooling, is given analytically as

$$
Q_{P}=J\left(\phi+\frac{2 K T}{e}\right)
$$

where

$$
\begin{aligned}
& Q_{P}=\begin{array}{l}
\text { the energy loss in watts by electrons evaporating } \\
\text { from the emitting surfaces }
\end{array} \\
& J=\begin{array}{l}
\text { the current in amperes appropriate to the emitting } \\
\text { temperature }
\end{array} \\
& \phi=\text { emitter work function in volts } \\
& \frac{2 \mathrm{k}}{\mathrm{e}}=\begin{array}{l}
\text { universal constants of Boltzmann and the electron } \\
\text { charge }
\end{array}
\end{aligned}
$$

The measurement procedure is as follows: At a given cell condition of known emitter temperature and cesium pressure, the short circuit current is determined from a voltage drop across a standard shunt. The bombardment power input to the cell is accurately measured for the given emitter temperature. The cell circuit is then opened, the evaporation of electrons from the emitting surface stops and the emitter temperature immediately rises (i.e. the emitter thermocouple response in millivolts is observed to increase and unbalance the potentiometer circuit that 
monitors the emitter temperature). The operator then decreases the bombardment power to the emitter by a sufficient amount to rebalance the potentiometer circuit. The new power input to the cell is measured.

The difference in emitter bombardment power yeilds the amount of Peltier cooling derived from the evaporation of electrons at short circuit current (no current flow at open circuit). Important to the measurements is the fact that any bombardment losses from radiation or conduction are virtually the same over the temperature range of experiment. In the same light, the entire experiment is by the method of differences: no standard or reference measurements are required. The results of the measurements are listed in Table I.

The average value of the work function (including the second order effects) is 2.54 volts. The accuracy in the measuring instruments is 0.5 percent and the temperature determination is accurate within 2 percent.

It should be noted that this direct measurement of work function yields a value that is lower than expected and is, in fact, below the value (about 3.04) consistent with the contact potential observed in the cell. This result may be anomalous; if so, it requires further attention.

The work function of an emitter obtained in this fashion is free from the encumbering emission constant $A$ in the Richardson equation which is strongly dependent on surface conditions. Restated, this method guarantees a true measurement of the lowest available work function of the emitting surface, regardless of patch effects. The most careful measurements (ref. 1) of the work function of 10:90 mol-\% UC-ZrC via vacuum emission techniques is given as 2.9 volts plus temperature dependent corrections not yet given. The work function of uranium carbide has been given as $2.94+1.1 \times 10^{-4} \mathrm{~T}$ volts (ref. 5).

The most convincing argument for the reduction of thermionic emission in Cell $\mathrm{D}$ is the small fractional area actually emitting with a work 
TAB LE I

Work function values for 10:90 MOL-\% UC-ZrC

\begin{tabular}{|c|c|c|c|c|c|}
\hline $\begin{array}{c}\text { emitter } \\
\text { temperature } \\
\text { in }{ }^{\circ} \mathrm{K} \\
\end{array}$ & $\begin{array}{c}\mathrm{J} \\
\text { in amps } \\
\end{array}$ & $\begin{array}{c}\mathrm{Q}_{\mathrm{o}} \\
\text { in watts }\end{array}$ & $\begin{array}{r}\frac{2 \mathrm{k}}{\mathrm{e}} \mathrm{T} \\
\text { in volts } \\
\end{array}$ & $\begin{array}{c}\phi \\
\text { in volts } \\
\end{array}$ & \\
\hline 2073 & 1.20 & 3.48 & .352 & 2.55 & \multirow{6}{*}{$\bar{\phi}=2.54$ volts } \\
\hline 2153 & 2.5 & 6.6 & .366 & 2.27 & \\
\hline 2203 & 2.88 & 6.42 & .375 & 2.86 & \\
\hline 2223 & 3.4 & 9.52 & .378 & 2.42 & \\
\hline 2293 & 5.26 & 15.09 & .39 & 2.48 & \\
\hline 2323 & 9.82 & 30.04 & .395 & 2.66 & \\
\hline
\end{tabular}


function of 2.54 volts. Of the remaining available area, there is a marked tendency, with time passage, to higher work function by the accumulation of unknown agents that raise the work function barrier, hence abating the flow of electrons. It is also possible that the plasma has become diluted with gases that are creating undesirable collisions or scattering of electrons in transit to the collector, hence lowering the current output of the cell.

\section{3 .2 Summary}

Reviewing the life testing record of the cell, the results are listed as follows:

1. The effective emissivity of the cell at various emitter temperatures from $1673^{\circ} \mathrm{K}$ to $2273^{\circ} \mathrm{K}$ remained in the range .35 to .43 during the 400 hours of cell operation. Figure A.38 is a record of these data.

2. The emitter integrity has been maintained throughout the life test and there has been no evidence of deterioration or material failure. The work function measurements taken after 350 hours of continuous operation y:elded a work function of 2.54 volts. The contact potential has remained about 1.2 volts, which added to the work function of cesium (I.8 volts) yields an approximate value of the emitter work function.

3. The cell output is low, however, the objectives sought in $l$ tems 1 and 2 were considered sufficient to allow continuous cell operation at low power. Moreover, as the cell operated, varrous possible causes for this adverse behavior were systematically elininated. 


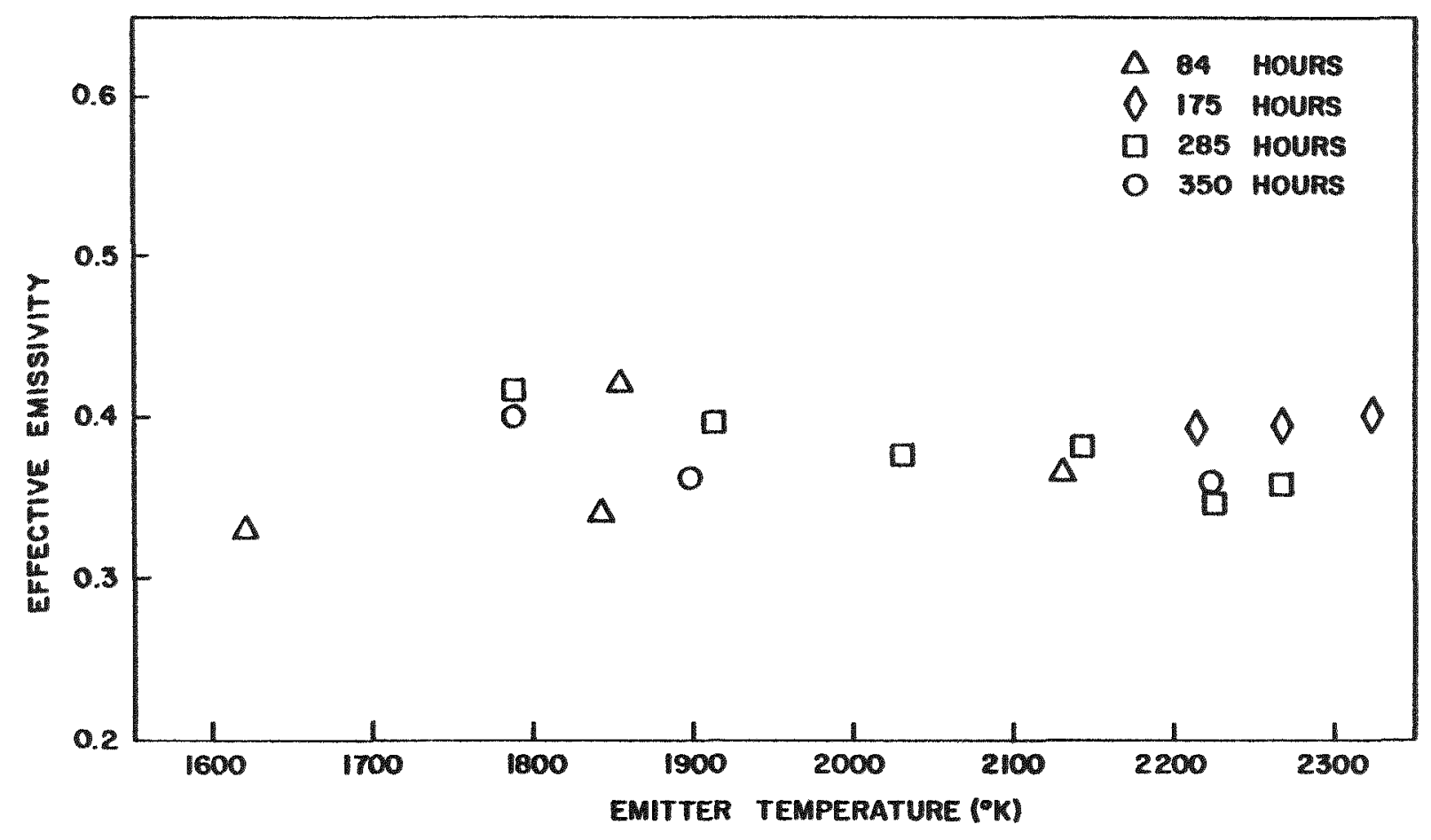

Fig. A.38 -. Effective emissivity versus emitte remperature during life tests. Small conduction and radiation losses neglected. All dati at open črcuit. 


\section{SUMMARY AND CONCLUSIONS}

\subsection{SUMMARY OF EMITTER FABRICATION TECHNIQUES}

A great amount of effort was placed initially on new techniques of fabricating the emitter. The earlier techniques called for the separate fabrication of a tantalum sleeve and of a carbide cup (emitter). The carbide cup was to be placed over the sleeve with a snug fit, and a metallurgical bond had to be created between the inner surface of the carbide cylinder and the outer surface of the tantalum sleeve. There was two drawbacks to this design. One was that the carbide cup had, of necessity, to be about $1 / 8$ inch thick. Since heat had to be delivered from the inner surface of the cup to the outer surface, a large temperature drop, of the order of $200^{\circ} \mathrm{C}$, had to be sustained. It was evident that a much thinner carbide cup would allow for a reduced temperature drop and therefore a lower inner surface temperature. This was an important objective because the upper temperature limit of the carbide-to-tantalum bond had been proven to be $2100^{\circ} \mathrm{C}$. Since outer surface temperatures of $2000^{\circ} \mathrm{C}$ had to be obtained in the testing program, the inner bond temperature had to be raised above the critical limit. On the other hand, the fabrication of a very thin carbide cup could not be attempted because of the chances of breakage during fabrication or assembly. A second factor was the problem of forming the bond between the pre-fabricated cup and sleeve.

Because of these limitations and difficulties, a completely new scheme of fabrication was attempted. This has proven to be successful and we now believe that this difficult matter, which has beset our program. since the beginning, has been satisfactorily resolved. The new scheme calls for the simultaneous fabrication of the sleeve and emitter. A cylinder of tantalum is embedded in the die chamber used for the hot pressing of the carbide powder. The carbide powder is added to the chamber so that it 
fully surrounds this tantalum slug and vibration techniques are used to achieve a very high density of powder in the outer zone. Temperature and pressure are then applied and the carbide powder is compacted direct. ly onto the tantalum piece; thus producing carbide shells of very high density. Next, the desired size and shape are achieved by further machining. The tantalum cylinder is drilled out so that it assumes the form of an open sleeve and the outer shell of carbide is cut down to size by use of a cavitron. Since the bond has already been formed, the thickness of the carbide can, in principle, be made arbitrarily small without fear of breakage.

Preliminary tests of this new structure showed an excellent bond and a resistance to bond breakage in cycling. These tests showed also that, since the carbide thickness had been greatly reduced, the whole system could be operated at full surface temperature without exceeding the theoretical bond limit. Several emitters of this kind have been made and tested, and reproducibility of the process has been proven.

Once the new emitter fabrication technique was fully proven, the cell as sembly program, which had been held in abeyance for a suitable emitter, was resumed. The emitter was also tested for thermionic emission characteristics and found to agree, within a factor of $1 / 2$, with prior measurements on emission characteristics for the 10:90 mole - \% UC $\mathrm{ZrC}$ composition. While this was a lower performance than desired, it was decided that the best course of action was to proceed with cell assembly since we still have to acquire information on the performance of the emitter in the cell environment. The copper collector was installed, the system was well baked and outgassed, a vac-ion pump was employed for the first time to achieve low pressure during the bakeout schedule and, after a low pressure was achieved at full operating temperature, the cell was sealed and the cesium ampule was broken. 


\subsection{SUMMARY OF CELL OPERATION}

Detailed analysis of cell operation is given in the remaining sections of this report. In this section we summarize only the special points of interest which were observed. First, a relatively low value of optical emissivity was observed for the emitter during all prior calibration tests. The value of total emissivity was about 0.4 . While values nearly this low had been observed before, we had usually found that the emissivity rose in value to nearly unity in cell operation. During the full period of tests of this new cell the low value of emissivity was preserved. Since this is the first time that such a low value has been obtained and maintained in operation, we cannot assert that we know the factors that would guarantee achieving the same result again. However, the fact that low emissivity was achieved this time shows that obtaining low values is possible in practice, and in any continuing program attention will be devoted to this point.

Second, voltage current diagrams were obtained giving evidence of the theoretical contact potential and space charge neutralization, the two factors which denote correct thermionic power generation. Contact potential and space charge neutralization were observed throughout the test.

Third, the effects of cesium vapor pressure were observed but were found to be in conflict with the results of prior studies at General Atomic. The prior studies indicated some enhancement of cell power as cesium pressure was raised in all cases. With this cell, a power peak was found and further increase of cesium pressure caused a reduced output. This conflict between this test result and those found in other cell tests remains to be resolved. It is to be noted that the performance figures for the new cell suffer because of the failure to obtain the benefits of cesium pressure enhancement.

Fourth, a steady deterioration of performance was noted for the entire period of operation. The initial thermionic emission, which was about $1 / 2$ 
of that previously observed for other samples, subsequently became less as operating time was logged. Experiments were performed which showed that this deterioration probably resulted from contaminant effects rather than from depletion of uranium from the emitter. We believe this to be a result of the utmost importance, since uranium depletion is a characteristic of the emitter that cannot be improved without resorting to completely new techniques. However, the effects of gaseous contamination can be solved by standard procedures of better outgassing and "gettering" within the cell chamber. We believe, therefore, that the deterioration of performance noted is a soluble problem and does not reflect on the intrinsic properties of the carbide as an emitter.

Fifth, a measurement of emission characteristic by the method of Peltier cooling was performed and has led to a new insight into the nature of carbide emission and the effects of poisoning. We regard this as one of the most significant findings of the entire program. Since the cell was of efficient design where thermal losses could be carefully controlled and observed, it was possible to measure the true work function of the emitter bv observing Peltier cooling. The experiment was simple; the cell was brought to operation under open circuit conditions, then the circuit was shorted and, because of Peltier cooling, the emitter temperature diminished. Then the input power was increased by an amount sufficient to raise the emitter temperature to the open circuit value. This increment must, of necessity, be the exact amount required to support the Peltier cooling Effect. Since the increment was known and the current could be directly observed, the true work function of the emitter could be directly found.

A true work function was found to be 2.5 volts even after deterioration. Allowing for possible errors, the maximum work function is taken to be 3.0 volts. Using this value, the emission current density at the operating temperature would have been about $90 \mathrm{amps} / \mathrm{cm}^{2}$ whereas only $3.5 \mathrm{amps} / \mathrm{cm}^{2}$ wis observed. If this be the case, the poisoning would have affected $3.5 / 90$ th of the area. This suggests a research program for controlling and improving 
emissions from the emitter. Diffusion of carbon into the tantalum support may also have some effect on the emission but this situation can be avoided in a reactor. While the 3.5 amp output is sub-marginal, an emission of 90 amps would greatly exceed the design objective of cell constructed for this program.

The original objectives of this program were to obtain data to show the feasibility of generator operation at 15 percent efficiency and to demonstrate operational lifetimes of 1000 hours. In the second phase of the program the objectives were raised. Under this program we were asked to show how 25 percent efficiency and 10,000 hour lifetime could be obtained. The results of our experimental program will be summarized here in relationship to the se objectives.

The two factors affecting efficiency are optical emissivity and the thermionic emission of the carbide emitter. We believe the observation of an effective emissivity of .35 to be of great significance to the question of efficiency. If the value of .35 for the emitter emissivity can be maintained, as our tests for 400 hours indicate, we can assume a black collector and still arrive at efficiency predictions in the 15-25 percent range. This may be an important fact for very long-term operation in which it will be impossible to control the optical characteristics of the collector. The more sensitive factor affecting efficiency is electron emission. The only cases so far in which superior emission have been observed have been in vacuum trials outside the cell. Unfortunately, these trials are limited to power densities below $1 \mathrm{amp} / \mathrm{cm}^{2}$ because excessive plate powers are required to observe higher currents. Therefore the currents that may be achieved in the operating temperature range must be deduced by extrapolation of the vacuum curves and such extrapolation is dangerous. The extrapolations we have made indicate a maximum current density of $40 \mathrm{amps} / \mathrm{cm}^{2}$ at $1950^{\circ} \mathrm{C}$. A current density of this value would substantially exceed the efficiency objectives of this program. The cell cathode area was about $10 \mathrm{~cm}^{2}$. The input power to supply radiation losses was about 500 watts. With an 
emission of $40 \mathrm{amps} / \mathrm{cm}^{2}$ the total output current would be 400 amps and the output power would exceed 400 watts. Thus, the efficiency in this case would approach 30 percent. However, current densities of such high value have not yet been obtained during cell operation. We believe that reaching the program objectives depends most sensitively on current emission, on controlling the factors that affect emission both in the preparation of the carbide and the operation of the carbide in the cell environment. A substantial amount of research remains to be done to prove that high performance can be achieved and maintained in an operating cell. However, there is nothing in the data to suggest that achieving high performance is not possible. The data obtained on predicting cell life is on a sounder footing. In a parallel program of research on the sublimation properties of the carbides, we have determined that a sublimation rate of $10^{-9} \mathrm{gms} / \mathrm{cm}^{2} / \mathrm{sec}$ occurs at a carbide surface temperature of $1830^{\circ} \mathrm{C}$. Tests of sample purity and of vacuum contamination have shown this to be a saturated value. For example, when the over-pressure of $10^{-6} \mathrm{~mm}$ of $\mathrm{Hg}$ was reduced to an extremely low value of $10^{-9} \mathrm{~mm}$ of $\mathrm{Hg}$. the vacuum sublimation rate was not altered. A sublimation rate of this value would correspond to a mass los of $30 \mathrm{mg} / \mathrm{cm}^{2} /$ year and would correspond to a dimensional change of the emitter of $3 / 1000$ of a $\mathrm{cm}$ per year or about $1 \mathrm{mil} /$ year. We have selected a dimensional change of $1 \mathrm{mil}$ as a criterion for cell life. This criterion is admittedly arbitrary and may be subjected to change. We believe; however, that, in a cell which has an interelectrode spacing of $20 \mathrm{mils}$, a net transport of $1 \mathrm{mil}$ of material should be tolerable but also should not be substantially exceeded.

The summary of the findings on both sublimation and emission allow a prediction of 25 percent efficiency at a one year life based on these criteria alone.

Given these performance objectives, a reactor of high performance for one-year life would be proven feasible. However, the performance and life characteristics depend on the intrinsic materials properties and 
since these properties may not be altered, the question should be raised "How can greater lives or higher performance be obtained?" We believe the answer lies in further investigations of sublimation rate in the cell environment. The vacuum sublimation rates that we have measured present the most pessimistic picture of emitter mass loss. The vacuum experiments are contrived to show net mass loss under the conditions where an atom that is lost from the surface will never be returned to that same surface. This is the appropriate means for measuring intrinsic sublimation rates but they may not be the conditions that pertain to an operating cell. There are two mechanisms that we consider to be of importance in the returning of sublimed atoms to the surface thereby reducing the net loss. One is the scattering of evaporated atoms by the cesium vapor present in the interelectrode space. Since there appears to be no reliable means of calculating the effect, we feel it has to be determined by direct recourse to experiment. The metallurgy program at General Atomic is now being altered to include the measurement of the sublimation rate of carbide emitters in the presence of cesium vapor densities appropriate to cell operation.

The second mechanism which can affect back-scattering is the presence of a high temperature collector. In some experiments that have been performed at General Atomic we have noted that there is complete condensation of the evaporated components of carbides on a collector when the collector temperature is at $300^{\circ} \mathrm{C}$. When the collector was held at $600^{\circ} \mathrm{C}$ we noted only partial condensation and at $900^{\circ} \mathrm{C}$ there was only a trace of condensation. In such experiments it was impossible to determine the fate of the emitter atoms which failed to condense on the high temperature collector. However, if a substantial fraction of those atoms condensed again on the emitter there would have been a substantial reduction of net emitter mass loss. The two factors affecting net mass transport remain to be investigated. However, it may be noted that those effects can only depress mass loss and not enhance it. We, therefore, believe that the 
lifetime of a cell predicted on the basis of vacuum evaporation is a pessimistic limit and that lifetimes in excess of one year may be possible.

The data that have been used to predict the performance of the thermionic generators are admittedly limited since the operational experience for all cells is less than one month of net operating time. The reason for the small amount of operating time is easily identified. The problems of simulating experimentally a reactor type module by electrical heating were much greater than we had anticipated at the onset of the program and a very large fraction of our effort had to be devoted to the problem of simulation. Electrical heating called for the solution of problems not germane to the problems of operating a reactor module. The main problem was that of preparing a vacuum-tight thermal bond between the emitter and its support structure. Now that this problem has been solved, we believe that the electrically heated cell can be studied intensively and that the large factor of uncertainty attending the prediction of generator life can be resolved. 


\section{PART B}

THERMIONIC REACTOR

FUEL ELEMENT CONCEPTUAL DESIGN STUDIES

I. GENERAL CONCEPT

The active core volume of a thermionic power reactor is directly proportional to the electrical power output of the reactor. This relationship can be visualized from the following equation:

$$
P_{e l}=J v\left(\frac{S}{V}\right)^{E} v_{f}^{E} V^{C}
$$

where $J$ is the current density at the emitter surface, $v$ is the output voltage produced across the thermionic converter, $\left(\frac{S}{V}\right) E$ is the surface-to-volume ratio of the emitter, $v_{f}^{E}$ is the volume fraction of the emitters in the reactor core, and $\mathrm{V}^{\mathrm{C}}$ is the volume of the core. For any given thermionic cell performance and fuel element core configuration, the product $J_{V}\left(\frac{S}{V}\right)^{E} v_{f}^{E}$ is fixed and the reactor electrical power level $\left(P_{e l}\right)$ is a function only of the size of the core.

This electrical-power reactor-size relationship is somewhat different from that found in the more conventional nuclear power systems where the reactor serves solely as the source of thermal power and the electrical conversion process is located external to the reactor. In such systems, the reactor size is determined primarily by heat transfer considerations. Core sizes are minimized consistent with maximum allowable fuel element surface heat fluxes which are in turn determined by the heat removal capability of the coolant and material temperature limitations within the fuel elements. With present technology, heat fluxes of 300,000 to $400,000 \mathrm{BTU} / \mathrm{hr}-\mathrm{ft}^{2}$ are readily achievable.

To compare this present heat removal capability with what might be required in a thermionic power reactor, consider a typical cylindrical thermionic fuel element. The emitter or series-connected array of emitters 
is located at the center of the fuel element and extends axially along the length of the element. Surrounding the mitters are the collectors and these in turn are encapsuled within the fuel element cladding. Heat is generated in the emitter, transferred to the collector, and then conducted radially through the collector and clad walls to the coolant. The clad heat fluxes are thus determined by the heat or power fluxes existing at the emitter surface. Since the cylindrical geometry of the fuel element results in an increase in clad surface with respect to the emitter surface, actual clad heat fluxes are substantially less than those present at the emitter surface. While the magnitude of this area increase or heat flux decrease depends strongly on the dimensional configuration of the fuel element, maximum values of clad heat fluxes can be obtained by considering directly the magnitude of expected heat fluxes at the emitter surface.

A typical value for the expected electrical power flux at the emitter surface $(J \mathrm{v})$ is in the order of $10 \mathrm{watts} / \mathrm{cm}^{2}$. If a conver aion efficiency of 15 percent is assumed, the heat transferred to the collector is 57 watts $/ \mathrm{cm}^{2}$ or in engineering units, 180,000 BTU/hr-ft ${ }^{2}$. Since heat fluxes of this magnitude are well within present heat transfer capability, it is generally concluded that core sizes for thermionic reactors are relatively independent of heat transfer considerations and are predominately controlled by the amount of emitter surface area required for a given electrical power output.

This power-volume dependency is particularly true for a space oriented thermionic power reactor. Efficient heat rejection from the power system necessitates high radiator temperatures and hence high coolant temperatures. The inherent advantages of a coolant offering a low vapor pressure at these temperatures plus the ability to be circulated by electromagnetic pumps dictates the use of a liquid metal such as lithium. Thus it is expected that the coolant used in conjunction with the space thermionic reactor will be more than adequate for the heat transfer rates anticipated.

The approximate size of a space thermionic reactor can be obtained as a function of power level by means of the equation previously stated. 
Rearranging the equation, the volume of the core is expressed as

$$
V^{C}=\frac{P e \ell}{J v\left(\frac{S}{V}\right)^{E} v_{f}^{E}}
$$

Typical values of the denominator terms are $J v=10$ watts $/ \mathrm{cm}^{2},\left(\frac{\mathrm{S}}{\mathrm{V}}\right)^{\mathrm{E}}=$ $3 \mathrm{~cm}^{-1}$, and $v_{f}^{E}=0.50$. Core volumes and spherical core diameters con. sistent with these values are listed below.

$$
\begin{array}{lccc}
\text { Electrical power, } \mathrm{P}_{\mathrm{el}} \text { (megawatts) } & 0.1 & 1 & 10 \\
\text { Core volume, }{ }^{\mathrm{C}}\left(\mathrm{cm}^{3}\right) & 6.7 \times 10^{+3} & 6.7 \times+0^{+4} & 6.7 \times 10^{+5} \\
\text { Core diameter }(\mathrm{cm}) & 23 & 50 & 110
\end{array}
$$

The very small core size at the 0.1 megawatt power level and the relatively small size for the 1 megawatt level are probably achievible only through the use of a high neutron energy spectrum or in a fast reactor. This is a result of the high temperatures anticupated for the space reactor (emitter temperatures of about 1500 to $2000^{\circ} \mathrm{C}$ ) and the lark of a hydrogen. bearing moderator capable of operation at the se temperatures. At the 10 megawatt power level, the core suze 's relativelv large and appears that the use of a beryllium oxide moderator would become - ftrat $x$ to reduce the core fuel requirements.

The problem of achieving a critical reactor of the s.ze s. $1 \mathrm{t}$ d for the 0.1 megawatt power level appears very difficult. Average fuel dersit es would have to be high which implies large emitter volume fractions. To achieve large values of $\mathrm{v}_{f}$, the fuel element configuration would trend toward large diameters with probably a single emitter extending the length of the core as opposed to a series-connected array of emyters. While permitting higher fuel densities, this results in lower values of $\frac{\mathrm{S}}{\mathrm{V}}$ with a probable over-all decrease in reactor power densitv and an increase in size over that stated. 
At the 1 megawatt power level and above, the criticality problem is considerably eased. The need for high fuel densities is relaxed and the design of the fuel element can be oriented toward higher power densities. The longer fuel elements plus the large emitter surface-to-volume ratio desired for these power levels introduce the need for short series-connected thermionic cells within the individual fuel elements. The multi-cell fuel element, then, is considered typical of the type of fuel element required for medium and high power ranges. The design calculations that follow are accordingly oriented toward the design of a thermionic fuel element applicable to a reactor electrical power level of approximately 1 megawatt. The interplay of the numerous variables is studied in the following sections and a preliminary fuel element conceptual design is established. 


\section{DESIGN CONSIDERATIONS}

As stated previously, for a 1 megawatt thermionic space reactor the fuel element design should consist of an array of series-connected thermionic cells rather than a single cell extending the entire length of the element. This conclusion results primarily from the desire to maintain the fractional power losses or voltage drops within the element itself to a relatively low level. These losses occur basically in three components of the fuel element. First, an electrical connection must be made between the high temperature emitter and the neighboring relatively low-temperature collector. In a single cell arrangement, this connection goes directly to the electrical load before it returns to the collector but a connection still must be made which involves a large temperature gradient across the connection. This lead then becomes a conduction path for heat losses from the emitter. In maximizing the cell performance with respect to this emitter connection or stem loss, it is found that the optimized stem voltage loss is dependent only on the material properties of the stem, the temperature difference existing along the stem, and the conversion efficiency of the cell. The expression for the loss is

$$
\text { voltage loss }(\text { stem })=\left(\rho^{s} k^{s} \Delta T^{s} \frac{2 \eta}{2-\eta}\right)^{1 / 2}
$$

where $\rho$ is the electrical resistivity and $k$ is the thermal conductivity of stem material. Thus the voltage loss in the stem is independent of the current and hence is unaffected by whether the emitter is a single unit or a multiplicity of small series-connected units.

The two remaining sources of voltage loss (the emitter and collector) are, however, dependent on the magnitude of the current associated with the fuel element. These losses can, of course, be reduced by lowering the electrical resistance of the components or otherwise increasing the cross 
section or the amount of material of the electrical conduction paths. There are restrictions on the extent to which the resistances can be varied. In the emitter, for example, the desire for high reactor power densities favors emitters of small radii. This results in high ratio of emissionto-conduction area along the emitter. Consider an emitter diameter of $1.50 \mathrm{~cm}$ and length $50 \mathrm{~cm}$, and an emitter surface current density of $6.25 \mathrm{amps} / \mathrm{cm}^{2}$, which are typical values for a 1 megawatt power system. The effective resistance of the emitter is approximately 0.003 ohms based on an emitter resistivity of $320 \times 10^{-6} \mathrm{ohm}-\mathrm{cm}$ (see Fig. B. 1). The total current emission is about 1500 amps which would result in an unworkable emitter voltage drop of 4.8 volts which far exceeds the open circuit voltage of the single cell. If, however, the emitter is divided into ten small components, the resistance of each component emitter is reduced approximately by a factor of ten. The total emission current per small emitter is a factor of ten less and the resultant voltage loss per cell is only 0.048 volts. It is concluded then, that for fuel elements containing an emitter section of the general dimensions and electrical resistivity as stated above, the subdivision of the emitter into an array of small series-connected emitters is a necessary and satisfactory means of reducing the voltage losses per emitter to a reasonable level.

A similar argument with one exception can be stated for the desirability of subdividing the collector. The exception is that the thickness of the collector can be increased without increasing the current that it must carry. In principle then, the cross sectional area of the collector could be made sufficiently large to transmit the entire current load of a single emitter extending the length of the fuel element. This added collector thickness constitutes additional non-emitter volume in the reactor with a resultant decrease in the average obtainable power density. The collector material also acts as a neutron poison to the reactor. Accordingly, the over-all effect of the large cross-section collector is an increase in reactor size for a given level of electrical power output. 


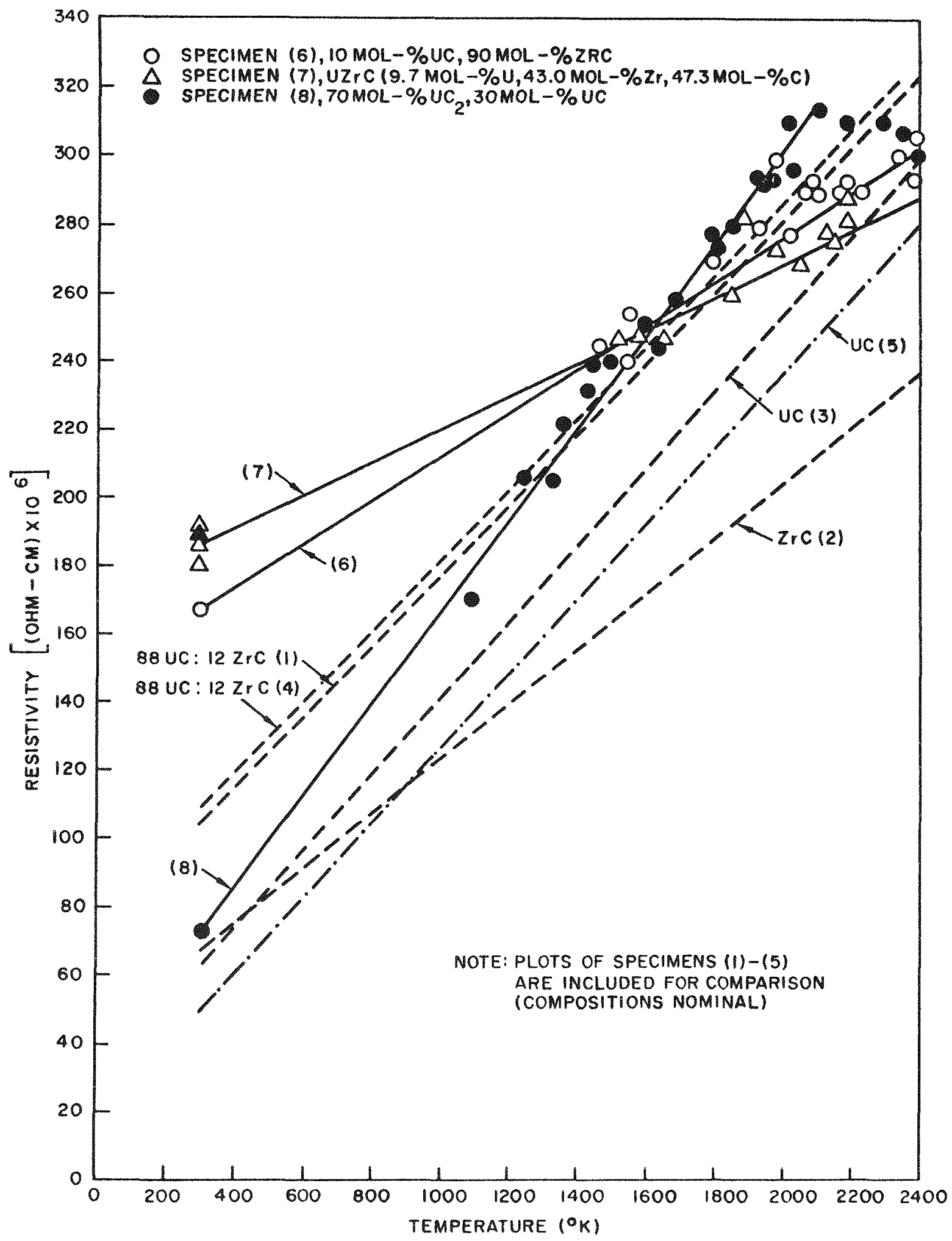

Fig. B.1 - - Resistivity of mixed carbides as a function of temperature (see ref.7) 
The fuel element design utilizing an array of small series-connected thermionic cells offers the additional opportunity of adjusting the design of the cells individually so that each emitter will operate at design temperature even though subjected to the ron-uniform flux distribution in the reactor. One means of accomplishing nearly uniform emitter temperatures is to adjust the fuel density in the emitters so that the fission density in each is uniform. An alternate way would be to adjust the surface-to-volume ratio of the emitters so that the ratio of the total power generated in each emitter to the surface area of the emitter is unform throughout the reactor. This implies varying the diameter of the emitters with small diameter emitters at the center of the reactor and large diameters at the outside. Such a method, it appears, would lead to complicate fabrication problems. Accordingly, the variable fuel loading scheme is assumed applicable for this study.

One potential problem associated with the multi-cell type fuel element is the consequence of a failure or partial failure of any one of the cells within the element. Since the cells are joined electrically in serzes, one cell failure causes a total fuel element electrical fallure. Similarly, since thermionic cells are essentiallv constant current devices, a reduction in the current capability of any one cell limits the current flow in the entire element. The fuel element cur rent output then is controlled or limited by the lowest performance cell. As a result, it appears that achieving design operating temperatures for each of the emitters within a multi-cell element is of paramount importance if a high performance fuel element is to be obtained. 


\section{FABRICATION CONSIDERATIONS}

In establishing a thermionic fuel element design incorporating a number of series-connected thermionic cells, consideration must be given to the means of fabricating or assembling the various components into a completed fuel element capable of fulfilling the necessary operational requirements. Included in these requirements are the need for

(a) a continuous fuel clad;

(b) means of establishing the series electrical connections between the cells;

(c) electrical insulation of the cells from the surrounding clad;

(d) positioning of the emitters within their individual collectors;

(e) high thermal conductances between the collectors and the surrounding clad;

(f) means of introducing cesium to the individual cells; and

(g) means of removing fission gases generated within and probably released from the emitters.

The fuel element design described in the next Section IV attempts to satisfy the above requirements while remaining amenzble to reasonable fabrication techniques.

One of the many particular fabrication tasks is the establishment of the electrical insulation between the individual collectors and the common clad. The cladding extends the full length of the element and forms the sealed container for the fuel element. It is expected that the clad will be a metalic material (niobium) in order to achieve capability with the coolant (lithium) of a space thermionic reactor. The clad and, additionally, the lithium coolant itself serve as an equi-potential body and accordingly 
the many thermionic cells located in the fuel element and in the reactor would be electrically shorted together if they were not insulated from this body.

The insulation material must serve a dual function; first, as an electrical insulator and second, as a thermal conductor. All the heat transferred to the collector by radiation from the emitter and Peltier heat. ing must be conducted across the insulation to the cladding where it can be rejected to the surrounding coolant. It is desirable that the temperature difference established across this conductance path be kept small. The size of the heat rejection radiator for the power system is a strong function of the coolant temperature and hence a coolant temperature only slightly lower than the operating temperature of the collectors is preferred when the over-all power system is considered. Accordingly, an insulator material with a high thermal conductivity and a thin cross-section is re quired. A further incentive for the small cross section is that the addition of insulator volume adversely affects the average power density that can be achieved in the fuel element.

Becalise of the desire for a small temperature difference between the collector and the 1 id as discussed above, the thrmal conductance across the interfaces between the collector and the insulation and similarly between the insulation and the clad must be maintained at high levels. Since these interfaces are located in the vacuum environment required for thermionic cell operation, high conductances can only be achieved through the use of metallurgical bonds or brazes between surfaces. Pressure contacts would lead to unpredictable and probably large temperature losses.

The entire fabrication task is aggravated by the relatively small size components required to achieve high reactor power densities. Typical dimensions of the cylindrical cladding for the fuel element are approximately $50 \mathrm{~cm}$ in length and $1.7 \mathrm{~cm}$ in drameter. Within this long slim tube 
must be located the individual cell components. The collectors must be positioned along the entire clad length and the interface bonds completed as discussed above. Within each collector, the emitter must be aligned and secured in close proximity $(0.05 \mathrm{~cm}$ or less) to the collector. Electrical connections between neighboring cells are required which, if they are to be reliable and are to exhibit low electrical resistances, should be braze-type junctions.

Inspection of the completed fuel element assembly also presents particular problems. Since each cell is an open circuit under non-operating conditions, possible electrical shorts or opens anywhere in the electrical circuit within the fuel element are difficult to detect with simple test devices. In general, then, it is concluded that the basic fuel element design must incorporate as many features as possible to ease the fabrication and assembly problems and also to permit internal inspection and testing of the element through most of its manufacture. 


\section{IV . FUEL ELEMENT DESCRIPTION}

The design features of a thermionic fuel element applicable to a space thermionic reactor are lllustrated in Figures B.2, B. 3, and B.4. The design is based on the series-connected multiple cell concept and utilizes a split component arrangement to ease the problems of fabrication and inspection discussed in the previous section. The element consists of two identical halt-cylindrical assemblies, each of which forms an independent series-connected array of thermonic cells. When the two half-assemblies are welded together, electrical connections at the ends join the two series arrays in parallel. While the parallel circuits are electrically insulated along the length of the fuel element, all the thermionic cells share a common cesium supply through the use of the interconnecting void space separating the joined half-assemblies. Cesium vapor permeates the length of the fuel element through this channel from the cesium reservorr located at one end of the element. The vold channel serves also as a means of evactiating the fuel element prior to operation and permits continuous purging of fission products during operation.

An individual thermionic cell consists of a collector, two collector end pieces, an emitter, two alignment insulators and a support pin, and an electrical connector bar. The convex surface of the collector is flame coated with a thin layer of electrical insulation. The insulation surface is metalized to permit brazung of the collector body to the surrounding clad. The emitter is aligned relative to its collector by means of a support at each end, the electrical connector stem serving as one support and the aligmment pin as the other. Small insulators surrounding each support electrically insulate the emitter from the collector. Supporting the emitter directly from its collector insures that the spacing between the emitter and collector is determined only by the two bodies themselves. As a result, 


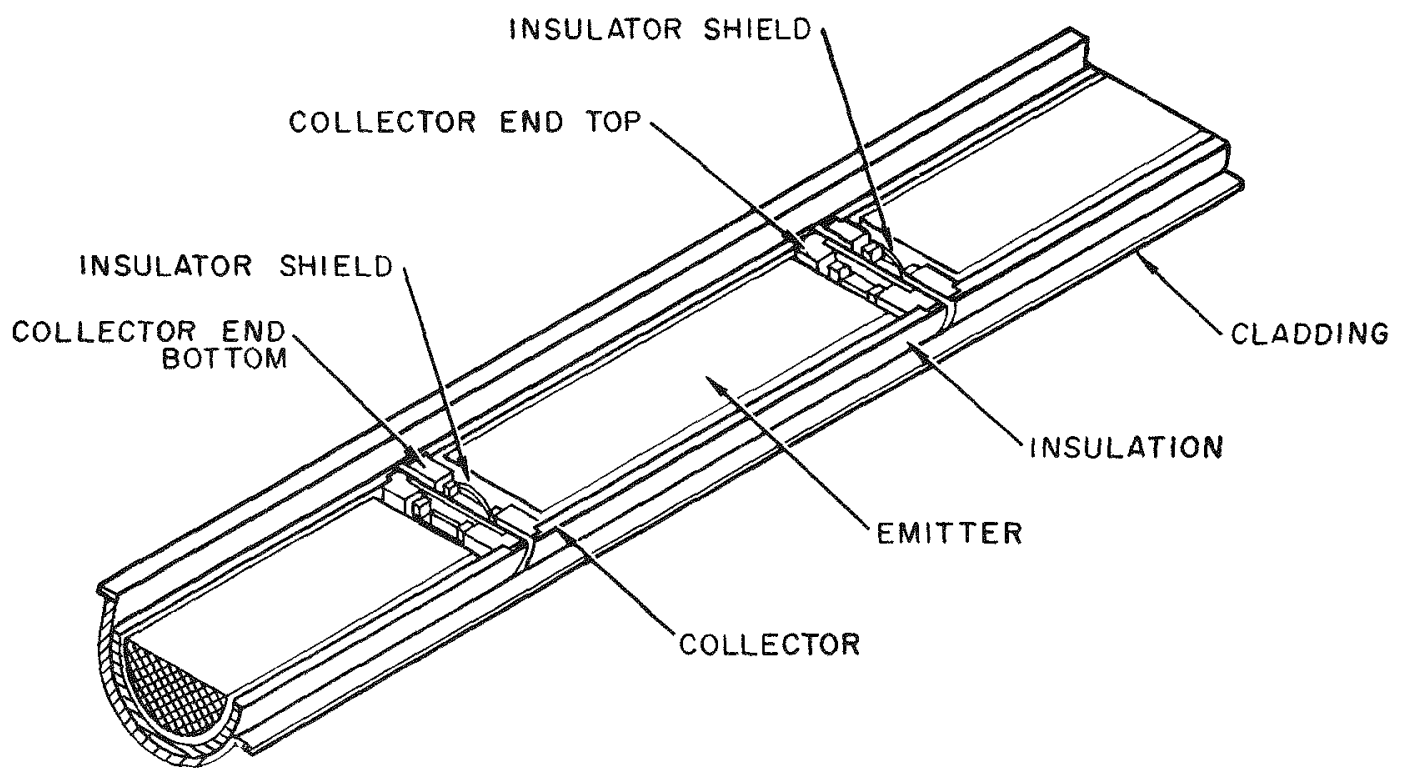

Fig. B. 2 - - Half-element assembly 


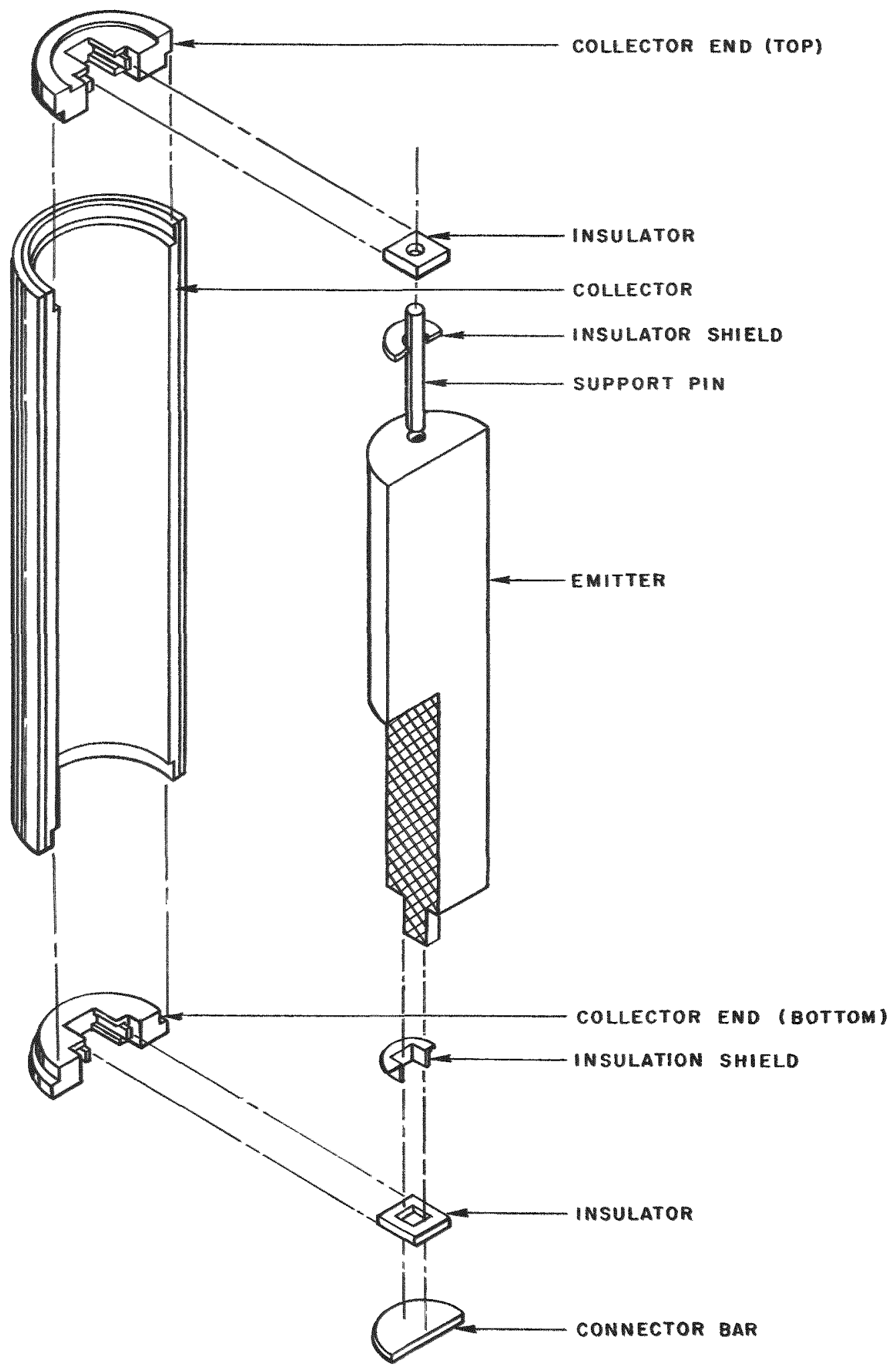

Fig. B.3 -- Exploded view of single cell 


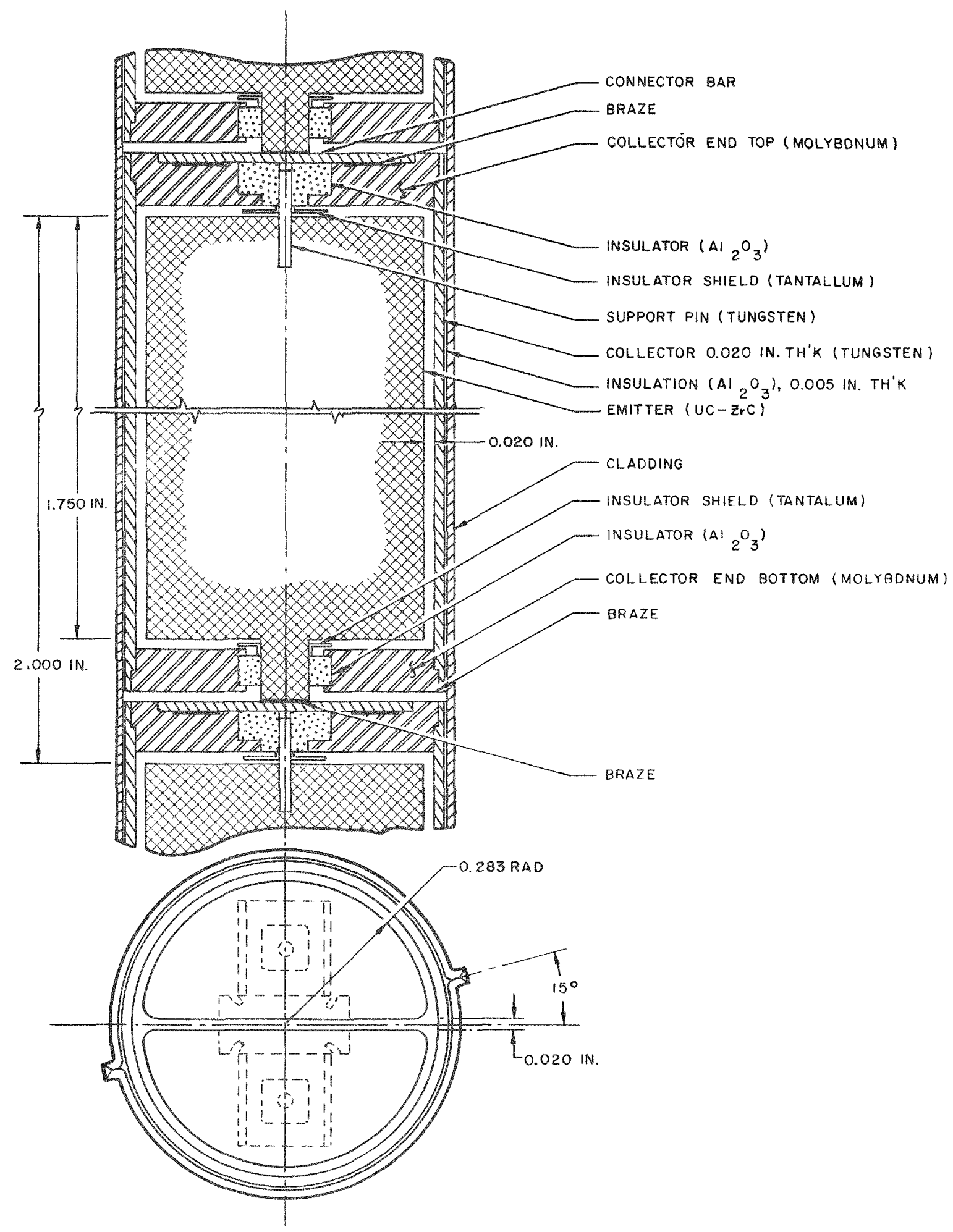

Fig. B.4 - - Cross section of single cell 
the spacing is unaffected by any possible misalignment or distortion of other cell components within the fuel element. The electrical connector bar joins the emitter of one cell electrically in series to the collector of the neighboring cell.

Assembly of the fuel element is visualized as consisting of the following major steps with adequate inspection and testing performed during each fabrication process to insure satisfactory completion:

1. A cylindrical shaped collector is coated with insulation, metalized, and cut into the required halfcylinder configuration.

2. End pieces are brazed to the individual collectors.

3. The collector components are positioned in the clad shell and brazed to the clad.

4. Emitters with alignment insulators in place and electrical connector bars attached are positioned in the collectors.

5. The alignment insulators are mechanically fastened to the collector end pieces and the electrical connector bars joined to the nerghboring collectors by brazing.

6. Two completed half-assemblues are positioned together and the axial seam welds made to join the clad.

7. End fixtures are fastened to the ends of the clad to complete the closure of the fuel element. 


\section{DESIGN CALCULATIONS}

The component sizes listed in Figure B-4 are representative of fuel element dimension compatible with requirements of a 1 electrical megawatt thermionic reactor. These dimensions were selected primarily to achieve a high average power density in the reactor and consequently a small reactor size, weight, and fuel loading. The selection was influenced somewhat by the output voltage desired from a single fuel element. After consideration of the design calculations that follow, it appears that a 28 volt output is best achieved by connecting two fuel elements in series rather than introducing suficient cells into one element to obtain 28 volts output from a single element. Further discussion is included in the conclusion section.

\subsection{COMPONENT DIMENSIONS}

The influence of the fuel element component dimensions on the average electrical power density in the reactor can be determined by considering the expression for electrical power output.

$$
P_{e \ell}=\operatorname{Jv}\left(\frac{S}{V}\right)^{E} v_{f} \quad C
$$

or

$$
\frac{P_{e \ell}}{V^{C}}=J v\left(\frac{S}{V}\right)^{E} v_{f}^{E}
$$

Assuming a constant current density $J$, the average power density is proportional to the product of the usable voltage output of a thermionic cell, the surface-to-volume ratio of the emitter, and the volume fraction of the reactor core occupied by emitters. The usable voltage developed by a cell is defined as the basic voltage produced minus the voltage loss incurred in the electrical leads. This lead loss is a function of both the radius and length of the emitter. Likewise, the terms $\left(\frac{S}{V}\right)$ and $v_{f}$ are both functions of emitter xadius and length. The dependency of the product of these three terms then is desired as a means of establishing component dimensions. 
The calculations as sume that the fuel element components consist of the following materials:

Emitter - Uranium carbide-zirconium carbide

Collector - Molybdenum

Insulation - Aluminum oxide

Clad - Niobium (columbium)

Dimensions considered constant for the calculations are:

Clad wall thickness -0.010 inch

Insulation thickness -0.005 inch

Collector wall thickness - 0.020 inch

Emitter-collector spacing - 0.020 inch

The nomenclature employed (see Fig. B. 5) is:

$L=$ length of a unit cell

$\ell=$ length of emitter

$x=$ radius of the emitter

$\mathrm{y}=$ void width between emitter halves

$v_{f}^{R}=$ volume fraction of the reactor core occupied by the fuel elements

a = sum of the clad, insulation, collector, and emitter-collector spacing thickness

$A_{s}=$ support stem area at each end of the emitter which is not available for emission

$\frac{A_{s}}{\pi r^{2}-2 r y}=$ emistion

$v_{0}=$ cell voltage before lead losses

$\mathrm{v}=$ usable cell voltage after lead losses

$K=$ stem voltage loss $=\sqrt{\rho^{s} k^{s} \Delta T^{s} \frac{2 \eta}{2-\eta}}$

$\rho^{s}=$ average stem electrical resistivity

$k^{\mathbf{S}}=$ average stem thermal conductivity

$\Delta T^{S}=$ temperature diffexence along stem

$\eta=$ over-all cell efficiency

$\rho^{E}=$ emitter electrical resistivity

$\rho^{C}=$ collector electrical resigtivity 


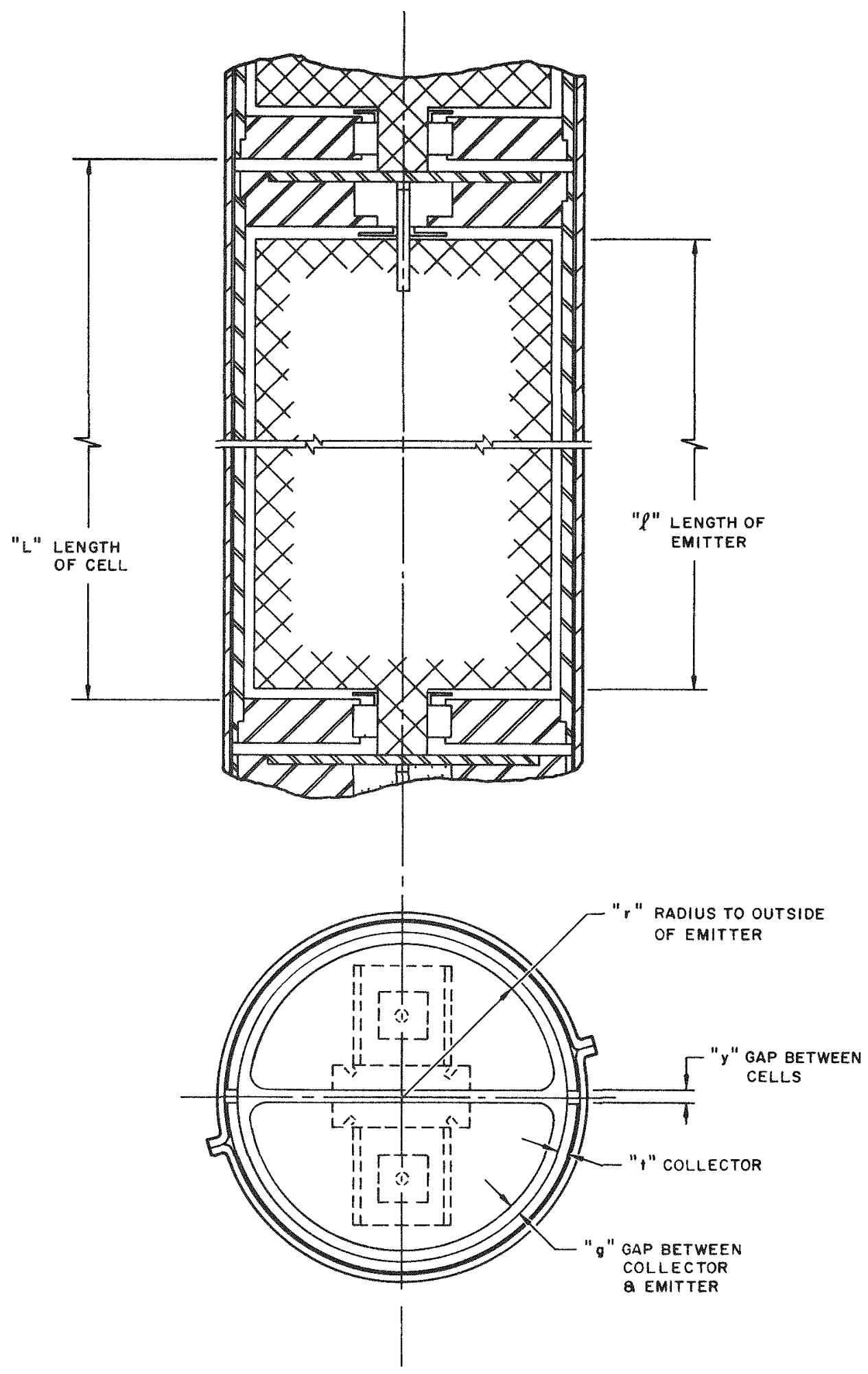

Fig.B.5-- Cell Didgram 


$$
\begin{aligned}
& \mathrm{g}=\text { emitter-collector spacing } \\
& =\text { collector wall thickness } \\
& \mathrm{f}=\text { voltage los ratio, } \frac{\text { emitter }+ \text { collector }}{\text { tem }}
\end{aligned}
$$

In terms of the quantities, the expression for the emitter volume fraction is

$$
v_{i}^{E}=v_{r}^{R} \frac{\pi r^{2} b-2 r y}{\pi(x+a)^{2} L}
$$

Similarly, the expresion for the emitter surface-to-volume ratio is

$$
\left(\frac{S}{V}\right)^{E}=\frac{2 \pi r \ell+2 \pi r^{2}-2 b y-4 r y-2 A B}{\pi r^{2} b-2 r b y}
$$

Combining the se two expressions, the product of emitter volume fraction and emitter surface-to-volume ratio is expresed a

$$
v_{f}^{E}\left(\frac{S}{V}\right)=v_{L}^{R}\left(\frac{l}{L}\right)\left(\frac{1}{\pi(x+a)^{2}}\left[2 \pi x-2 y+\frac{2 \pi r^{2}-4 r y}{l}\left(1-\frac{2 A B}{2 \pi r^{2}-4 r y}\right)\right]\right)
$$

The length of the emitter is expressed as a function of the ratio (f) of the sum of the fractional power losses in the emitter and collector to the fraction power los in the efficiency optimized emitter stem (K). In terms of the cell quantities, this relationship can be stated as

Emitter fractional loss + collector fractional loss = f stem fractional loss

$$
\begin{aligned}
& \frac{2}{2} J_{p}^{E} \ell^{2}\left[(\pi r-y)+\left(\frac{\pi r^{2}-2 r y}{\ell}\right)\left(1-\frac{A s}{\pi r^{2}-2 r y}\right)\right] \\
& \left(\pi x^{2}-2 x y\right) v_{0} \\
& +\frac{\frac{2}{3} J \rho^{C} l^{2}\left[(\pi x-y)+\left(\frac{\pi x^{2}-2 r y}{l}\left(1-\frac{A g}{\pi r^{2}-2 r y}\right)\right]\right.}{\left.\mid \pi\left[(x+g+t)^{2}-(x+g)^{2}\right]-2 y t\right) v_{0}}=\frac{K}{v_{0}}
\end{aligned}
$$


Rearranging and solving for $l$, the resultant expression becomes

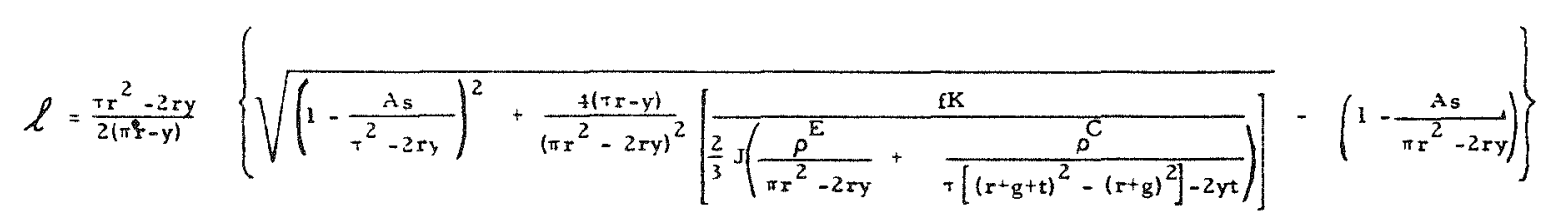

The remaining term to be established in the tri-product expression for reactor power density is $(v)$, the usable voltage per cell available to the electrical load.

$$
\begin{aligned}
\mathrm{v}(\text { usable voltage }) & =\mathrm{v}_{0}-\text { sum of voltage loss } \\
& =\mathrm{v}_{0}-\mathrm{K}(1+\mathrm{f})
\end{aligned}
$$

All three terms, then, are expressable as functions of the emitter radius ( $r$ ), the fractional power loss or voltage loss ratio (f), and various constants assumed in the cell configuration. In addition to the dimensions already stated, the following values are assumed applicable:

$\begin{array}{lll}\frac{A_{s}}{\pi r^{2}-2 r y} & =0.25 \\ J & = & 6.25 \mathrm{amps} / \mathrm{cm}^{2} \\ \mathrm{~V}_{\mathrm{O}} & =1.6 \mathrm{volts} \\ \mathrm{L} & =(\ell+.635) \mathrm{cm} \\ \mathrm{K} & =0.085 \mathrm{volts} \\ \mathrm{O}^{\mathrm{E}} & =320 \times 10^{-6} \mathrm{ohm}-\mathrm{cm} \\ \rho^{\mathrm{C}} & =26 \times 10^{-6} \mathrm{ohm}-\mathrm{cm} \\ \rho^{\mathrm{s}} & =220 \times 10^{-6} \mathrm{ohm}-\mathrm{cm} \\ \mathrm{k}^{\mathrm{s}} & =0.168 \times 10^{-6} \mathrm{ohm}-\mathrm{cm} \\ \Delta \mathrm{T}^{\mathrm{S}} & =1200^{\circ} \mathrm{C} \\ \eta & =0.15\end{array}$

In Figure B.6 the length (l) of the emitter is plotted as a function of the voltage loss ratio ( $f$ ) with the emitter radius $(r)$ as a parameter. The 


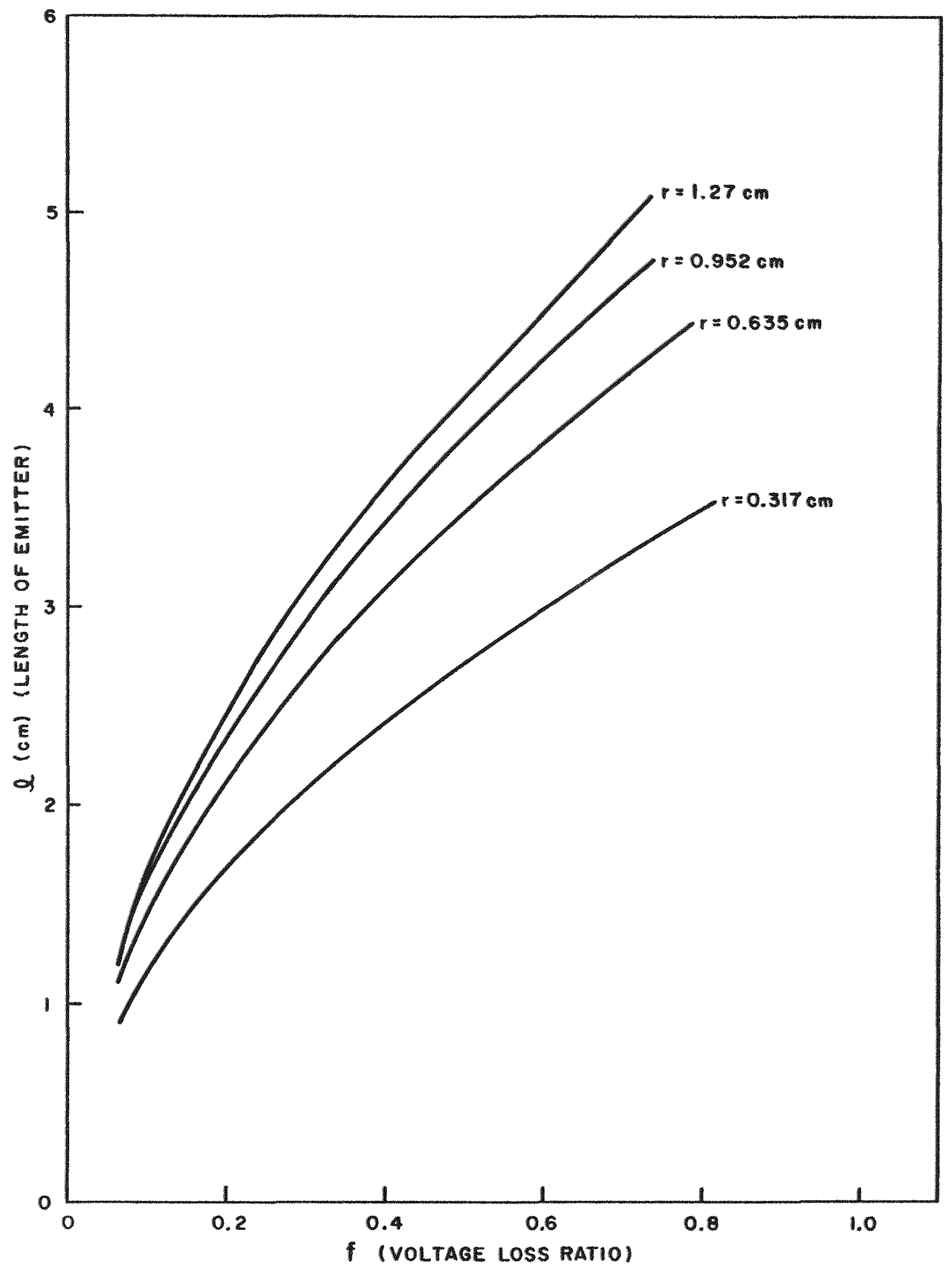

Fig. B.6 - Relationship of emitter length to voltage loss 
emitter length increases both with increasing $f$ and with increasing $r$. The increase of $\ell$ with increasing $f$ results primarily from the fact that larger values of $\mathrm{f}$ imply larger allowable voltage losses and consequently the cell length can be increased. The increase of $l$ with increasing $r$ is a consequence of the radius squared dependency of the electrical conduction path in the emitter while the emission area is proportional to the first power of the radius.

Figure $B-7$ shows the emitter volume fraction $\left(v_{f}^{E}\right)$ as a function of $f$ and the parameter $r$. Increases in both $f$ and $r$ result in higher values of $v_{f}^{E}$. The influence of $f$ is best observed through its effect on $l$. Since increasing $f$ results in increase $l$, the over-all effect of increasing $x$ or $f$ is to increase the size of the individual emitters and hence higher emitter volume fractions are realized.

The tri-product quantity $\left(v_{v_{f}} E\left(\frac{S}{V}\right)\right.$ E which is proportional to the average reactor electrical power density is shown in Figure B-8. As expected, the power density term increases with decreasing emitter radius. The dependency on $f$, however, depends on the size of the emitter. For small $\mathrm{r}$, increasing $\mathrm{f}$ results in increases in power density. For large $\mathrm{r}$, increasing $f$ results in decreases in power density.

Both the emitter volume fraction and the average power density are slowly varying functions of the quantity for values of $f$ in the range of 0.5 to 1.0 . This range corresponds to emitter sizes in the order of 2.5 to $5.0 \mathrm{~cm}$ in length. Smaller $f$ values and accordingly shorter emitter lengths tend to penalize the emitter volume fractions.

The general range of emitter radii which appears applicable to the 1 megawatt power level is about 0.6 to $0.9 \mathrm{~cm}$. These radii result in relatively high emitter volume fractions and are sufficiently large to ease the fabrication problems. The applicable range of emitter volume fractions is discussed in the following section. 


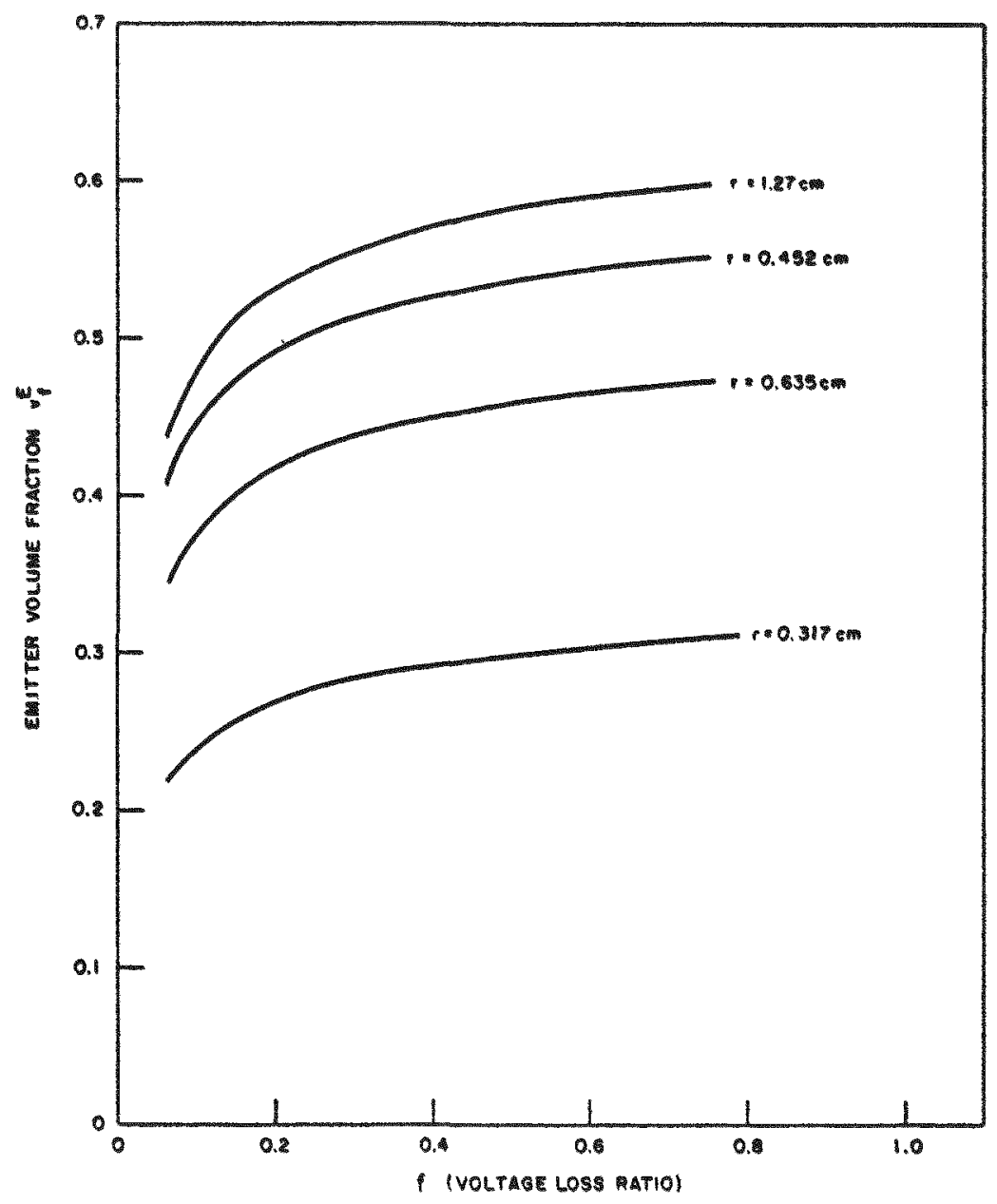

Fig. B. 7 - - Relationship of emitter volume fraction to voltage loss

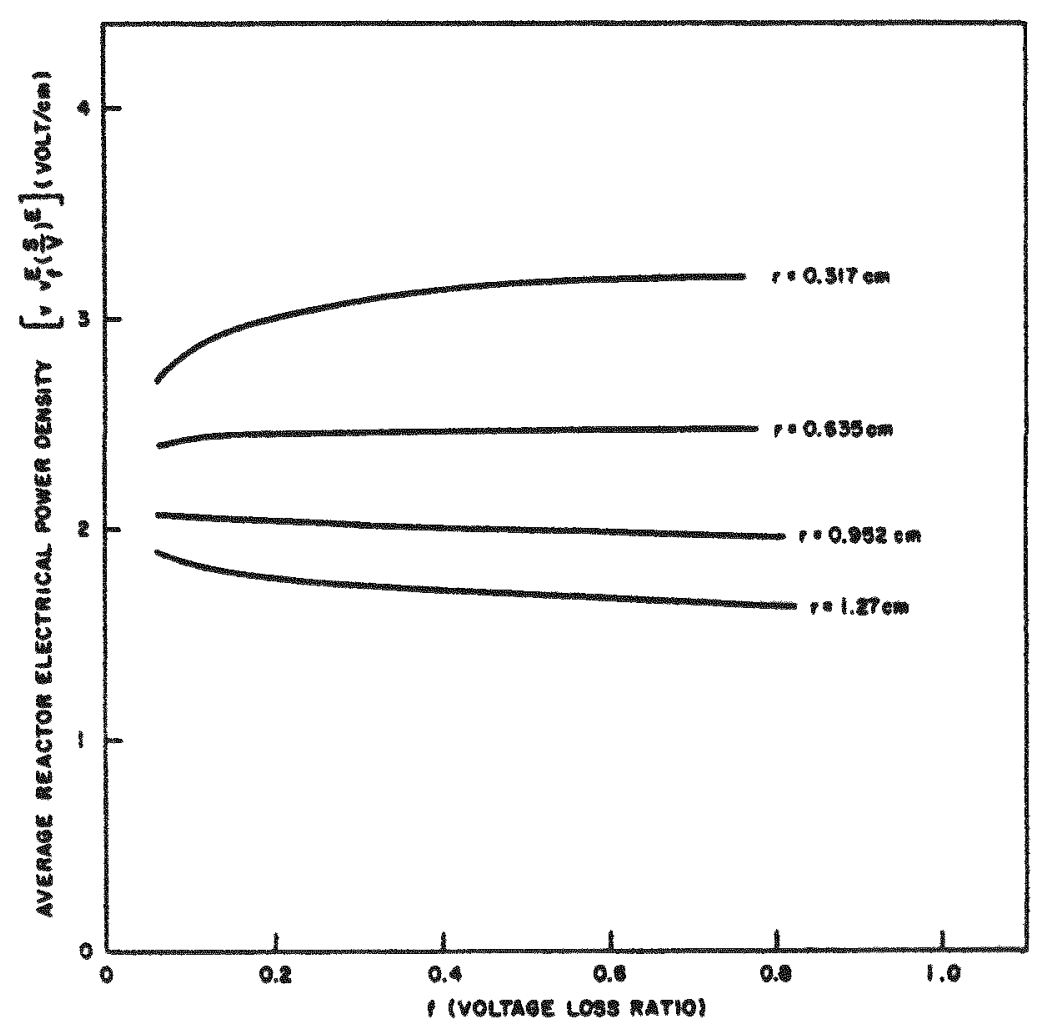

Fig. B. - - Relationship of average reactor electrical power density factor to voltage loss 


\subsection{REACTOR SPECIFICATIONS}

In the previou section, relationships were established which permit the calculation of the average electrical power density in the reactor for a particular fuel element configuration and for assumed thermionic performance data. Reactor criticality must now be considered to establish critical core sizes for these fuel element configurations or otherwise to determine the total, electrical power output of the reactor.

The critical size of a fast reactor is primarily controlled, as suming a given reflector, by the average fuel density in the core. Since, in a thermionic reactor, fission heating is restricted to the emitter components only and the fuel is accordingly located only in the emitters, the average core fuel density is determined by the local emitter fuel density and the core volume fraction occupied by the emitters. Compact or small diameter reactors demand both high local fuel densities plus high emitter volume fractions. As the size of the core is increased, either or both of these factors may be reduced.

To investigate the effect of the local emitter fuel density on the reactor specifications, critical calculations were performed assuming the following component volume fractions:

$\begin{array}{ll}\text { emitter } & 0.50 \\ \text { coolant } & 0.15 \\ \text { collector } & 0.13 \\ \text { clad } & 0.06 \\ \text { insulation } & 0.03 \\ \text { void } & 0.13\end{array}$

The fuel density in the emitters was adjusted by varying the UC weight fraction in the UC-ZrC emitter material. Variations in UC weight fraction were also used to achieve approximate power flattening throughout the core. Power flattening necessitates high fuel densities in the outer regions of the core with gradual decreasing fuel density toward the center regions. Each calculation, then, is referred to by means of the particular 
maximum UC weight fraction employed at the outer region of the core the inner regions having UC weight fractions of lesser magnitudes.

The details of the calculational methods employed are presented in Section VI. In general, the calculations were performed using the DSN transport code with 10 neutron groups. A spherical reactor geometry was assumed with a 2 inch beryllium reflector considered constant for all cases. The fuel was considered as 93 percent enriched (in $U^{235}$ ) uranium and the coolant as natural isotopic content lithium. The core was divided into 8 regions to permit fuel density variations for power flattening.

The computed core diameter, fuel loading, core weight, and total reactor weight are presented in Figures B.9, B. 10, and B. 11, and B. 12 as a function of the maximum UC weight fraction in the emitters. The maximum fuel density was varied from that corresponding to a 1.00 weight fraction UC emitter to a 0.50 weight fraction $\mathrm{UC}-0.50$ weight fraction $\mathrm{Z}$ rC emitter. If the fuel element configuration shown in Figure B. 4 is assumed generally representative over this fuel density range, the corres ponding total reactor electrical power range can be obtained. The average electrical power density for this fuel element configuration is 14.3 watts/ $\mathrm{cm}^{3}$. Accordingly, the 0.50 UC emitter weight fraction corresponds to a reactor electrical power of about 5 megawatts, the $0.80 \mathrm{UC}$ weight fraction about 1 megawatt, and the $1.00 \mathrm{UC}$ weight fraction about $1 / 3$ megawatt.

The average fuel density and hence the critical reactor size can also be adjusted by varying the core volume fraction of the emitters. The 0.80 maximum UC weight fraction case was assumed typical of the emitter fuel densities pertaining to a 1 megawatt power level. With this maximum fuel density held constant, the emitter volume fraction was varied by substituting emitter volume fraction for coolant volume fraction. All other material volume fractions were held constant. The resultant reactor specifications are shown in Figures $B .13, B .14, B .15$, and $B .16$ as a function of emitter volume fraction. Again the trend of reactor size, weight, and fuel loading is observed as the average fuel density is varied; lower emitter volume 


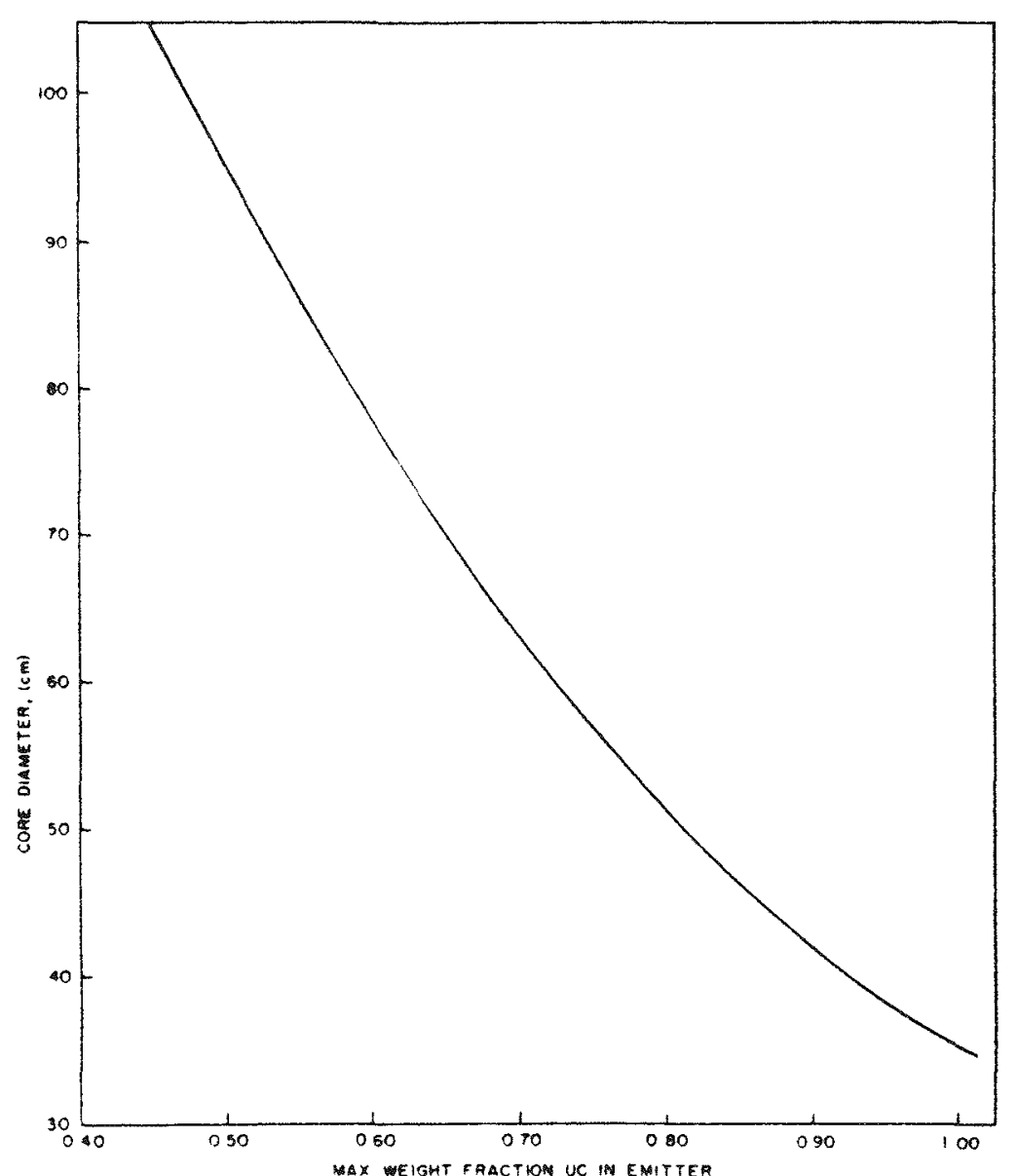

F:g, B.9. Compited cort dizmeier ty a function of the maximim if weight fration in em $i \uparrow \in \mathrm{r}$

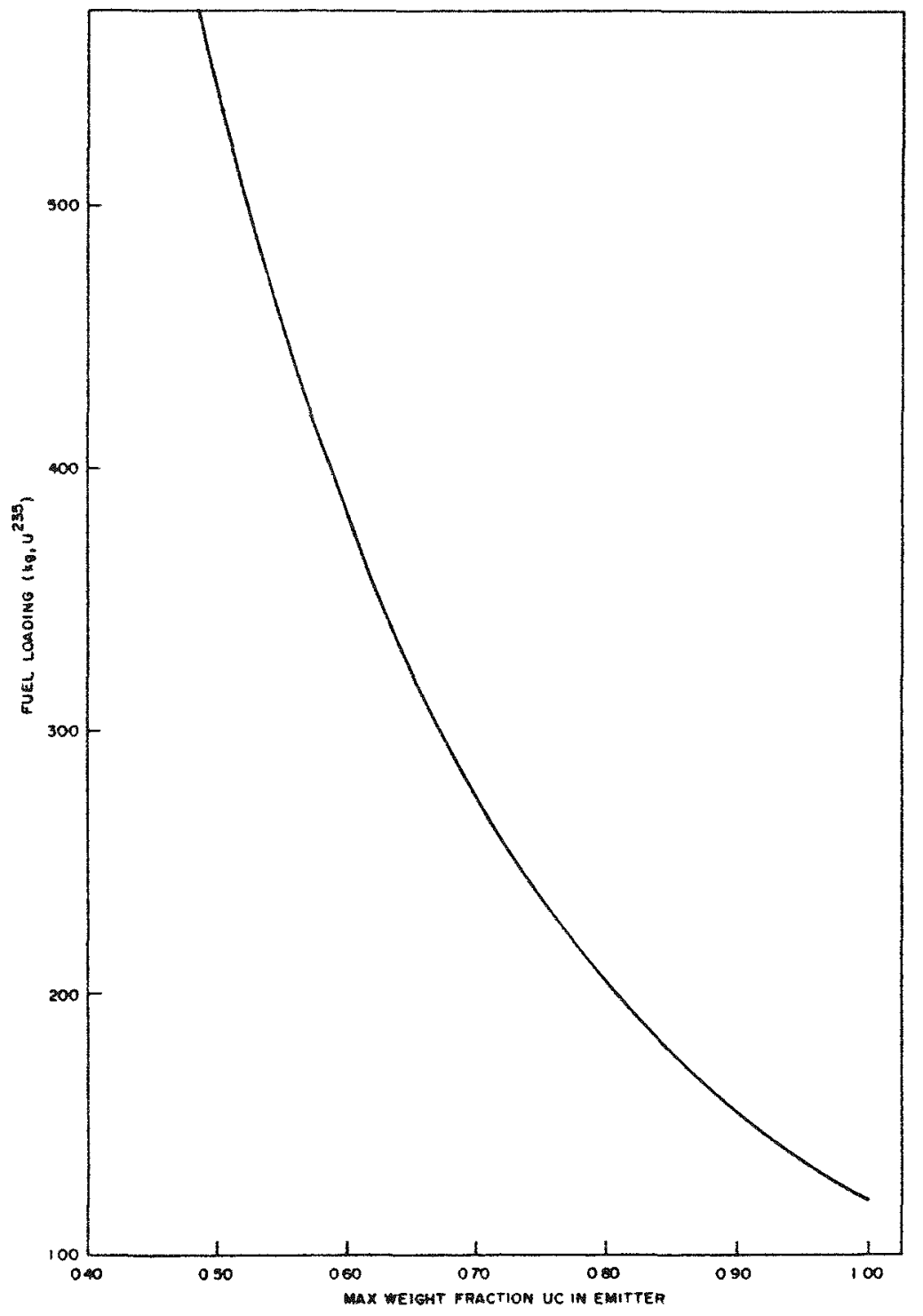

Fig. B. $10=$ - Computed fuel lozding lin $\mathrm{kg}$ of $\mathrm{U}^{235}$, is a function of the maximum UC weight fraction in emitter 


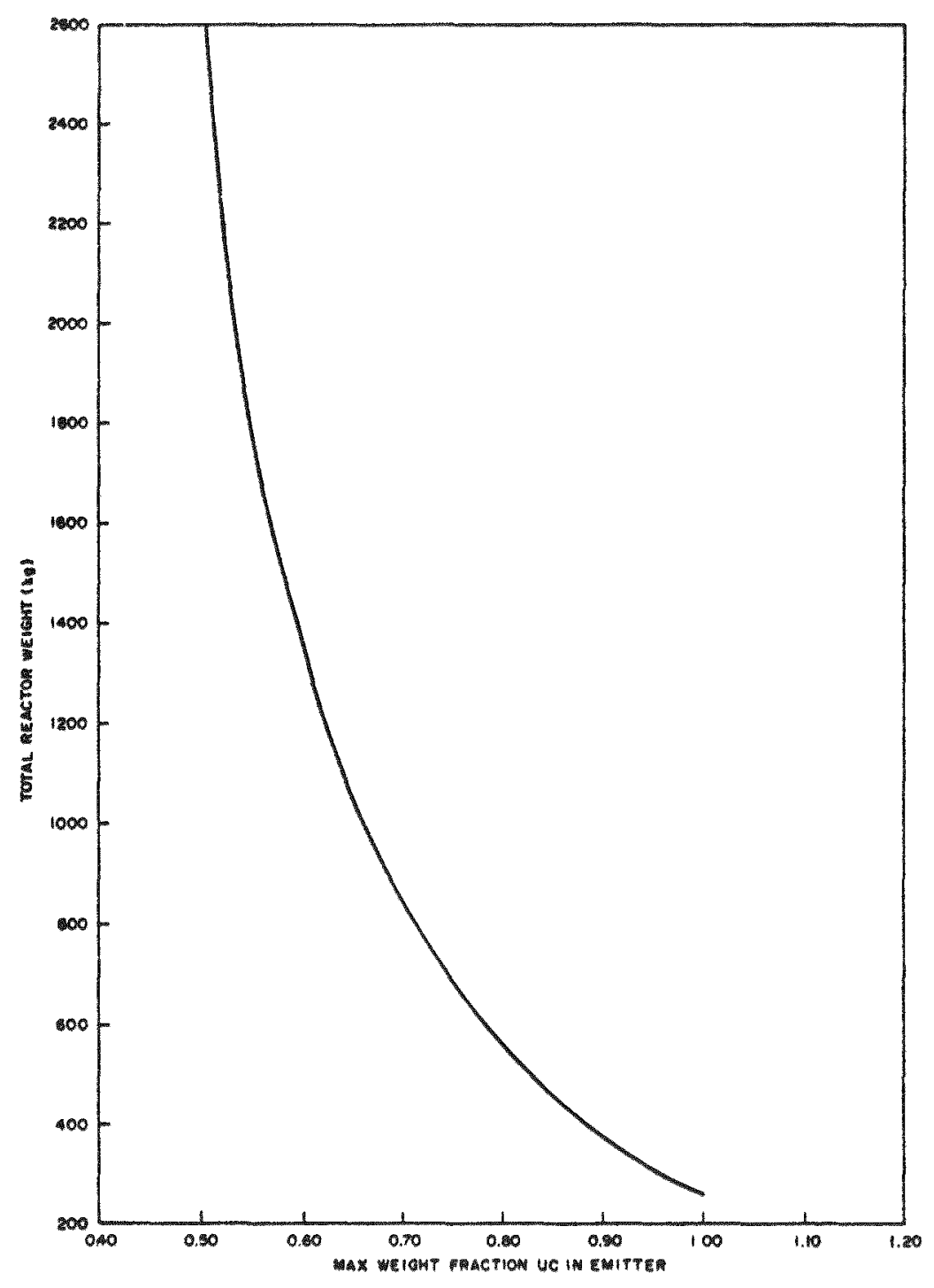

Fig. B.11-- Computed core weight (in kg) as a function of the maximum UC weight fraction in emitter

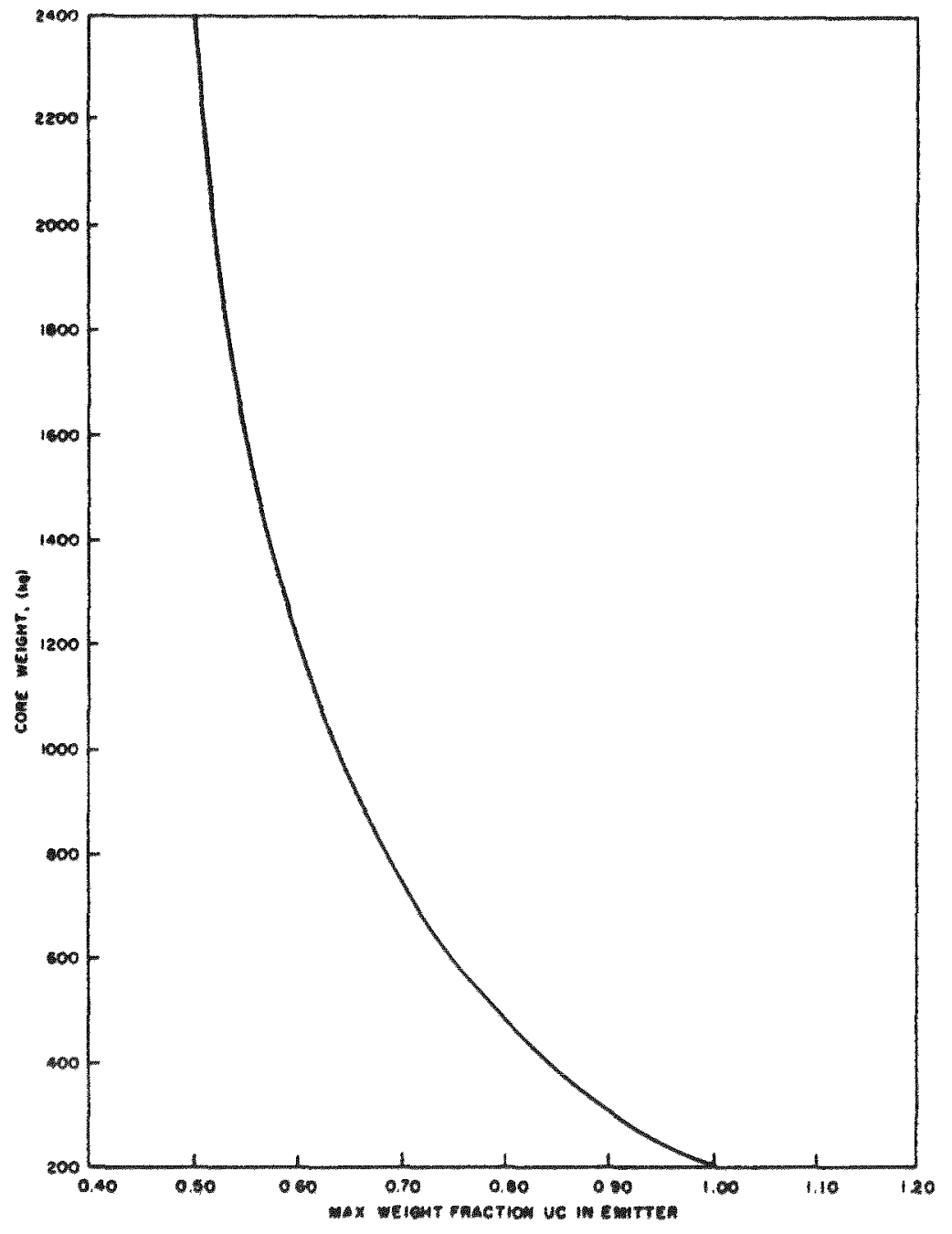

Fig. B.12 - - Computed total reactor weight (in kg) as a function of the maximum UC weight fraction in emitter 


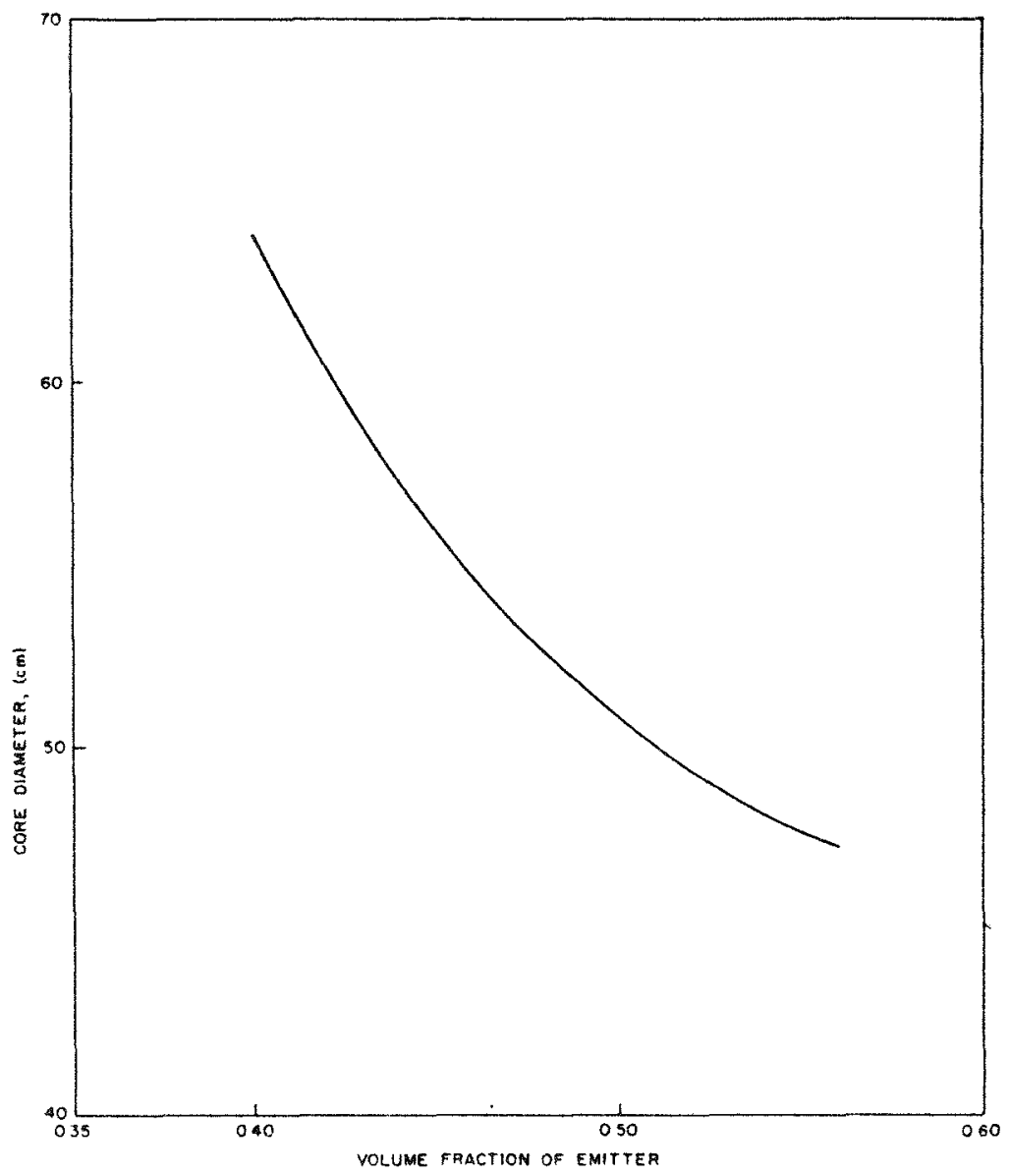

Fig. B. 13 - Computed core diameter as a function of the emitter volume fraction

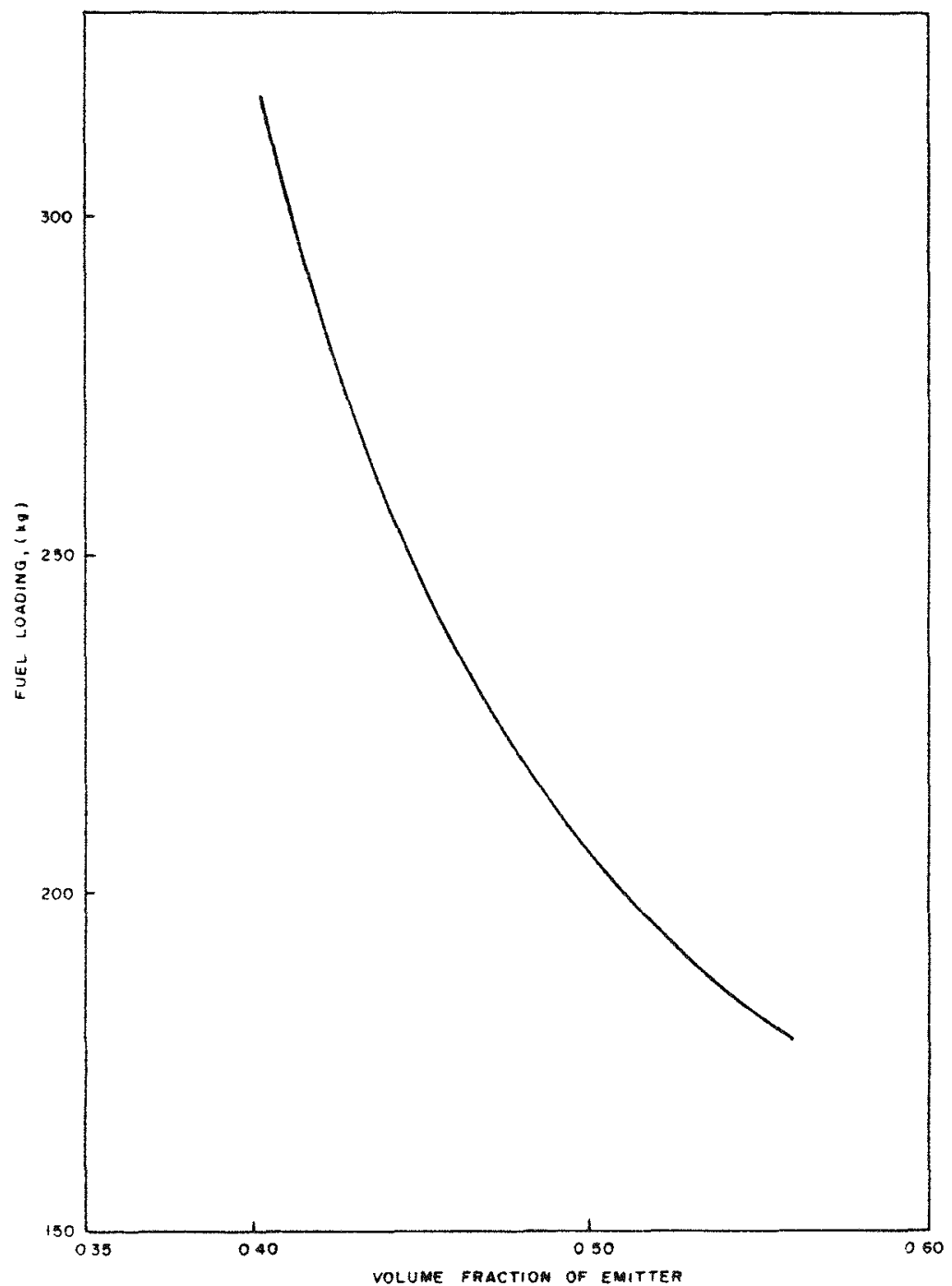

Fig. B.14 - Computed fuel loading (in $\mathrm{kg}$ of $\mathrm{U}^{235}$ ) as a function of the emitter volume fraction 


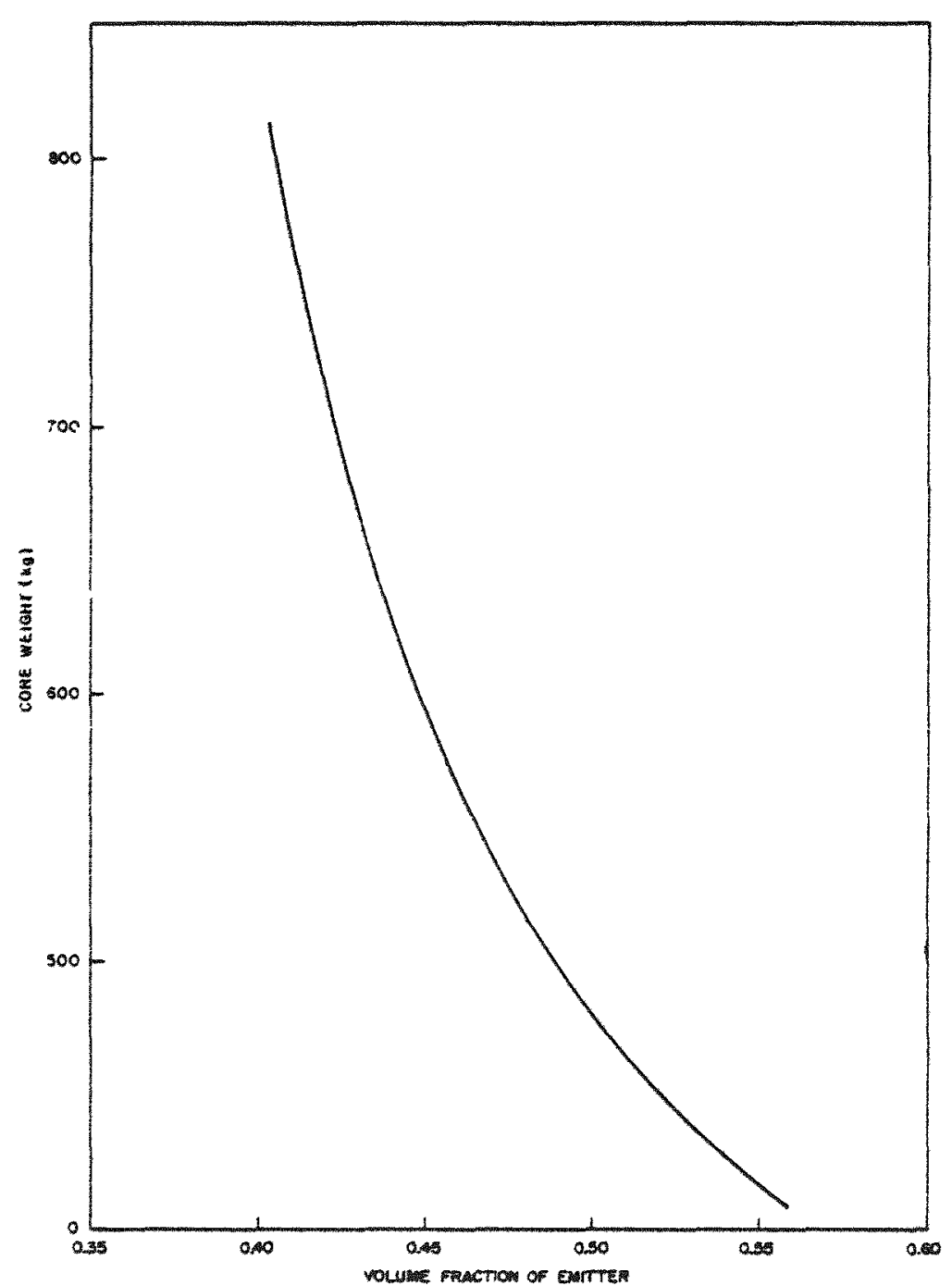

Fig. B. 15 - Computed core weight (in $\mathrm{kg}$ ) as a function of the emitter volume fraction

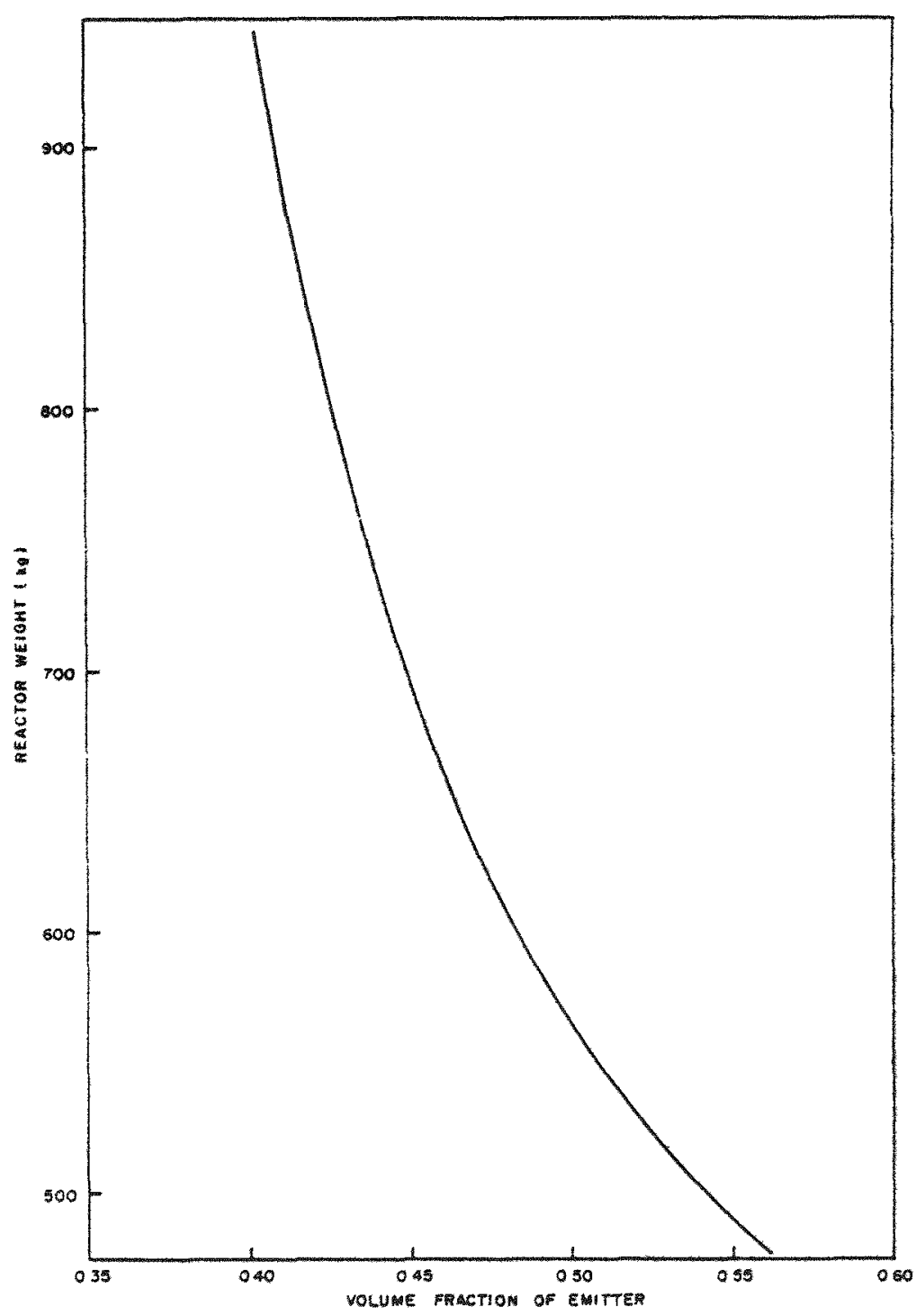

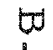

Fig. B. $16=-$ Compited total reactor weight (in $\mathrm{kg}$ ) ${ }_{0}^{\mathfrak{w}}$ as a function of the emitter volume fraction 
fractions imply lower average fuel densities with resultant increases in reactor diameter, fuel loading, and weight.

Mutually compatible values of reactor electrical power level and critical core diameter are presented in Figure B.17. These values are generated by correlating the emitter volume fraction, power density, and core diameter data presented in Figures B.7, B. 8, and B.13. For a 1 megawatt power level, the range of applicable core diameters is approximately 50 to $55 \mathrm{~cm}$. Referring to Figure B. 13, the corresponding emitte $x$ volume fraction range is about 0.46 to 0.51 . A representative emitter volume fraction of 0.50 (assuming a maximum $\mathrm{UC}$ weight fraction of 0.80 ) was selected for the fuel element design point.

\subsection{CONCLUSIONS}

In studying the design data presented in the previous sections, it should be noted that the final fuel element design point selection is based on a large number of uncertain design parameters. Because of these uncertainties, an exhaustive study has not been carried out to optimize the design with respect to any particular quantity. The correct interpretation of the results is that the listed design represents a typical thermionic fuel element configuration which is believed to be compatible with the over-all requirements of a space thermionic reactor operating at an electrical power level of approximately 1 megawatt. Further refinement is necessary to establish specific component dimensions for any particular set of requirements.

Changes in thermionic performance $\left(J, v_{0}\right)$, differences in total voltage output required per fuel element, possible adjustments in the allowable emitter UC weight fractions as a result of metallurgical considerations, changes in reactor power level, etc., all affect the fuel element component dimensions. The choice of an approximate 14 -volt fuel element output, for example, was made in order to achieve relatively high values of both the average power density and the emitter volume fraction. At a 


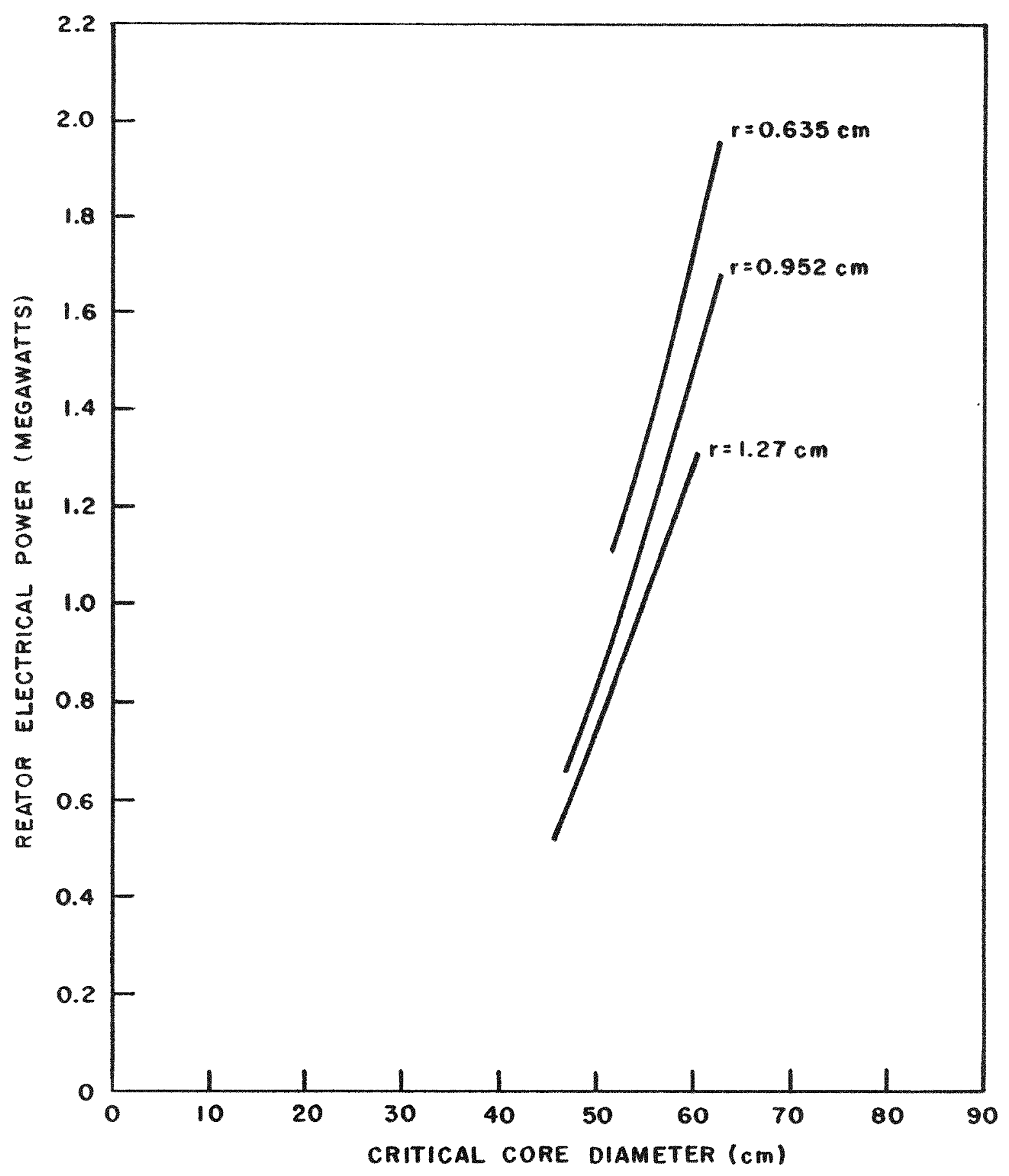

Fig. B. 17 - Relationship of reactor electrical power level to critical core diameter 
reactor power level of 1 megawatt, these high values are difficult to achieve simultaneously if a large number of thermionic cell are located in the fuel element. As a result, a compromise was made in the voltage output and the cell lengths were sized to permit only 10 cells per element. If the reactor power level is increased or if other parameters are substantially altered, the choice of cell dimensions and accordingly the fuel element voltage output should be re-examined.

With the above reservations in mind, the following data summary pertaining to the selected fuel element design is presented:

\begin{tabular}{|c|c|}
\hline Fuel element length & 20 inches \\
\hline Thermionic cell length & 2 inches \\
\hline Emitter length & 1.75 inches \\
\hline $\begin{array}{c}\text { Number of series cells } \\
\text { per element }\end{array}$ & 10 \\
\hline Load voltage per cell & 1.45 volts \\
\hline Load voltage per element & 14.5 volts \\
\hline Stem voltage loss per cell & 0.085 volt \\
\hline $\begin{array}{c}\text { Emitter plus collector voltage } \\
\text { loss per cell }\end{array}$ & 0.064 volt \\
\hline Fuel element diameter & $0.677 \mathrm{inch}$ \\
\hline Emitter radius & 0.283 inch \\
\hline Reactor-average power density & $14.3 \mathrm{watts} / \mathrm{cm}^{3}$ \\
\hline $\begin{array}{c}\text { Reactor-average emitter volume } \\
\text { fraction }\end{array}$ & 0.50 \\
\hline
\end{tabular}




\section{NUCLEAR CALCULATIONS}

\subsection{GROUP CROSS SECTIONS}

The critical calculations were performed using the DSN transport code in the $\mathrm{S}_{4}$ approximation. Ten neutron groups were enployed with the energy range per group as follows:

\begin{tabular}{cll} 
Range & Energy Range & Emission Spectrum \\
\cline { 2 - 3 } 1 & $3-8 \mathrm{mev}$ & 0.204 \\
2 & $1.4-3 \mathrm{mev}$ & 0.344 \\
3 & $0.9-1.4 \mathrm{mev}$ & 0.168 \\
4 & $0.4-0.9 \mathrm{mev}$ & 0.180 \\
5 & $0.1-0.4 \mathrm{mev}$ & 0.090 \\
6 & $17-100 \mathrm{kev}$ & 0.014 \\
7 & $3-17 \mathrm{kev}$ & 0 \\
8 & $0.55-3 \mathrm{kev}$ & 0 \\
9 & $100-550 \mathrm{ev}$ & 0 \\
10 & $30-100 \mathrm{ev}$ & 0
\end{tabular}

Group cross sections were obtained from the sixteen group cross sections prepared by Hansen and Roach at Los Alamos (ref.6). The top five energy groups employ fission spectrum weighting. The remaining groups are flux weighted by means of a flat collision density; for example

$$
\left(\sigma_{t r}\right)_{i}=\int_{i} \frac{d u}{\sigma_{t}} / \int_{i} \frac{d u}{\sigma_{t} \sigma_{t r}}
$$

Details of the specification of the capture and fission group cross sections in the resonance regions are given in reference 6.

The ten group cross sections for the individual materials considered in the thermionic reactor calculations are listed in the following pages. 


\begin{tabular}{|c|c|c|c|c|c|c|c|c|}
\hline \multicolumn{9}{|c|}{$U^{235}$} \\
\hline$\overline{\text { Group }}$ & $o_{f}$ & $\sigma_{t x}$ & $\sigma_{i \rightarrow i}$ & $\sigma_{i \rightarrow i+1}$ & $\sigma_{i \rightarrow i+2}$ & $\sigma_{i \rightarrow i+3}$ & $\sigma_{i \rightarrow i+4}$ & $\sigma_{i \rightarrow i+5}$ \\
\hline 1 & 1.21 & 4.25 & 1.20 & 0.27 & 0.37 & 0.65 & 0.44 & 0.06 \\
\hline 2 & 1.22 & 4.50 & 1.77 & 0.24 & 0.67 & 0.45 & 0.07 & \\
\hline 3 & 1.22 & 4.62 & 2.30 & 0.55 & 0.40 & 0.07 & & \\
\hline 4 & 1.20 & 5.2 & 3.42 & 0.35 & 0.08 & & & \\
\hline 5 & 1.43 & 7.9 & 6.16 & 0.08 & & & & \\
\hline 6 & 2.5 & 12.4 & 9.2 & 0.05 & & & & \\
\hline 7 & 4.2 & 15.1 & 9.55 & 0.05 & & & & \\
\hline 8 & 7.9 & 21.1 & 9.95 & 0.05 & & & & \\
\hline 9 & 18.7 & 37.2 & 9.95 & 0.05 & & & & \\
\hline 10 & 38.0 & 68.0 & 9.95 & 0.05 & & & & \\
\hline
\end{tabular}

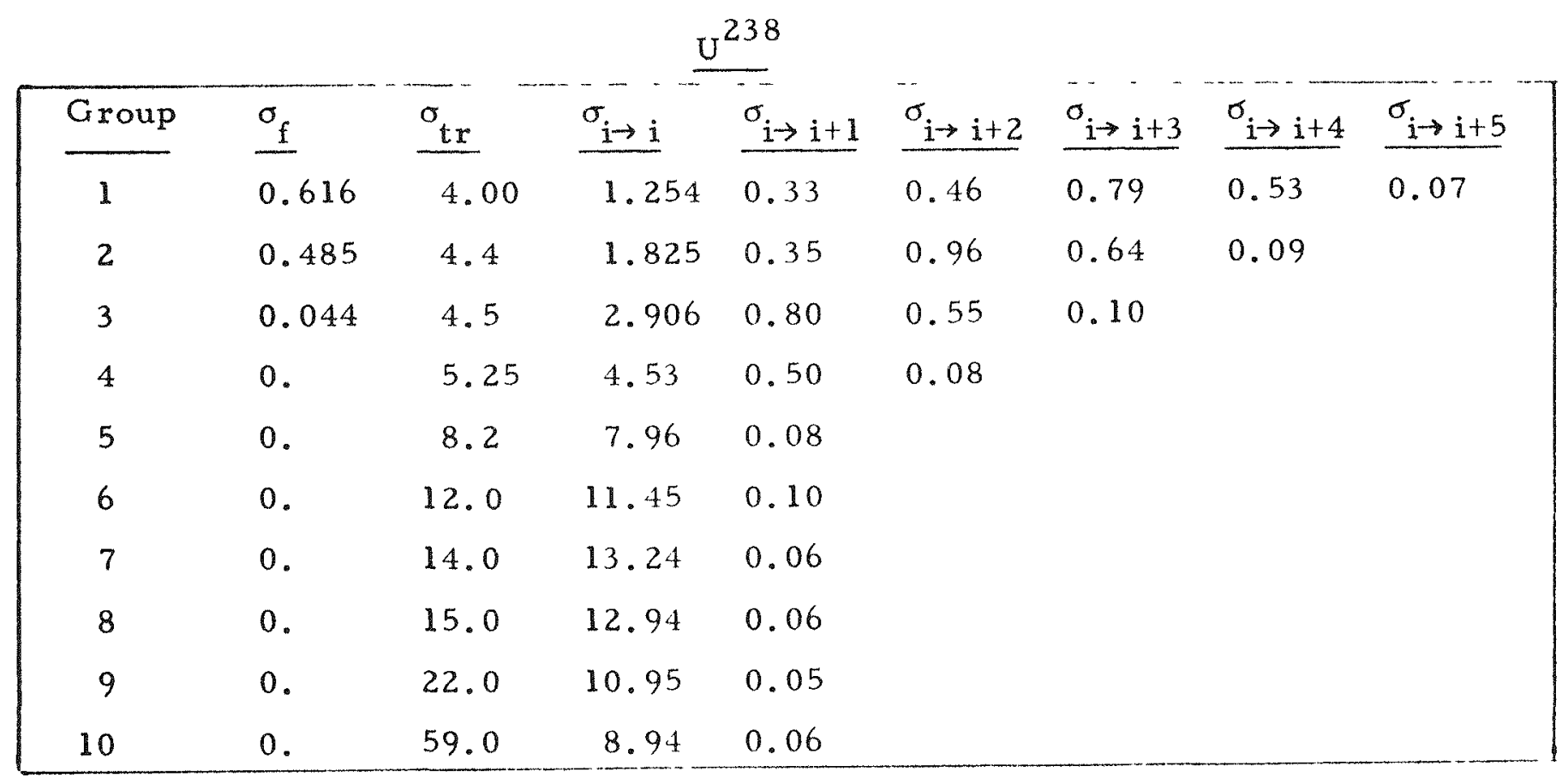


$\mathrm{Zx}$

\begin{tabular}{|c|c|c|c|c|c|}
\hline Group & $o_{t r}$ & $\sigma_{i \rightarrow i}$ & $o_{i \rightarrow i+1}$ & $\sigma_{i \rightarrow 1+2}$ & $\sigma_{i \rightarrow i+3}$ \\
\hline 1 & 2.60 & 1.497 & 0.6 & 0.3 & 0.2 \\
\hline 2 & 3.10 & 2.395 & 0.4 & 0.2 & 0.1 \\
\hline 3 & 3.84 & 3.343 & 0.3 & 0.150 & \\
\hline 4 & 6.21 & 5.978 & 0.22 & & \\
\hline 5 & 7.21 & 7.060 & & & \\
\hline 6 & 7.91 & 7.788 & & & \\
\hline 7 & 7.644 & 7.533 & & & \\
\hline 8 & 6.552 & 6.453 & & & \\
\hline 9 & 6.383 & 6.257 & & & \\
\hline 10 & 6.155 & 6.028 & & & \\
\hline
\end{tabular}

C

\begin{tabular}{|cccc|}
\hline Group & $\sigma_{t r}$ & $\sigma_{i \rightarrow i}$ & $\sigma_{i \rightarrow i+1}$ \\
\hline 1 & 1.23 & 0.715 & 0.515 \\
2 & 1.42 & 1.106 & 0.314 \\
3 & 2.26 & 1.404 & 0.856 \\
4 & 2.93 & 2.326 & 0.604 \\
5 & 3.59 & 3.157 & 0.433 \\
6 & 4.25 & 3.849 & 0.401 \\
7 & 4.44 & 4.012 & 0.428 \\
8 & 4.34 & 3.912 & 0.428 \\
9 & 4.34 & 3.912 & 0.428 \\
10 & 4.34 & 3.737 & 0.603 \\
\hline
\end{tabular}




\begin{tabular}{|lllll|}
\hline Group & \multicolumn{5}{c|}{ Li $^{6}$} & & \\
\hline 1 & $\frac{\sigma_{t r}}{\sigma_{i \rightarrow i}}$ & $\frac{\sigma_{i \rightarrow i+1}}{0.486}$ & $\sigma_{i \rightarrow i+2}$ \\
2 & 1.03 & 0.434 & 0.298 & 0.034 \\
3 & 1.00 & 0.438 & 0.590 & \\
4 & 1.12 & 0.270 & 0.498 & \\
6 & 1.70 & 0.702 & 0.611 & \\
7 & 4.47 & 1.909 & 0.152 & \\
9 & 1.65 & 0.648 & 0.155 \\
10 & 2.2 & 0.645 & 0.158 \\
\hline
\end{tabular}

\begin{tabular}{|c|c|c|c|c|}
\hline Group & ${ }_{\mathrm{tr}}$ & $\sigma_{i \rightarrow i}$ & $\sigma_{i \rightarrow i+1}$ & $\sigma_{i \rightarrow i+2}$ \\
\hline 1 & 1.10 & 0.43 & 0.67 & \\
\hline 2 & 1.14 & 0.67 & 0.45 & 0.02 \\
\hline 3 & 1.24 & 0.41 & 0.83 & \\
\hline 4 & 1.11 & 0.692 & 0.416 & 0.002 \\
\hline 5 & 2.99 & 2.37 & 0.62 & \\
\hline 6 & 0.94 & 0.79 & 0.15 & \\
\hline 7 & 0.97 & 0.81 & 0.16 & \\
\hline 8 & 0.97 & 0.81 & 0.16 & \\
\hline 9 & 0.97 & 0.81 & 0.16 & \\
\hline 10 & 0.968 & 0.736 & 0.231 & \\
\hline
\end{tabular}


Mo

\begin{tabular}{|c|c|c|c|c|c|}
\hline Group & $\sigma_{t r}$ & $\sigma_{i \rightarrow 1}$ & $0_{i \rightarrow i+1}$ & $\sigma_{i \rightarrow i+2}$ & $\sigma_{i \rightarrow i+3}$ \\
\hline 1 & 2.4 & 1.39 & 0.5 & 0.03 & 0.2 \\
\hline 2 & 2.9 & 2.13 & 0.4 & 0.25 & 0.1 \\
\hline 3 & 3.9 & 3.46 & 0.3 & 0.1 & \\
\hline 4 & 6.2 & 5.93 & 0.20 & & \\
\hline 5 & 8.2 & 7.98 & 0.13 & & \\
\hline 6 & 7.9 & 7.63 & 0.10 & & \\
\hline 7 & 7.1 & 6.62 & 0.08 & & \\
\hline 8 & 8.05 & 6.47 & 0.08 & & \\
\hline 9 & 9.16 & 6.18 & 0.08 & & \\
\hline 10 & 9.36 & 5.86 & 0.10 & & \\
\hline
\end{tabular}

$\mathrm{Nb}$

\begin{tabular}{|llllll|}
\hline Group & $\sigma_{t 1}$ & $\sigma_{i \rightarrow 1}$ & $\sigma_{i \rightarrow i+1}$ & $\sigma_{i \rightarrow 1+2}$ & $\sigma_{i \rightarrow i+3}$ \\
\hline 1 & 2.4 & 1.39 & 0.5 & 0.3 & 0.2 \\
3 & 2.9 & 2.13 & 0.4 & 0.25 & 0.1 \\
4 & 3.9 & 3.46 & 0.30 & 0.1 & \\
5 & 6.2 & 5.95 & 0.20 & & \\
6 & 8.2 & 7.99 & 0.13 & & \\
7 & 8.0 & 7.50 & 0.10 & & \\
8 & 7.2 & 5.92 & 0.08 & & \\
9 & 8.6 & 5.92 & 0.08 & & \\
10 & 6.8 & 5.92 & 0.08 & & \\
\hline
\end{tabular}


Al

\begin{tabular}{|c|c|c|c|c|c|}
\hline Group & $\sigma_{t r}$ & $\sigma_{i \rightarrow i}$ & $\sigma_{i \rightarrow i+1}$ & $\sigma_{i \rightarrow i+2}$ & $\sigma_{i \rightarrow i+3}$ \\
\hline 1 & 1.8059 & 1.10 & 0.56 & 0.10 & 0.03 \\
\hline 2 & 2.02235 & 1.662 & 0.23 & 0.11 & 0.02 \\
\hline 3 & 2.14038 & 1.61 & 0.38 & 0.14 & 0.01 \\
\hline 4 & 2.7207 & 2.47 & 0.25 & & \\
\hline 5 & 2.832 & 6.69 & 0.14 & & \\
\hline 6 & 1.435 & 1.36 & 0.07 & & \\
\hline 7 & 1.463 & 1.398 & 0.063 & & \\
\hline 8 & 1.365 & 1.304 & 0.060 & & \\
\hline 9 & 1.366 & 1.303 & 0.060 & & \\
\hline 10 & 1.366 & 1.276 & 0.084 & & \\
\hline
\end{tabular}

\begin{tabular}{|llll|}
\hline Group & \multicolumn{1}{c}{$\mathrm{O}^{16}$} & $\sigma_{\mathrm{i} \rightarrow \mathrm{i}}$ & \\
\hline 1 & $\frac{\sigma_{\mathrm{tr}}}{1.33}$ & 0.866 & $\sigma_{\mathrm{i} \rightarrow \mathrm{i}+1}$ \\
2 & 1.18 & 0.989 & 0.424 \\
4 & 3.23 & 3.328 & 0.191 \\
5 & 3.63 & 3.074 & 0.902 \\
6 & 3.71 & 3.373 & 0.556 \\
7 & 3.26 & 3.029 & 0.337 \\
8 & 3.55 & 3.295 & 0.231 \\
9 & 3.64 & 3.370 & 0.255 \\
10 & 3.64 & 3.370 & 0.270 \\
\hline
\end{tabular}




\begin{tabular}{|lllll|}
\hline Group & $\sigma_{\mathrm{tr}}$ & $\sigma_{\mathrm{i} \rightarrow \mathrm{i}}$ & $\sigma_{\mathrm{i} \rightarrow \mathrm{i}+1}$ & $\sigma_{\mathrm{i} \rightarrow \mathrm{i}+2}$ \\
\hline 1 & 1.291 & 0.432 & 0.818 & 0.35 \\
2 & 1.475 & 0.934 & 0.509 & 0.12 \\
3 & 2.38 & 1.173 & 1.207 & \\
4 & 3.31 & 2.397 & 0.913 & 0.634 \\
5 & 3.94 & 3.306 & 0.655 & \\
6 & 5.18 & 4.525 & 0.68 & \\
7 & 5.28 & 4.60 & 0.71 & 0.71 \\
9 & 5.37 & 4.66 & 1.01 \\
\hline
\end{tabular}




\subsection{POWER FLATTENING}

The approximate effects of power flattening on reactor size, weight, and fuel loading were included in the calculations by varying the local fuel density as a function of radius in the reactor. This fuel density variation was made in eight discrete zones throughout the core with the densities uniform in any one zone. The distribution of fuel from zone to zone was estimated by one-group diffusion theory.

For the core region, the applicable neutron balance equation is

$$
\begin{aligned}
& D_{c} \nabla_{c}^{2} \phi_{c}+\left(\nu \Sigma_{f}^{c}-\Sigma_{a}^{c}\right) \phi_{c}=0 \\
& \nabla^{2} \phi_{c}+\left(\frac{\nu \Sigma_{f}^{c}-\Sigma_{a}^{c}}{D_{c}}\right) \phi_{c}=0
\end{aligned}
$$

To achieve a uniform power distribution, the product of $\Sigma_{f}^{c} \phi_{c}$ is a constant independent of radius. To simplify the equation, the assumption is made that $\Sigma_{a}^{c}$ is primarily dependent on the fuel contribution and the term $\Sigma_{a}^{c} \phi_{c}$ is, therefore, a constant. If it is further assumed that $D_{c}$ is relatively insensative to fuel variations, the entire right hand term in the equation is a constant and the equation becomes

$$
\nabla^{2} \phi_{c}+z=0
$$

where

$$
Z=\left(\frac{\nu \Sigma_{f}^{c}-\Sigma_{a}^{c}}{D_{c}}\right) \phi^{c}=\text { constant }
$$

The solution of this equation, in spherical geometry, is

$$
\phi_{c}=C_{1}-\frac{z_{x}^{2}}{6}
$$

In the reflector, the neutron balance equation takes the form

$$
D_{R} \nabla^{2} \phi_{R}-\Sigma_{a}^{R} \phi_{R}=0
$$


with the solution

$$
\phi_{R}=\frac{C_{2} \sinh x(R+T-r)}{x r}
$$

where

$$
x^{2}=\frac{\Sigma_{a}^{R}}{D_{R}}
$$

Applying the conditions of continuity of flux and net current at the interface between the core and the reflector

$$
\begin{aligned}
& \phi_{C}(r=R)=\phi_{R}(r=R) \\
& D_{C} \nabla \phi_{C}(r=R)=D_{R} \nabla \phi_{R}(r=R)
\end{aligned}
$$

The constants $C_{1}$ and $C_{2}$ are evaluated

$$
\begin{aligned}
& \mathrm{C}_{1}=\frac{\mathrm{ZR}^{2}}{6}+\frac{\mathrm{D}_{\mathrm{C}}}{\mathrm{D}_{\mathrm{R}}} \frac{\mathrm{ZR}}{3} / x\left(\operatorname{coth} x \mathrm{~T}+\frac{1}{\mathrm{R} x}\right) \\
& \mathrm{C}_{2}=\frac{\mathrm{D}_{\mathrm{c}}}{\mathrm{D}_{\mathrm{R}}} \frac{\mathrm{ZR}^{3}}{3} \int_{\left(\mathrm{R} \cosh x \mathrm{~T}+\frac{\sinh \mathrm{kT}}{x}\right)}
\end{aligned}
$$

The flux distribution in the core then becomes

$$
\phi_{c}=\frac{Z}{6}\left(R^{2}-r^{2}\right)+\frac{D_{c} Z R}{3 D_{R} x\left(\operatorname{coth} x T+\frac{1}{R} x\right.}
$$

For $\Sigma_{a}^{R} \rightarrow 0$ and consequently $x \rightarrow 0$, the expression for $\phi_{c}$ reduces to

$$
\phi_{c}=\frac{Z}{6}\left(R^{2}-r^{2}\right)+\frac{Z D_{c} R^{2} T}{3 D_{R}(R+T)}
$$

Substituting the expression for $\mathrm{Z}$ and realizing that

$$
\left(\nu \Sigma_{f}-\Sigma_{a}\right) \approx N^{F}\left(\nu \sigma_{f}-\sigma_{a}\right)
$$


The core flux equation is rearranged to yield the relative fuel density as a function of radius

$$
N^{F}=\left(\frac{D_{c}}{v_{\sigma_{f}-\sigma_{a}}} /\left(\frac{R^{2}-r^{2}}{6}\right)+\frac{D_{c}}{3 D_{R}} \frac{R^{2} T}{R+T}\right.
$$

\subsection{CALCULATION RESULTS}

A summary of the critical reactor conditions calculated for a range of maximum emitter UC weight fractions from 1.00 to 0.50 and for a range of emitter volume fractions from 0.56 to 0.40 is as follows:

\begin{tabular}{|c|c|c|c|c|c|}
\hline $\begin{array}{l}\text { Run } \\
\text { No. } \\
\end{array}$ & $\begin{array}{c}\text { Max. UC wgt. } \\
\text { fraction } \\
\end{array}$ & $\begin{array}{r}\text { emitter } \\
\text { volume } \\
\text { fraction } \\
\end{array}$ & $\begin{array}{l}\text { critical } \\
\text { diameter } \\
(\mathrm{cm}) \\
\end{array}$ & $\begin{array}{c}\text { critical } \\
\text { fuel loading } \\
(\mathrm{kg}) \\
\end{array}$ & $\begin{array}{c}\text { ratio of } \\
\text { max. to avg. } \\
\text { power density }\end{array}$ \\
\hline 1.0 & 1.00 & 0.50 & 36.6 & 119 & 1.068 \\
\hline 1.1 & 0.90 & 0.50 & 43.2 & 156 & 1.037 \\
\hline 1.24 & 0.80 & 0.50 & 50.8 & 203 & 1.070 \\
\hline 1.3 & 0.60 & 0.50 & 72.4 & 369 & 1.064 \\
\hline 1.4 & 0.50 & 0.50 & 91.3 & 568 & 1.119 \\
\hline 1.23 & 0.80 & 0.56 & 47.2 & 181 & 1.068 \\
\hline 1.22 & 0.80 & 0.45 & 56.7 & 250 & 1.069 \\
\hline 1.21 & 0.80 & 0.40 & 63.9 & 318 & 1.074 \\
\hline
\end{tabular}

The $U^{235}$ fuel densities employed and their distribution by zone in the core are as follows: 


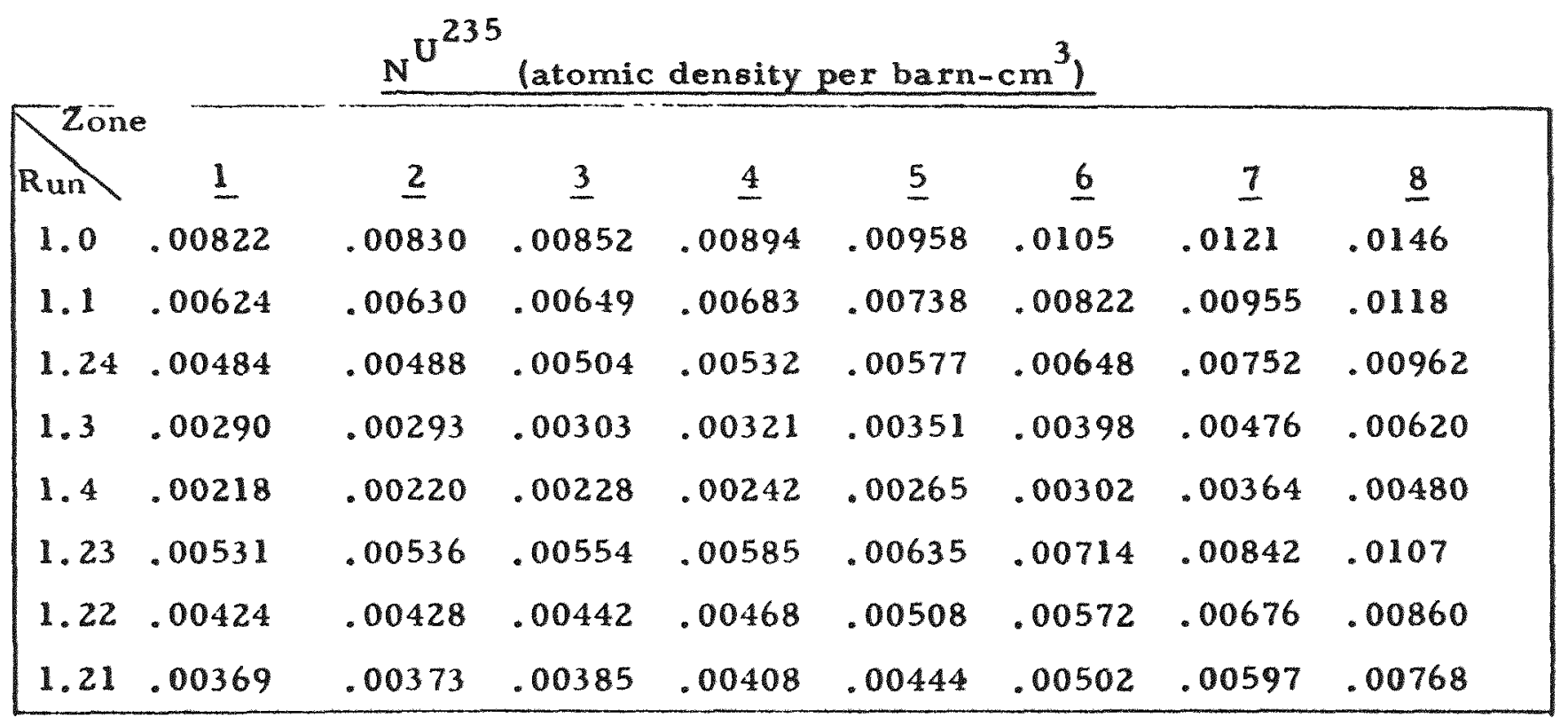

For the fuel element design point of .50 emitter volume fraction and 0.80 maximum UC weight fraction (Run No. 1.24), the relative fuel density, group flux distribution, and total power density are shown in Figures B.18, B. 19, and B. 20 as a function of core radius. 


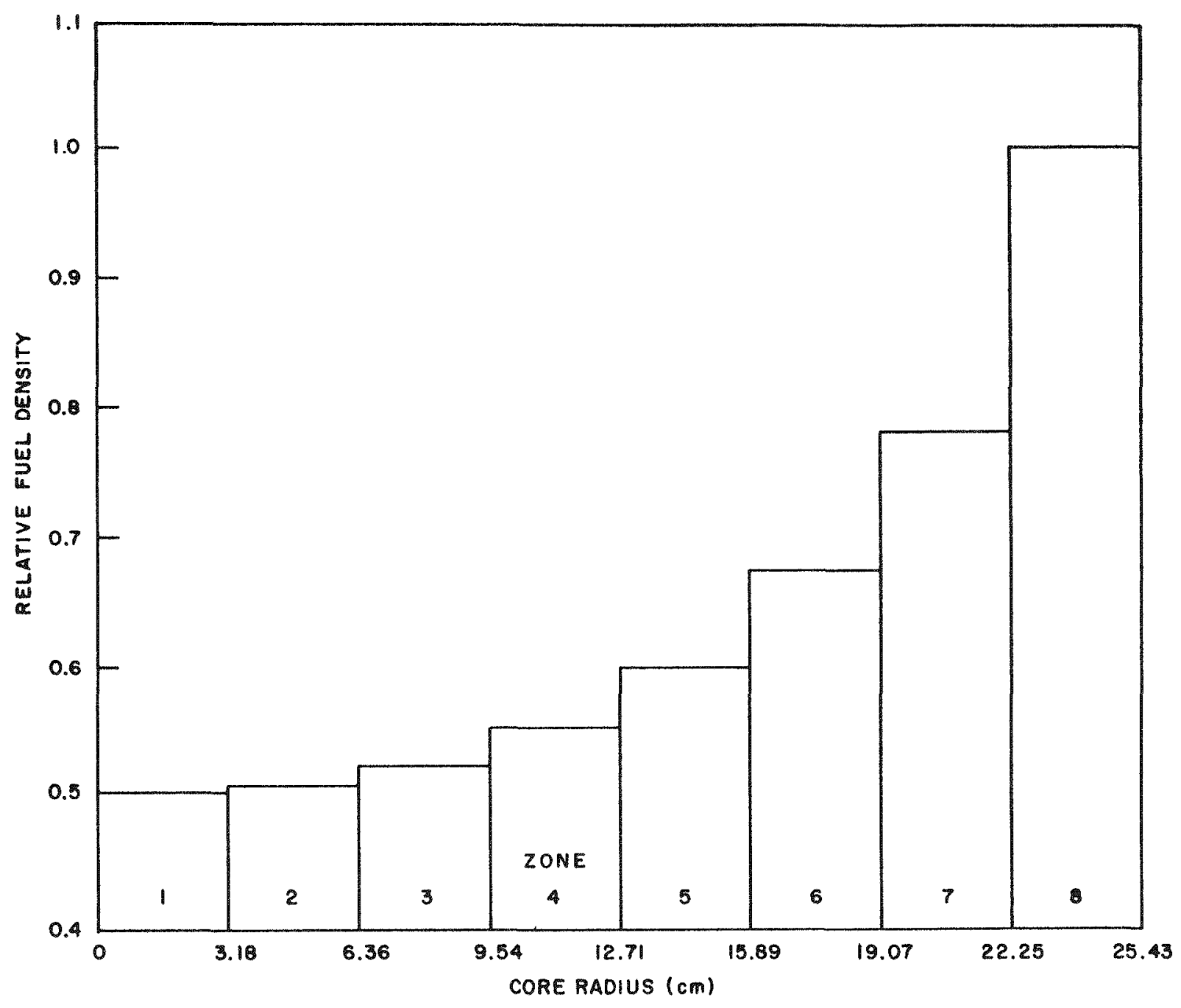

Fig. B.18 - - Relctive fuel density as a function of core padius 


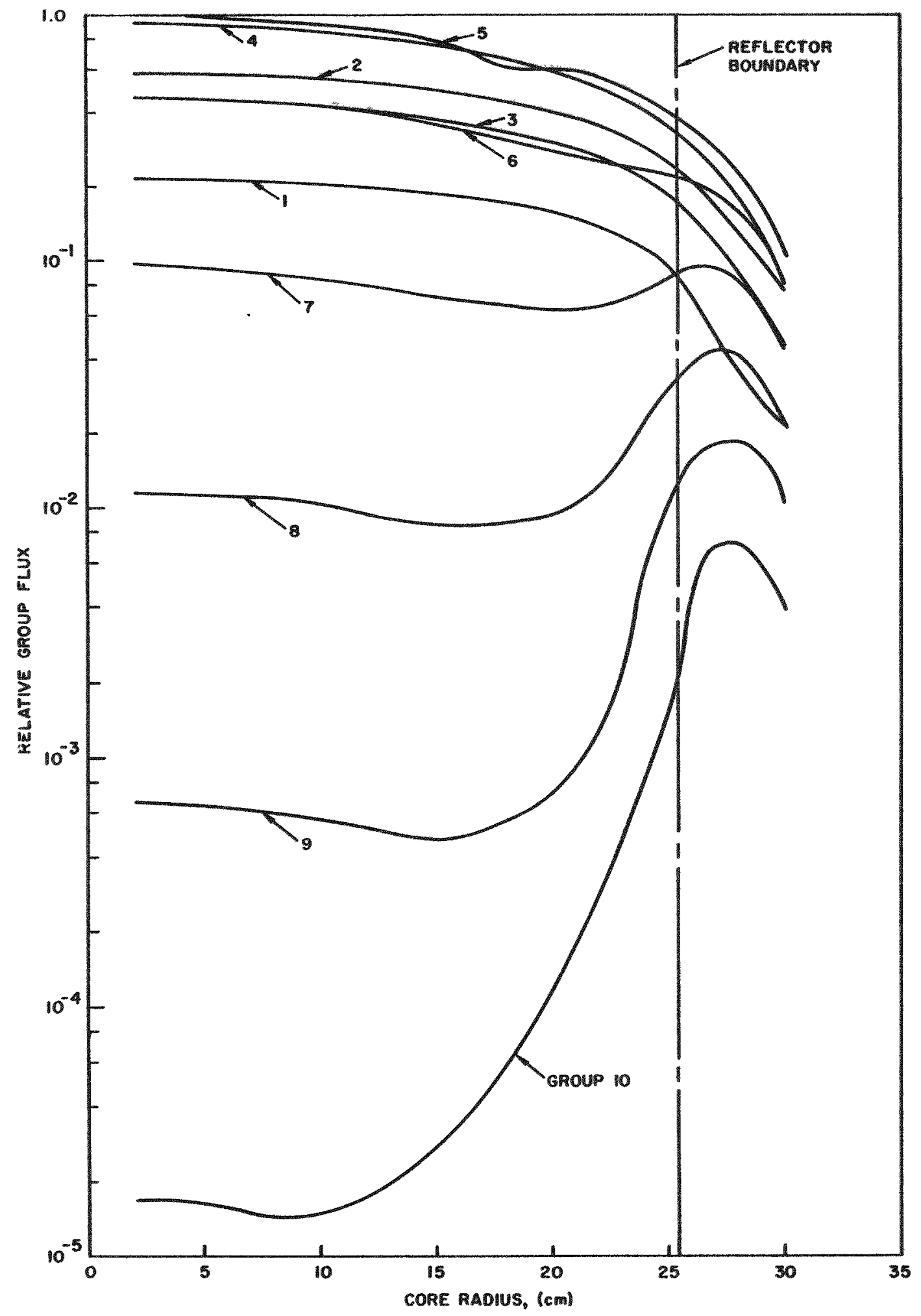

Fig. B. 19 -- Relative flux distribution as function of core radius 


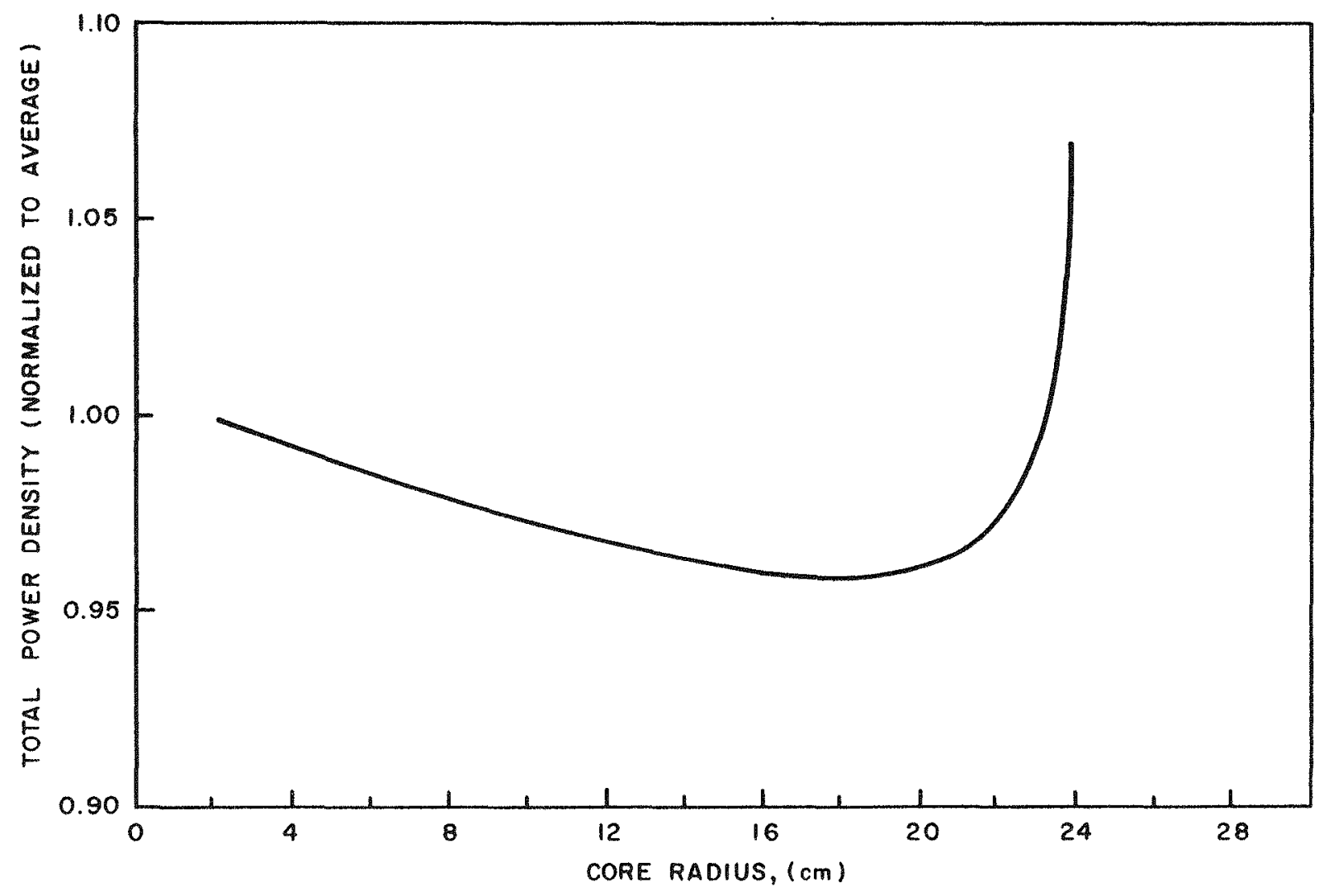

Fig. B. 20 - - Iotal power density as a function of core radius 
-

- 


\section{REF ERENCES}

1. F. Carpenter, J. Dunlay, R. Howard, L. Yang, "High-Temperature, Vapor-Filled Thermionic Converter,"ASD Technical Report 61-513 (General Atomic Report GA-2530 dated 31 August 1961) covering period of $1 \mathrm{July} 1960$ through $31 \mathrm{July}$ 1961, for contract AF33(616)-7422

2. H. L. Garvin and R. W. Pidd, "Research on Cesium-Vapor Cells employing Carbide Cathodes", yearly technical summary report for the period of 1 May 1960 through 31 January 1961, for contract Nonr-3103(00). General Atomic report GA-1973

3. H. L. Garvin, "Research on Cesium-Vapor Cells Employing Carbide Cathodes", Yearly Technical Summary Report for the period of 1 February 1961 through 31 January 1962, for contract Nonr-3193(00). General Atomic report GA-2900

4. G. A. Haas, Naval Research Laboratories, private communication to H. L. Garvin of General Atomic

5. "Thermionic Electron Sources," Naval Research Laboratories report 5657

6. G. E. Hansen and W. H. Roach, "Sixteen Group Cross Sections", N-2-753, Rev. 1

7. Weinberg, A. F. et al, "Investigations of carbides as Cathodes for Thermionic Space Reactors", Quarterly Progress Report for period ending 30 November 1961, for contract NAS 5-1253, General Atomic report GA-2670 


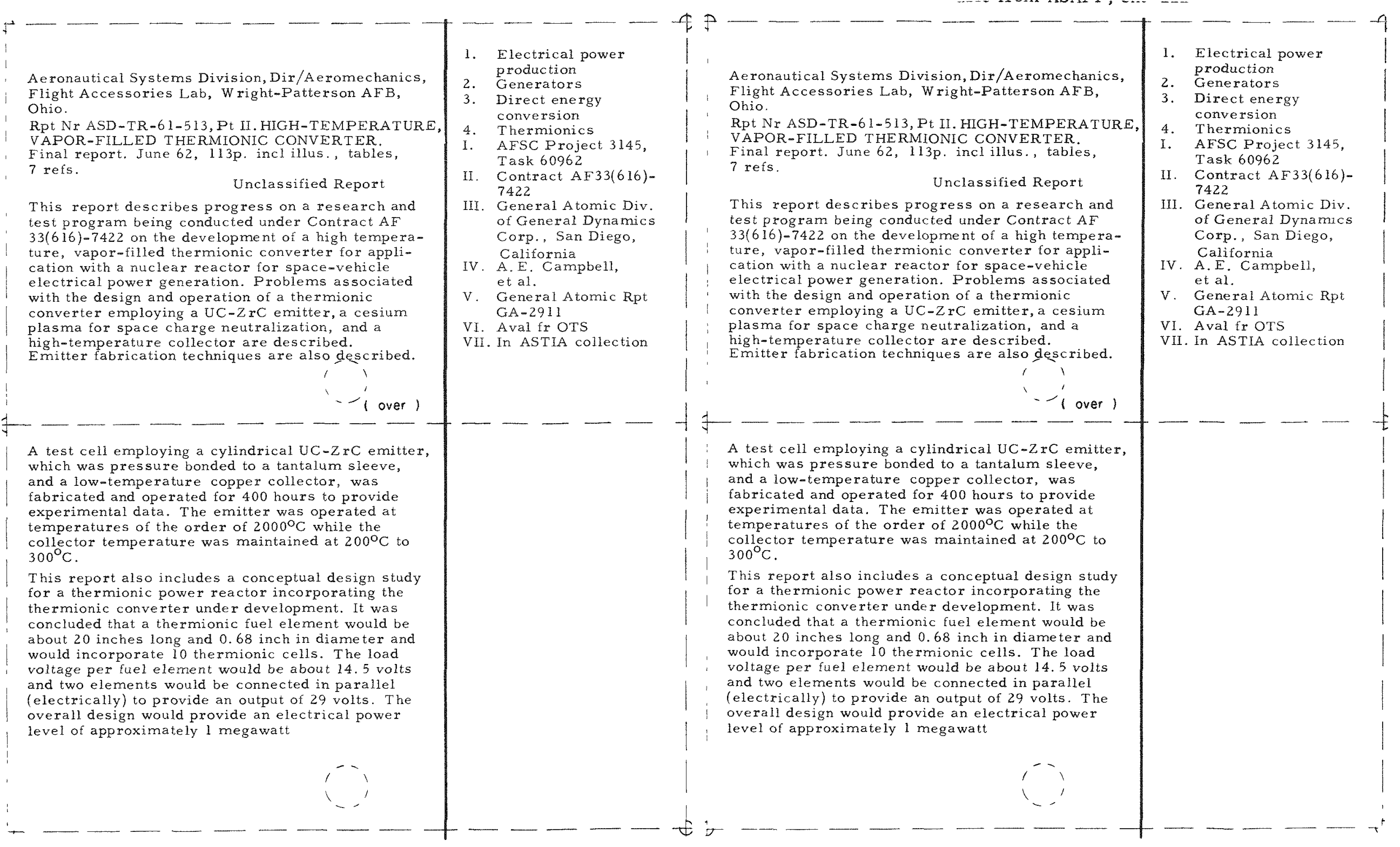




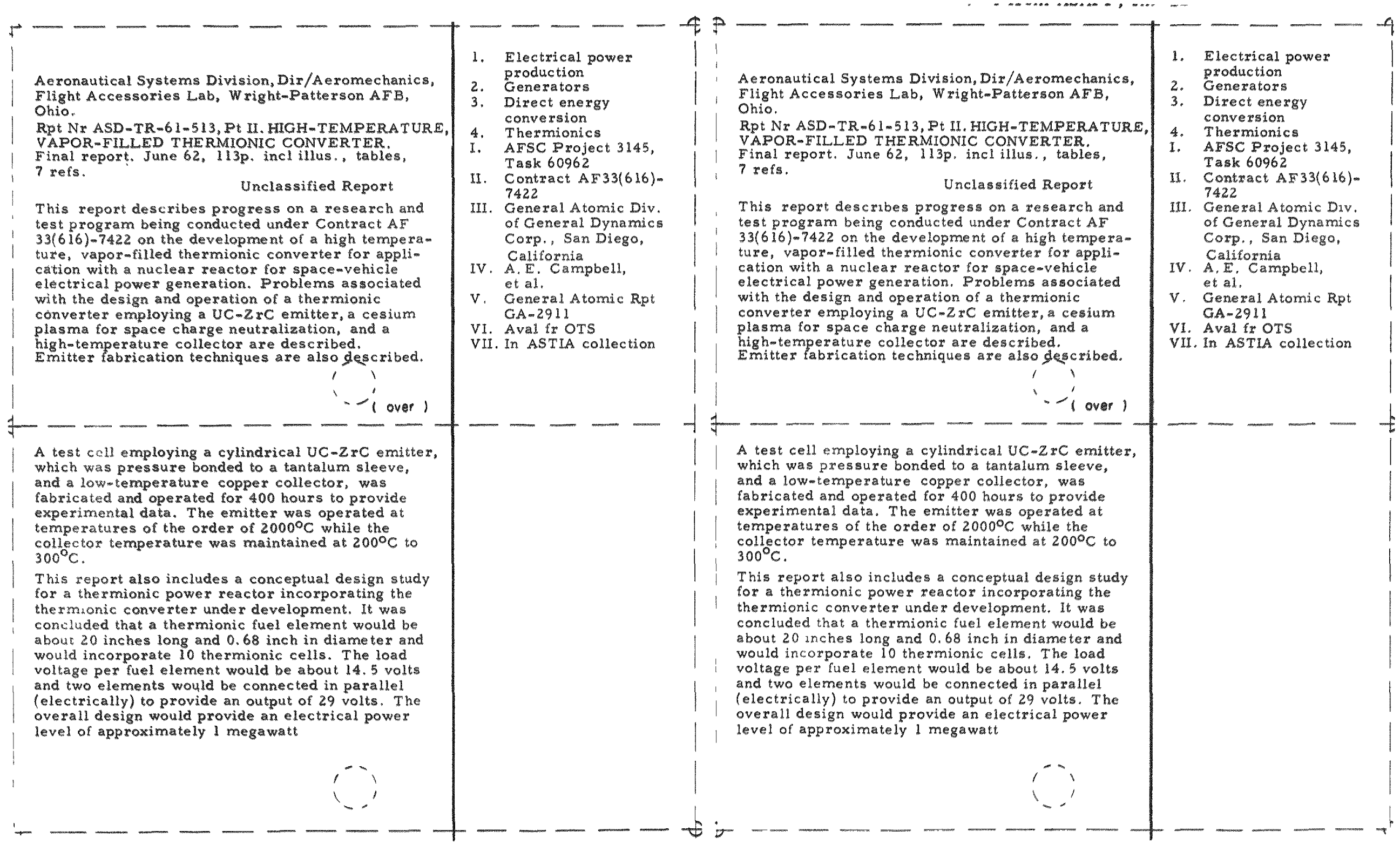


A test cell employing a cylindrical UC-ZrC emitter, which was pressure bonded to a tantalum sleeve, and a low-temperature copper collector, was fabricated and operated for 400 hours to provide experimental data. The emitter was operated at temperatures of the order of $2000^{\circ} \mathrm{C}$ while the

This report also includes a conceptual design study for a thermionic power reactor incorporating the thermionic converter under development. It was concluded that a thermonic fuel element would be about 20 unches long and 068 inch in diameter and would incorporate 10 thermionc cells The load voltage per fuel element would be about 145 volts and two elements would be connected in parallel (electrically) to provide an output of 29 volts The overall design would provide an electrical power level of approximately 1 megawatt

\section{Unclassified Report} This report describes progress on a research and $33(616)-7422$ being conducted under Contract AF ture, vapor-fulled thermionic converter for applielectrical power generation Problems associated
with the design and operation of a thermonic plasma for employing a UC-ZrC emitter, a cesium high-temperature collector are described
Emitter fabrication techniques are also described $1, \cdots$
1

Aeronautical Systems Division, Dir/Aeromechanics, Flight Accessories Lab, Wright-Patterson AFB, Rpt NI ASD-TR-61-513, Pt II. HIGH-TEMPERAT Final report June 62 , $113 p$ mcl allus, tables, 


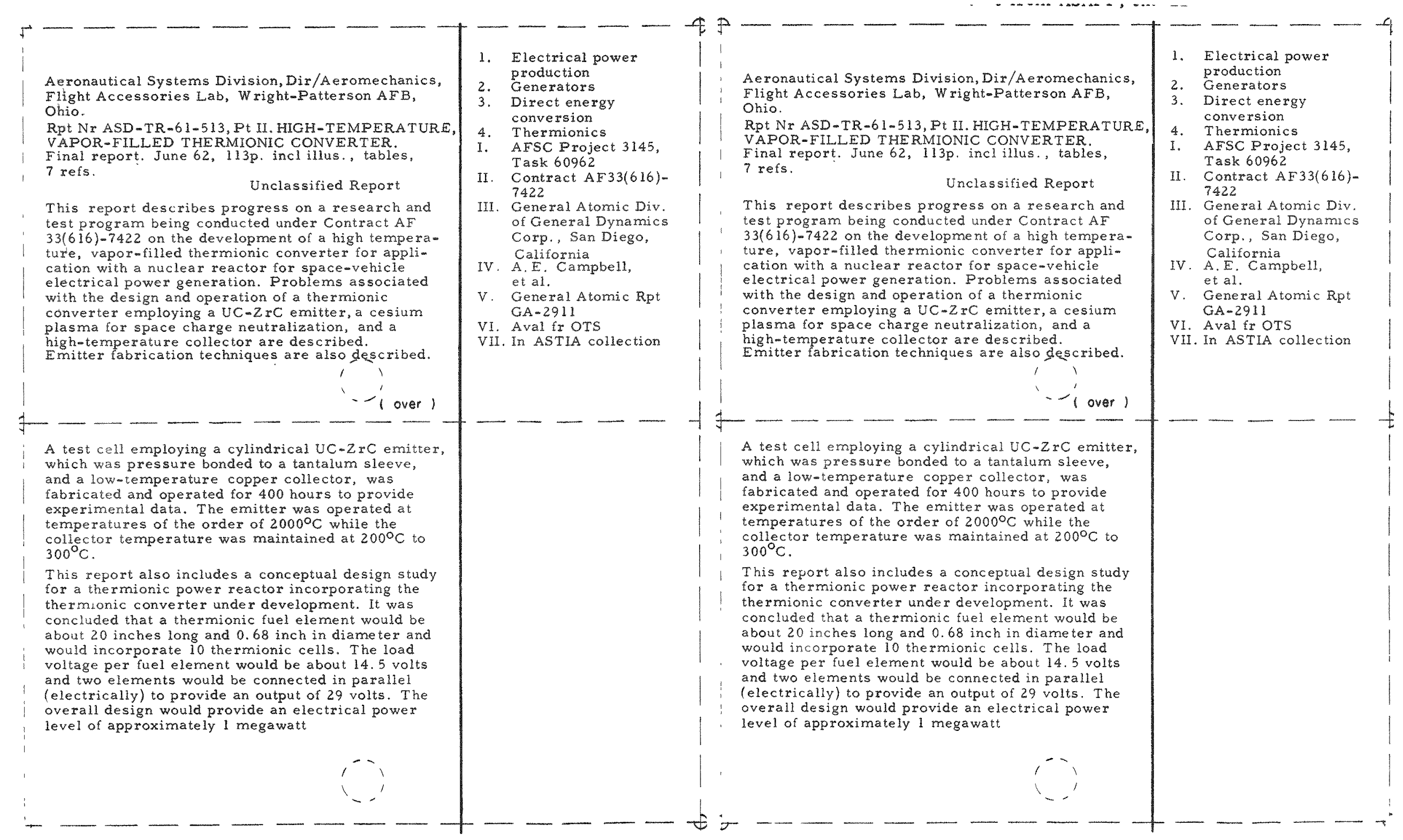

